\title{
Potential of Laser for SPS Power Transmission
}

October 1978

\section{U.S. Department of Energy} Office of Energy Research

Satellite Power System Project Office

Washington, D.C. 20545

Under Contract No. EG-77-C-01-4024

\section{DOE/NASA}

SATELLITE POWER SYSTEM

Concept Development

and

Evaluation Program 


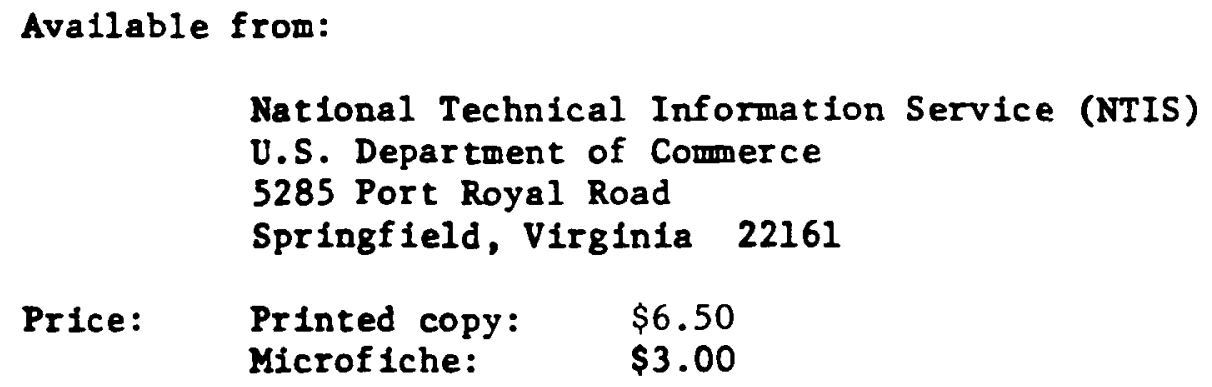




\section{Potential of Laser for SPS Power Transmission}

October 1978

Prepared by:

Claud N. Bain

PRC Energy Analysis Company

McLean, Virginia 22102

Prepared for:

U.S. Department of Energy

Office of Energy Research

Satellite Power System Project Office

Washington, D.C. 20545

Under Contract No. EG-77-C-01-4024

\section{DOE/NASA}

SATELLITE POWER SYSTEM

Concept Development

and

Evaluation Program 


\section{NOTICE}

This report was prepared as an account of work sponsored by the United States Government. Neither the United States nor the United States Department of Energy, nor any of their employees, makes any warranty, express or implied, or assumes any legal liability or responsibility for the accuracy, completeness, or usefulness of any information, apparatus, product, or process disclosed, or represents that its use would not infringe privately owned rights. Reference herein to any specific commercial product, process, or service by trade name, mark, manufacturer, or otherwise, does not necessarily constitute or imply its endorsement, recommendation, or favoring by the United States Government or any agency thereof. The views and opinions of authors expressed herein do not necessarily state or reflect those of the United States Government or any agency thereof. 


\section{ACKNOWLEDGEMENTS}

Thanks are extended to Charles Bloomquist and Michael Wei for critical reviews and to Michael Wei for consulting support in the areas of environmental and social impacts. I particularly wish to thank the group of professionals of the high-powerlaser community who served as contributors and/or reviewers. Listed below are the names of the individuals who supplied appendices and of those who read the "review draft," constructively criticized it, and provided information for inclusion into the body of this final version of the report.

Supplied Appendices

David L. Huestis

Wayne S. Jones

John M. J. Madey

John D. G. Rather

Reviewed Draft

Kenneth W. Billman, Physicist

Abraham Hertzberg, Aerophysicist

David M. Karnes, Electrical Engineer

Frederick A. Koomanoff, Systems Engineer

Richard B. Lancashire, Mechanical Engineer

Robert J. Mackin, Physicist

John M. J. Madey, Physicist

Lucian L. Morgan, Mechanical Engineer 


\section{PREFACE}

This report documents the findings of an initial study to determine the state of the art of laser technology and, specifically, to evaluate the potential of the laser for use in transmitting large quantities of power from space to earth as envisioned in the Satellite Power System (SPS) concept. 


\section{ABSTRACT}

The Satellite Power System (SPS), conceived to collect solar energy in space and transmit it to earth by microwaves, has been under study by National Aeronautics and Space Administration (NASA) since 1972. During the past year several studies by the Department of Energy (DOE) and other organizations have resulted in the identification of potential problems associated with the transmission of large amounts of power via microwave from space to earth. These problems involve the impact of directed (and scattered) radiation on electronic and electromagnetic systems, the ionosphere, the troposphere, and other elements of the environment that affect ecosystems and public health. A preliminary study has been conducted into the feasibility of using a laser subsystem (an additional option) for the transmission of SPS power from space to earth. Study findings indicate that state of the art laser technology currently is not adequate to meet the SPS Laser Power Transmission Subsystem (LPTS) requirements. However, past laser progress, current laser work, and predictions for future laser performance provide a reasonable level of confidence that the development of an LPTS is technologically feasible in the time frame required to develop the SPS. In addition, there may be significant economic advantages in lower ground distribution costs and a reduction of more than two orders of magnitude in real estate requirements for ground-based receiving/conversion sites. 


\section{TABLE OF CONTENTS}

PREFACE

Page

ABSTRACT

vii

LIST OF FIGURES

$x i$

LIST OF TABLES

xii

GLOSSARY OF TERMS

xiii

I. INTRODUCTION

1.0 Description of SPS for Solar Generation of Electricity

I.I Microwave Power Transmission Subsystem (MPTS)

1

I.2 Task Objectives

1.3 Organization of Report

2

3

4

11. GROUND RULES OF THE STUDY 5

III. LASER SYSTEMS STATE OF THE ART 9

3.0 High-Power Laser (HPL) Types 10

3.0.1 Chemical Laser

3.0.2 Gas Dynamic Laser

3.0.3 Electric Discharge Laser

3.0.4 Laser Scaling

3.1 Other Technical Factors Affecting Choice of LPTS Laser 19

3.1.1 Beam Shaping 19

3.1.2 Optics

3.1.3 Laser Energy Conversion Systems

3.2 LPTS Performance/Cost Considerations 33

3.2.1 Power Output 34

$\begin{array}{ll}3.2 .2 & \text { Laser Efficiency } \\ 3.2 .3 & 35\end{array}$

$\begin{array}{lll}3.2 .3 \text { Costs } & 39\end{array}$

$\begin{array}{ll}3.2 .4 & \text { Weights }\end{array}$ 
IV. EVALUATION OF IMPACTS/ISSUES

4.0 Technological Impacts 47

4.1 Environmental impacts $\quad 49$

4.2 Societal Impacts 51

4.3 Economic Impacts $\quad 54$

V. CONCLUSIONS 57

VI. REFERENCES

VII. BIBLIOGRAPHY 63

APPENDIX A: POTENTIAL MICROWAVE IMPACTS A-I

$\begin{array}{ll}\text { APPENDIX B: } & \begin{array}{l}\text { NASA BASELINE SATELLITE POWER SYSTEM } \\ \text { CONCEPTS }\end{array}\end{array}$

$\begin{array}{ll}\text { APPENDIX C: } & \text { FREE-ELECTRON LASERS } \\ & \text { (Dr. John M. J. Madey) }\end{array}$

APPENDIX D: $\begin{aligned} & \text { HIGH-POWER, SHORT-WAVELENGTH LASERS } \\ & \text { (Dr. David L. Huestis) }\end{aligned}$

$\begin{array}{ll}\text { APPENDIX E: } & \begin{array}{l}\text { SOLAR PUMPING OF LASERS } \\ \text { (Mr. C. N. Bain) }\end{array} \text { E-I }\end{array}$

APPENDIX F: LASERS VERSUS MICROWAVES FOR SOLAR SPACE POWER

(Dr. John D. G. Rather) F-I

APPENDIX G: SPACE LASER POWER SYSTEM

(Mr. Wayne S. Jones) G-I 


\section{LIST OF FIGURES}

Poge

1.1 Major Elements of a Satellite Power System (SPS) 2

3.1 Example Optics and Beam Characteristics of LPTS Concepts 10

3.2 Lasing Gas lonized by Large Area Electron Beam 12

3.3 Closed-Cycle Subsonic Electric Discharge Laser System for Space 12

3.4 Relationship of Radiator Operating Temperature and Radiator Area 17

3.5 Intensity Distribution From a Circular Aperture 23

3.6 Vertical Transmittance for Receiver at Altitude $\mathrm{H}$ for Selected Laser Wavelengths

3.7 Comparison of Efficiencies of MPTS and LPTS Concepts 37

3.8 Comparison of Efficiencies of Solar-Pumped Laser LPTS

$\begin{array}{ll}\text { Concepts and the MPTS } & 40\end{array}$

3.9 LPTS Spaceborne Mass Versus Projected Front-End Efficiency 45 


\section{LIST OF TABLES}

$\underline{\text { Page }}$

I.I Microwave Energy Transmission

2.1 Weight and Performance Data of Elements of a 10-GW SPS 5

2.2 MPTS Parameters and Preliminary Estimates of LPTS Requirements 6

3.1 State-of-the-Art Characteristics of Some Electric Discharge Lasers 14

3.2 Parameters of State-of-the-Art and Conceptual High-Power Lasers 15

3.3 Relationship of Number of Apertures, Area, Diameter of Arrays, and Aperture Radiancy

3.4 Pattern at Earth (42.2-m Aperture at GEO, $\lambda=10.6 \mu \mathrm{m})$

3.5 Aerosol Absorption and Scattering Coefficients--Sea Level 26

3.6 Optical Absorption in RAP-Grown Alkali Halides at $\mathrm{Nd}^{3+}, \mathrm{HF}, \mathrm{DF}$, and $\mathrm{CO}_{2}$ Laser Wavelengths

3.7 Characteristics of Laser Energy Conversion Systems 31

3.8 Masses of Spaceborne Components of the JSC MPTS, a CO 2 EDL LPTS, and Related Power Collection Subsystems

4.1 Curripurison of $\bar{L} \bar{P} T S$ and MPTS Parameters 48

4.2 Comparison of Environmental Effects 52

4.3 Comparison of Societal Effects 55

4.4 Economic Advantages and Disadvantages 56 


\section{GLOSSARY OF TERMS}

\begin{tabular}{|c|c|}
\hline$\stackrel{0}{A}$ & Angstrom \\
\hline $\mathrm{cm}$ & Centimeter \\
\hline $\mathrm{CO}$ & Carbon Monoxide \\
\hline $\mathrm{CO}_{2}$ & Carbon Dioxide \\
\hline$C W$ & Continuous Wave \\
\hline DARPA & Defense Advance Research Projects Agency \\
\hline DF & Deuterium Fluoride \\
\hline DOD & Department of Defense \\
\hline DOE & Department of Energy \\
\hline EDL & Electric Discharge Laser \\
\hline EE & Wave Energy Exchanger \\
\hline EMC & Electromagnetic Compatibility \\
\hline eV & Electronvolt \\
\hline FEL & Free Electron Laser \\
\hline $\begin{array}{l}\text { Front-end } \\
\text { Efficiency }\end{array}$ & Ratio of Laser/Microwave Power Output to Solar Power Input \\
\hline GDL & Gas Dynamic Laser \\
\hline GEO & Geostationary Earth Orbit \\
\hline $\mathrm{GHz}$ & Gigahertz \\
\hline GW & Gigawatt \\
\hline $\mathrm{He}$ & Helium \\
\hline HEX & Heat Exchanger \\
\hline HF & High Frequency; Hydrogen Fluoride \\
\hline HPL & High-Power Laser \\
\hline $\mathrm{Hz}$ & Hertz \\
\hline IR & Infrared \\
\hline Irradiance & $\begin{array}{l}\text { Power per unit area incident on a surface - watts per square } \\
\text { centimeter }\end{array}$ \\
\hline$J$ & Joule \\
\hline JSC & Johnson Space Center \\
\hline
\end{tabular}




\section{GLOSSARY OF TERMS (Continued)}

\begin{tabular}{|c|c|}
\hline${ }^{\circ} \mathrm{K}$ & Degree Kelvin \\
\hline kJ & Kilojoule \\
\hline $\mathrm{km}$ & Kilometer \\
\hline kV & Kilovolt \\
\hline $\mathrm{kW}$ & Kilowatt \\
\hline Laser & 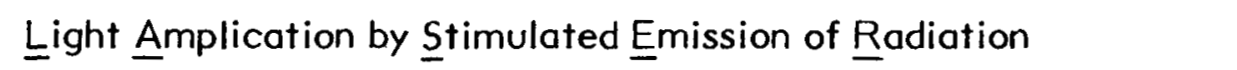 \\
\hline Lasant & Medium in which laser action occurs \\
\hline LPTS & Laser Power Transmission Subsystem \\
\hline $\mathrm{m}$ & Meter \\
\hline mi & Mile \\
\hline $\mathrm{mW}$ & Milliwatt \\
\hline $\mathrm{NWW}$ & Megawatt \\
\hline MOS & Metal-Oxide Semiconductor \\
\hline MPTS & Microwave Power Transmission Subsystem \\
\hline MSFC & Marshall Space Flight Center \\
\hline $\mathrm{N}_{2}$ & Nitrogen \\
\hline NASA & National Aeronautics and Space Administration \\
\hline NRL & Naval Research Laboratory \\
\hline rad & Radian \\
\hline Radiancy & $\begin{array}{l}\text { Radiant power per unit area emanating from a surface - watts per } \\
\text { square centimeter }\end{array}$ \\
\hline RAP & Reactive Atmosphere Processing \\
\hline $\mathrm{RFI} / \mathrm{EMI}$ & $\begin{array}{l}\text { Radio Frequency Interference/ } \\
\text { Electromagnetic Interference }\end{array}$ \\
\hline SPS & Satellite Power System \\
\hline TELEC & Thermoelectronic Laser Energy Converter \\
\hline Torr & $\begin{array}{l}\text { Unit of Pressure ( } 1 \text { Torr }=1 \mathrm{~mm} \text { of mercury - standard gravity, } \\
\left.0^{\circ} \mathrm{C}\right)\end{array}$ \\
\hline ULE & Ultra-Low Expansion \\
\hline UV & Ultraviolet \\
\hline VHF & Very-High Frequency \\
\hline VLF & Very-Low Frequency \\
\hline$\mu \mathrm{m}$ & Micrometer \\
\hline
\end{tabular}




\section{INTRODUCTION}

This report represents the findings of a preliminary study into the technical feasibility and the environmental, social, and economic implications of using a Laser Power Transmission Subsystem (LPTS) instead of the Microwave Power Transmission Subsystem (MPTS) for transmitting Satellite Power System (SPS) power from space to earth. This section provides brief descriptions of the SPS and MPTS, as well as the study task objectives and organization of the report.

\section{I.0 DESCRIPTION OF SPS}

The following paragraphs and figure 1.1 provide a brief description and illustration of the SPS.

Although the sun is, in effect, an unlimited source of energy, two factors prevent the extensive use of solar energy. First, the sun's energy is diffuse, and, second, solar energy at the earth's surface is intermittent. The sun shines only part of each 24 hours and is often obscured by clouds. Baseload electricity (24-hour operation) can be generated, however, by placing a solar energy collector in space where it is illuminated by the sun more than 99 percent of the time, regardless of weather or the day-night cycles of the earth. Such a Satellite Power System (SPS) was first suggested in 1968 by Dr. Peter Glaser and has been under study by the National Aeronautics and Space Administration (NASA) since 1972.

Figure 1.1 shows how such a system would function. A large collector, $38 \mathrm{sq} . \mathrm{mi}$ in area and covered with photovoltaic solar cells, converts solar power into electricity. The electricity is continuously converted into microwave power for transmission to large, receiving/rectifying antennas (rectennas) on earth. These rectennas, in turn, reconvert the beamed microwave power into electricity and feed it into a utility grid. Such a satellite might weigh as much as 100,000 tons and produce 10,000 MW of power continuously. A system of 10 to 30 or more of these satellites (or twice as many 5,000 $M W$ units) in geostationary orbit $22,300 \mathrm{mi}$ above the earth would provide a significant portion of the total U.S. electric power requirements. 1,2 


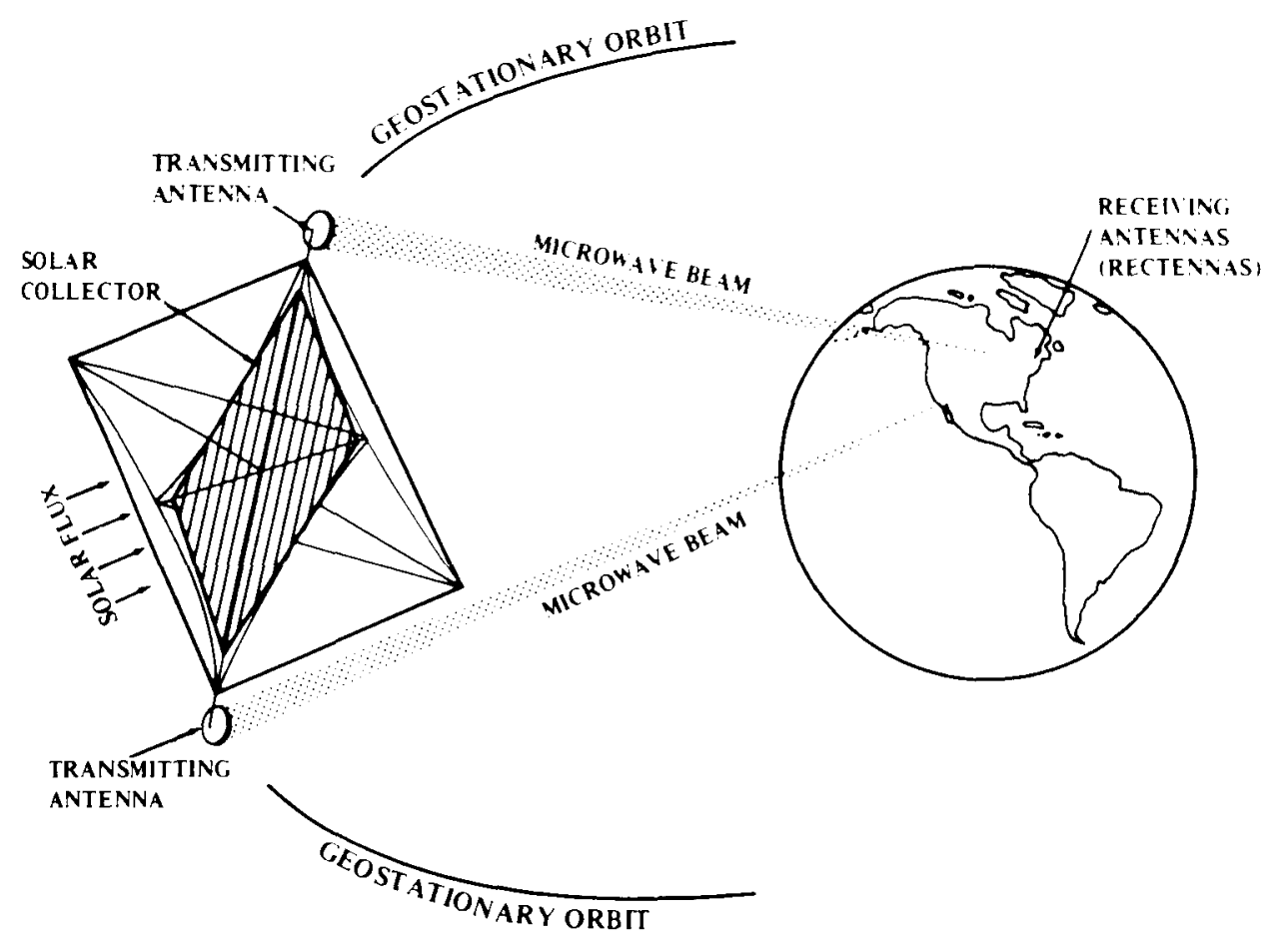

Figure I.I Major Elements of a Satellite Power System (SPS) I

Studies have been planned and are underway to identify environmental and socioeconomic issues and to configure an SPS that represents an acceptable solution to these issues.

\section{I.I MICROWAVE POWER TRANSMISSION SUBSYSTEM (MPTS)}

The major characteristics of the MPTS as initially defined by NASA along with comments of the task group are given in table 1.1.1 These and other MPTS characteristics are under investigation at NASA and are being updated as knowledge and technology permit. The expected efficiency of the microwave system varies, depending on the estimator, from 45 percent to 66 percent. $^{3}$ When this is coupled with the expected efficiency of silicon solar cells ( 12 percent to 17 percent) and a degradation factor is added, total system efficiency is estimated to be in the range of 6 percent to 8 percent--an efficiency that is believed will make the SPS economically competitive with other power generating systems. Environmental and public health questions are currently being identified and needed research and investigations are being planned. The major questions concerning the microwave subsystem involve the impact of its directed (and scattered) radiation on electronic and electromagnetic systems, the ionosphere, the troposphere, and other elements of the environment that affect ecosystems and public health (see appendix A). 
Table 1.1 Microwave Energy Transmission

\begin{tabular}{|c|c|c|}
\hline Parameter & $\begin{array}{l}\text { NASA Initial } \\
\text { Assumption }\end{array}$ & Task Group Comment \\
\hline Antenna size & 1-km diameter & $\begin{array}{l}\text { Must be phased flat to } 1 / 4 \text { wave- } \\
\text { length }(2.5 \mathrm{~cm})\end{array}$ \\
\hline Frequency & $2.45 \mathrm{GHz}$ & $\begin{array}{l}\text { Reserved for industrial, scientific, } \\
\text { and medical use }\end{array}$ \\
\hline Pointing accuracy & I arc min. & Requires active (upbeam) control \\
\hline $\begin{array}{l}\text { Ground receiver } \\
\text { (rectenna) size }\end{array}$ & $10 \times 14 \mathrm{~km}$ & Additional protected area required \\
\hline Beam flux & $\begin{array}{l}20 \mathrm{~mW} / \mathrm{cm}^{2} \max . \\
\text { at center }\end{array}$ & $\begin{array}{l}\text { Potential problem with microwave } \\
\text { exposure standards; ionosphere in- } \\
\text { teractions ( } 23 \mathrm{~mW} / \mathrm{cm}^{2}--H F \text {, VHF } \\
\text { communications, VLF navigation } \\
\text { interference) }\end{array}$ \\
\hline
\end{tabular}

\section{I.2 TASK OBJECTIVES}

The objectives taken from the task assignment ${ }^{4}$ are as follows:

1. Specify the present state of the art of high-energy lasers (technical description).

2. Describe high-energy lasers as a transmission medium for the SPS, e.g., capabilities and size limitations.

3. Specify the benefits and disadvantages by category:

- Technological;

- Environmental; .

- Societal;

- Economic. 


\section{I.3 ORGANIZATION OF REPORT}

The report contains five sections. The following section describes study constraints and establishes the preliminary power transmission subsystem requirements used for the study. Section III then discusses high-power-laser state of the art, efficiency, beam propagation, optical components, and the power conversion units that are available for use with the LPTS. Section IV deals with technical, environmental, societal, and economic impacts, and section $V$ presents conclusions. 


\section{GROUND RULES OF THE STUDY}

This study was conducted on an unclassified basis and was limited to technologies and equipment that are compatible with the geostationary orbit of the National Aeronautics and Space Administration's (NASA's) Baseline System Concept. This last limitation has facilitated evaluation of the laser in the context of the larger NASA effort. - The Marshall Space Flight Center (MSFC) and Johnson Space Center (JSC) versions of this concept are similar, as shown by the concept comparisons and by the point design resumes (for some of the more important characteristics see appendix $B$ ). The JSC system weight and efficiency data given in table 2.1 have been used to

Table 2.I Weight and Performance Data of Elements of a $10-G W S^{2} S^{7}$

\begin{tabular}{lccc}
\hline Item & Weight $\left(\mathrm{kg} \times 10^{6}\right)$ & Efficiency & Power Out (GW) \\
\hline $\begin{array}{l}\text { Power Collection } \\
\text { subsystem }\end{array}$ & 52 & 0.151 & 21.12 \\
$\begin{array}{l}\text { Miscellaneous } \\
\text { (summer solstice, } \\
\text { cosine, I }{ }^{2} \text { R, and } \\
\text { panel area losses) }\end{array}$ & 25 & 0.800 & 16.90 \\
$\begin{array}{l}\text { Power transmission } \\
\text { subsystem } \\
\text { Propagation }\end{array}$ & 0.800 & 13.52 \\
Rectenna & 0.860 & 11.62 \\
& 0.860 & 10.00 \\
\hline
\end{tabular}

a/ The geostationary orbit is believed by some to eliminate many potential advantages of the laser (and the microwave) subsystems. See papers by Frank Coneybear, ${ }^{5}$ Wayne Jones (appendix G), ${ }^{5}$ John Rather (appendix F), and J. E. Drummond. ${ }^{6}$ 
establish preliminary estimates of these requirements for the SPS. MPTS parameter values and preliminary estimates of LPTS requirements are shown in table 2.2. Cost data are considered too soft for detailed tabulation. Reliability and maintainability are important requirements but have not been considered in any more detail than to assume that they must be high and at least equal to those of the Microwave Power Transmission Subsystem (MPTS).

Table 2.2 MPTS Parameters and Preliminary Estimates of LPTS Requirements

\begin{tabular}{llll}
\hline Item & $\mathrm{kg} / \mathrm{kW}$ & Efficiency & Power Out (GW) \\
\hline $\begin{array}{l}\text { Parameter values of } \\
\text { MPTS concept }\end{array}$ & 3.85 & 0.151 & 21.12 \\
$\begin{array}{l}\text { Power collection } \\
\text { subsystem }\end{array}$ & & & \\
$\begin{array}{l}\text { Miscellaneous } \\
\text { (summer solstice, } \\
\text { cosine, I'R, and } \\
\text { panel area losses) }\end{array}$ & 1.85 & 0.800 & 16.90 \\
$\begin{array}{l}\text { Power transmitter } \\
\text { Propagation }\end{array}$ & & 0.800 & 13.52 \\
$\begin{array}{l}\text { Receiver/power } \\
\text { converter }\end{array}$ & & 0.860 & 11.62 \\
$\begin{array}{l}\text { LPTS Requirements } \\
\text { SPS system totals* }\end{array}$ & 5.70 & 0.860 & 10.00 \\
\hline
\end{tabular}

* LPTS Requirements:

- Weight per kilowatt is based on power out of power transmitter of 13.52 GW.

- Total power out is busbar output. This power can be supplied by two or more units (smaller SPS's or smaller LPTS's from single SPS) should this be desirable. 
If the MPTS proves to be a sound concept from the standpoints of the environment, public health, EMC, frequency availability, and international considerations, then a Laser Power Transmission Subsystem (LPTS) will be able to replace the microwave system only if it is equally acceptable and improves SPS performance, or reduces costs. To replace the MPTS, the LPTS physical, performance, and cost characteristics should allow SPS cost benefits to be equal to or better than those that result when the MPTS is used. However, if the MPTS is unacceptable because of its impact(s) on one or more of the areas mentioned above, LPTS performance requirements must then be set only high enough to make the electricity from the SPS competitive in cost with electricity from alternative systems (e.g., fossil, nuclear, wind), provided the resulting LPTS is environmentally and socially acceptable. Two types of LPTS equipment have been visualized: (a) the LPTS-I that uses a highly concentrated beam, and (b) the LPTS-2 that disperses energy over a broad area in a manner not unlike the MPTS. These two concepts are described briefly in section III, "Laser Systems State of the Art," and are considered separately in section IV, "Evaluation of Impacts/Issues." 


\section{LASER SYSTEMS STATE OF THE ART}

Stimulated emission of light was postulated early in this century by Albert Einstein and was first observed experimentally in 1960 . By $1971^{8}$ various laser systems were available, such as $\mathrm{CO}_{2}$ lasers having an average power of $60 \mathrm{~kW}$, lasers having peak powers of $2.5 \times 10^{12} \mathrm{~W}$ at $1.06 \mu \mathrm{m}$, chemical lasers with efficiencies of 4 to 5 percent, laser operation at many wavelengths from submillimeter to $1532 \AA$, and lasers that could be tuned over wide bands. Lasers are now commonly used in industry (for cutting, welding, and alignment), in medicine, and in many other areas including military applications. The research, development, production, and application efforts that are responsible for this variety of laser equipment and uses have contributed and are continuing to contribute to high-power-laser technology. Because the laser function of immediate interest to the SPS is the transmission of power, this investigation was limited to questions involving Laser Power Transmission Subsystems (LPTS's). The types of subsystems visualized were an LPTS-I that transmits power through a narrow, highly concentrated beam and an LPTS-2 that transmits power through a wide (dispersed) beam. Example optics and beam characteristics for LPTS-1 and LPTS-2 are shown in figure 3.1. 9 /

Both subsystems require high-power lasers, large and sophisticated optics, power conversion units, and reasonable transmission efficiencies. During this investigation it was considered too early, and the available data too soft, to establish definitive designs for these two concepts. However, their general features are understood well enough to allow them to be considered in some detail in section IV, "Evaluation of Impacts/Issues."

The performance characteristics of currently available and projected high-power lasers, laser radiation propagation, high-power-laser optics and laser energy conversion systems are discussed in the following paragraphs and related to LPTS-I concentrated and LPTS-2 dispersed beam subsystems as appropriate.

a/ The projection characteristics of LPTS-2 are similar to the MPTS (see appendix G, figure G.2). The advantage of one system over the other can be determined by analyzing a combination of factors, including mass required in space, end-to-end efficiencies, costs, and environmental (e.g., health, safety, RFI/EMI) and societal issues. 


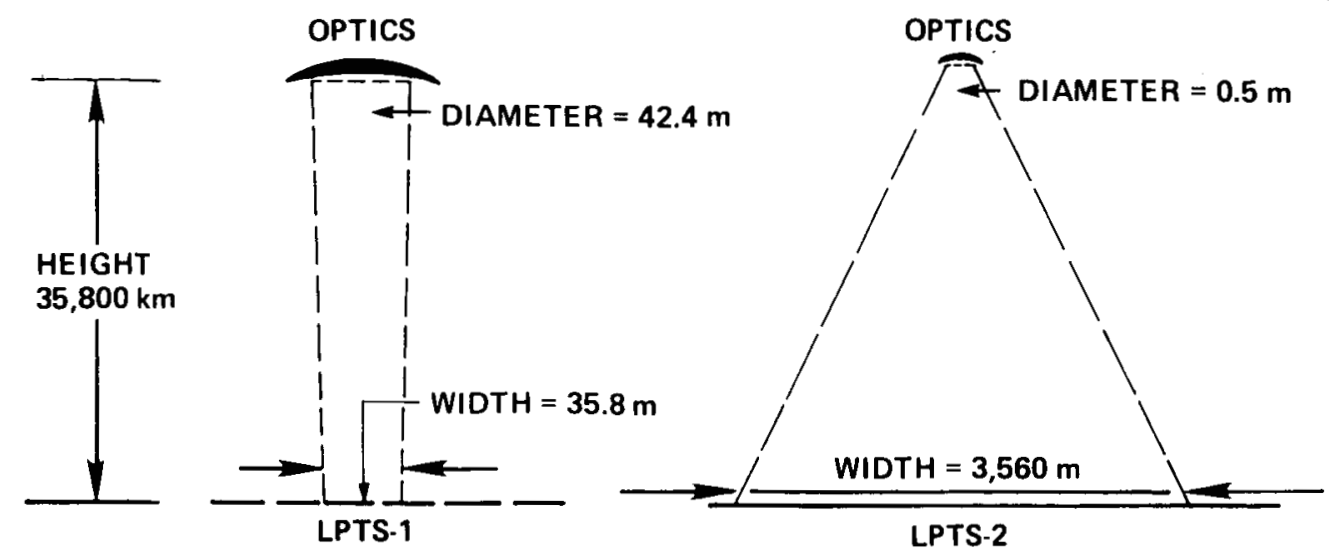

Figure 3.I Example Optics and Beam Characteristics of LPTS Concepts

\subsection{HIGH-POWER-LASER (HPL) TYPES}

The gas dynamic laser $\left(\mathrm{CO}_{2}-\mathrm{N}_{2}-\mathrm{H}_{2} \mathrm{O}\right.$ or $\left.\mathrm{He}\right)$ has been prominent in the successes achieved in high-power-laser research. Development has also produced significant advancements in gas dynamic, chemical, and electric-discharge lasers. All of these devices use gases as lasants. Energy is extracted from these gases in the form of radiation, the photons of which have energies that are characteristic of the distinct differences in the energy states of the atoms and molecules in the quantum system. The characteristics of these three basic types of HPL are discussed below.

\subsubsection{Chemical Laser}

High-power chemical lasers combine an oxidizer and fuel to produce a high-energy-density chemical reaction and provide the chemical components, free atoms or free radicals, that are required for the complex lasing system. By using the chemical energy directly, powerful yet compact systems can be built. Some of the hydrogen fluoride/deuterium fluoride (HF/DF) systems take on the appearance of jet engines. Operating pressures in the lasing cavity may be 10-Torr or less. Normally, 
the highly toxic gases are continually expelled to the atmosphere during operation; however, there are some systems designed to recirculate these exhaust gases. Optical gain can be realized on several spectral lines in the 2.5 to $3.0 \mu \mathrm{m}$ band for $H F$ and in the 3.5 to $4.0 \mu \mathrm{m}$ band for DF. ${ }^{9}$ Efficiencies can range from 2 to 4.5 percent. The low atmospheric absorption of the $3.8 \mu \mathrm{m}$ line, the convenience and compactness of a fuel-fired system, and the high powers available make the DF chemical laser ideal for some applications where efficiency and continuous operation are not critical requirements. Chemical lasers are not being considered for Satellite Power System (SPS) application because they are fuel fired.

3.0.2 Gas Dynamic Laser

This laser employs a high-temperature, high-pressure gas that is expanded through a supersonic nozzle. During the expansion, the temperature of the gas is lowered, thus creating a lasing medium from which energy can be extracted.

The gas dynamic laser (GDL) was the first high-power laser. The $\mathrm{CO} / \mathrm{CO}_{2} \mathrm{GDL}$ can be scaled to provide high power output, but the massive, costly gas supply systems needed to operate the laser require large amounts of drive power, thus reducing the overall efficiency of most current systems to less than I percent. 10 The efficiencies of GDL lasers would have to be increased significantly above 1.0 percent before the laser would be suitable for the SPS power transmission application. A recent study 1 I dealt with the optimization of the physical and performance characteristics of closedcycle GDL's to increase their suitability for space use.

\subsubsection{Electric-Discharge Laser}

The first electric-discharge laser (EDL) developed was the carbon dioxide laser. Some of the early units were constructed using tubes $1 \mathrm{~m}$ in length and $1.5 \mathrm{~cm}$ in diameter that were filled with $\mathrm{CO}_{2}$ (I Torr pressure), $\mathrm{N}_{2}$ (1 Torr), and He (5 Torr). A potential of $7 \mathrm{kV}$ was used to supply $35 \mathrm{~mA}$ of current to the $1.5 \mathrm{~cm}$ diameter tube; waste heat was conducted to the wall. ${ }^{12}$ The follow-on to this laser (and models using multiple tubes) has been the fast-flow gas $\mathrm{N}_{2}-\mathrm{CO}_{2}$ laser. An electron beam controls the discharge and a fast gas flow dissipates waste heat. The details of a typical lasing cavity are shown in figure 3.2. This unit is shown integrated into a closed-cycle subsonic system in figure 3.3. Operation of the unit begins when the temperature of the gas in the lasing cavity is reduced to $300^{\circ} \mathrm{K}$ and will stop lasing at a gas 


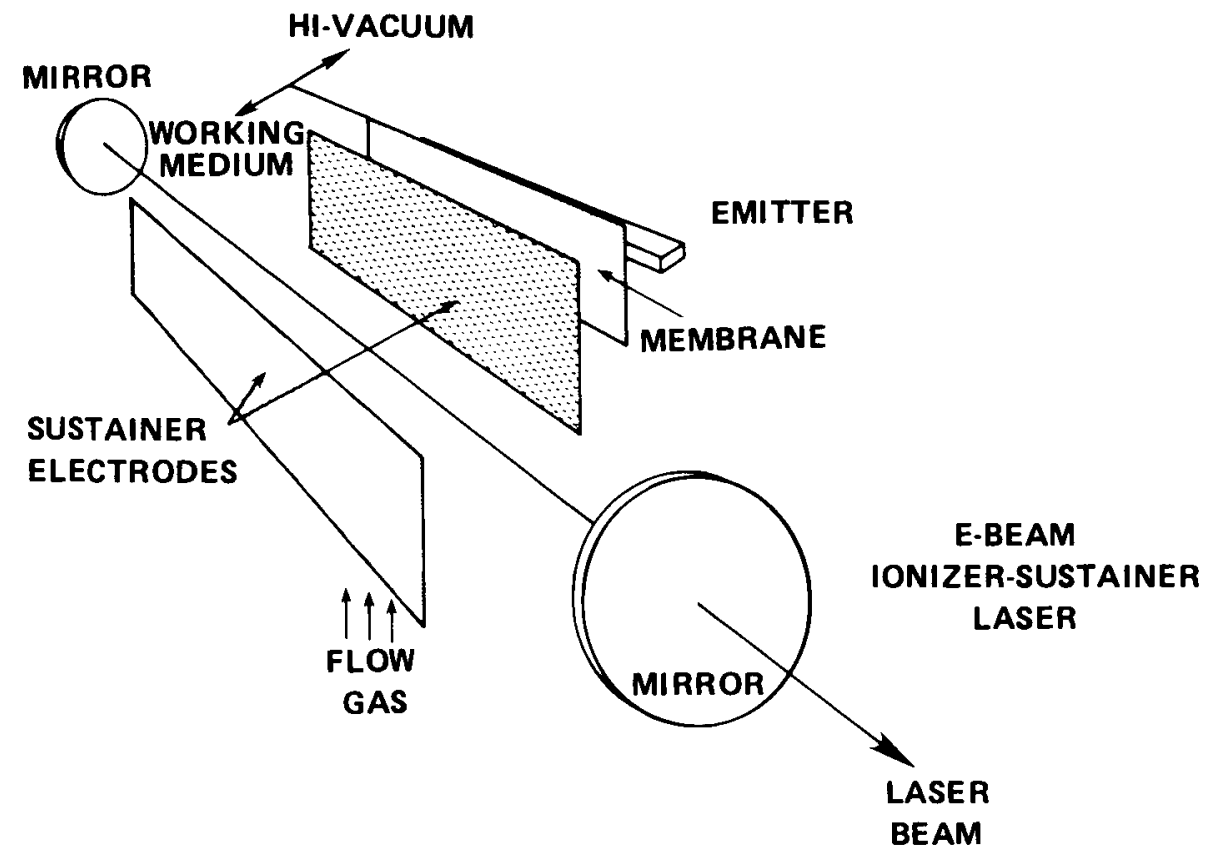

Figure 3.2 Lasing Gas lonized by Large Area Electron Beam (After Locke ${ }^{13}$ )

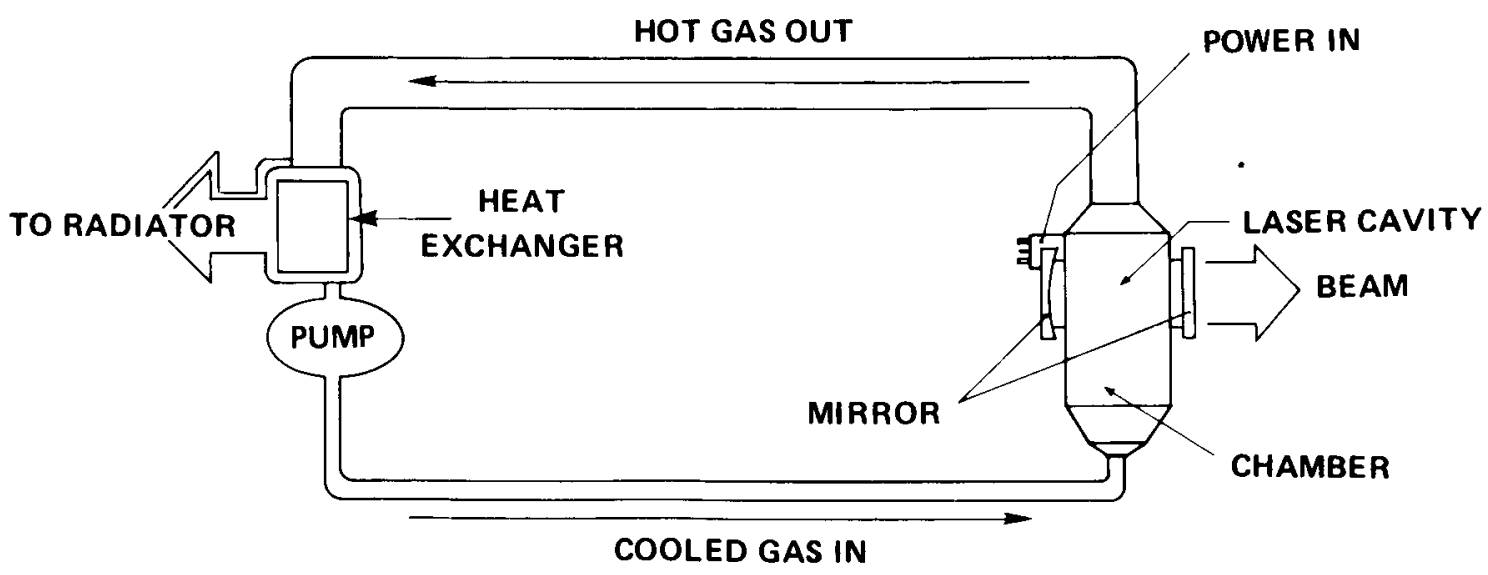

Figure 3.3 Closed-Cycle Subsonic Electric Discharge Laser System for Space 
temperature of approximately $600^{\circ} \mathrm{K}$. The laser being scalable, these temperatures and desired power output can be used to design the cavity and electrodes, determine gas flow rates, ${ }^{9}$ and size system components. This laser can give a single line output at $10.6 \mu \mathrm{m}$ and at other wavelengths close to $10.6 \mu \mathrm{m}$ and will provide open-cycle efficiencies up to 30 percent; some lasant reconditioning would be necessary for closed-cycle continuous operation. 13,14

The operation of the $\mathrm{CO}$ laser is very similar to the $\mathrm{CO}_{2}$ laser previously described except that lasing is initiated when the gas is at a lower temperature (near $60^{\circ} \mathrm{K}$ ). Maintaining the lasant at this temperature requires a supersonic gas flow. The $\mathrm{CO}$ laser converts electric energy to radiation very efficiently (approximately 50 percent); however, the auxiliary power required for supersonic gas flow reduces this efficiency to around 30 percent for an overall system value. (This compares to 18 percent for a closed-cycle $\mathrm{CO}_{2} \mathrm{EDL}$.) The energy is extracted from a set of spectral lines, perhaps a hundred in the $4.8 \mu \mathrm{m}$ to $5.3 \mu \mathrm{m}$ band. Atmospheric attenuation varies depending on the spectral line. - / This laser could not be phased with other CO lasers to increase output power unless a single line were used, and in this case the efficiency of the phased array of lasers would be much less than 30 percent.

Work is underway on the development of high-power electric discharge lasers using several other lasants. Table 3.1 compares the efficiencies of some of these gases with those of $\mathrm{CO}_{2}$ and $\mathrm{CO}$. The lasant temperatures at which laser action starts are shown for some of the lasers, and the major spectral line of interest (CO excepted) for each is also shown.

The carbon dioxide, carbon monoxide, mercury chloride, and mercury bromide lasers may be possible SPS power transmission subsystem candidates provided continuing development efforts bring their performances into the useful range. Continuous wave (CW) lasers probably will be used for power transmission to reduce optics requirements and improve propagation. Wavelength, which affects beam formation and determines equipment sizes and tolerances, is also important from atmospheric transmission and environmental standpoints. In addition, lasant operating temperature is important in determining gas flow rates and the design for waste heat rejection.

b/ The detailed investigation of the atmospheric attentuation of various spectral lines is beyond the scope of this study. For information on the atmospheric transmission of selected $\mathrm{CO}$ (and $\mathrm{CO}_{2}$ ) laser wavelengths see reference 15 . 
Efficiency has a direct effect on the size of the solar collectors and determines the amount of waste heat that must be rejected. The significance of laser wavelength on system characteristics is discussed in section 3.1. The relationship of laser efficiency and lasant operating temperature to waste heat and its removal is discussed briefly below. Table 3.2 provides estimates of the parameters of four lasers. Laser \#1 $\left.\right|^{18}$ and laser $\# 2^{14}$ are $\mathrm{CO}_{2}$ EDL's and represent roughly the state of the art in HPL equipment. The $\mathrm{CO}_{2} \mathrm{EDL} \# 3^{19}$ is a conceptual laser proposed for laser aircraft propulsion. Laser $\$ 4$ is a projection of current HPL state of the art to a level that would, when operating in conjunction with subsystem components with the efficiencies shown, approximately meet LPTS requirements (see table 2.2). The efficiency (0.83) is considered to be speculative, if possible at all.

Table 3.1 State-of-the Art Characteristics

of Some Electric Discharge Lasers

\begin{tabular}{|c|c|c|c|}
\hline Laser Type & $\begin{array}{l}\text { Wavelength } \\
\text { (micrometer) }\end{array}$ & $\begin{array}{l}\text { Lasant Operating } \\
\text { Temperature }\left({ }^{\circ} \mathrm{K}\right)\end{array}$ & $\begin{array}{l}\text { Open-Cycle } \\
\text { Efficiency }\end{array}$ \\
\hline Carbon dioxide & 10.6 & 300 & $0.20-0.30$ \\
\hline Carbon monoxide & $4.8-5.3$ & $60-100$ & $0.25-0.50$ \\
\hline Krypton fluoride & $\begin{array}{l}0.2500 \\
\text { absorbed by } \\
\text { ozone layer }\end{array}$ & & $0.10-0.12^{*}$ \\
\hline Xenon fluoride & 0.3505 & & $0.025-0.03^{*}$ \\
\hline Xenon chloride & $\begin{array}{l}0.3100 \\
\text { absorbed by } \\
\text { ozone layer }\end{array}$ & & $0.025-0.03 *$ \\
\hline Mercury chloride & 0.5500 & 500 & $0.10-0.12^{*}$ \\
\hline Mercury bromide & 0.5700 & 500 & $0.10-0.12^{*}$ \\
\hline
\end{tabular}

* Reference 17 is the source for these pulsed laser efficiencies. 


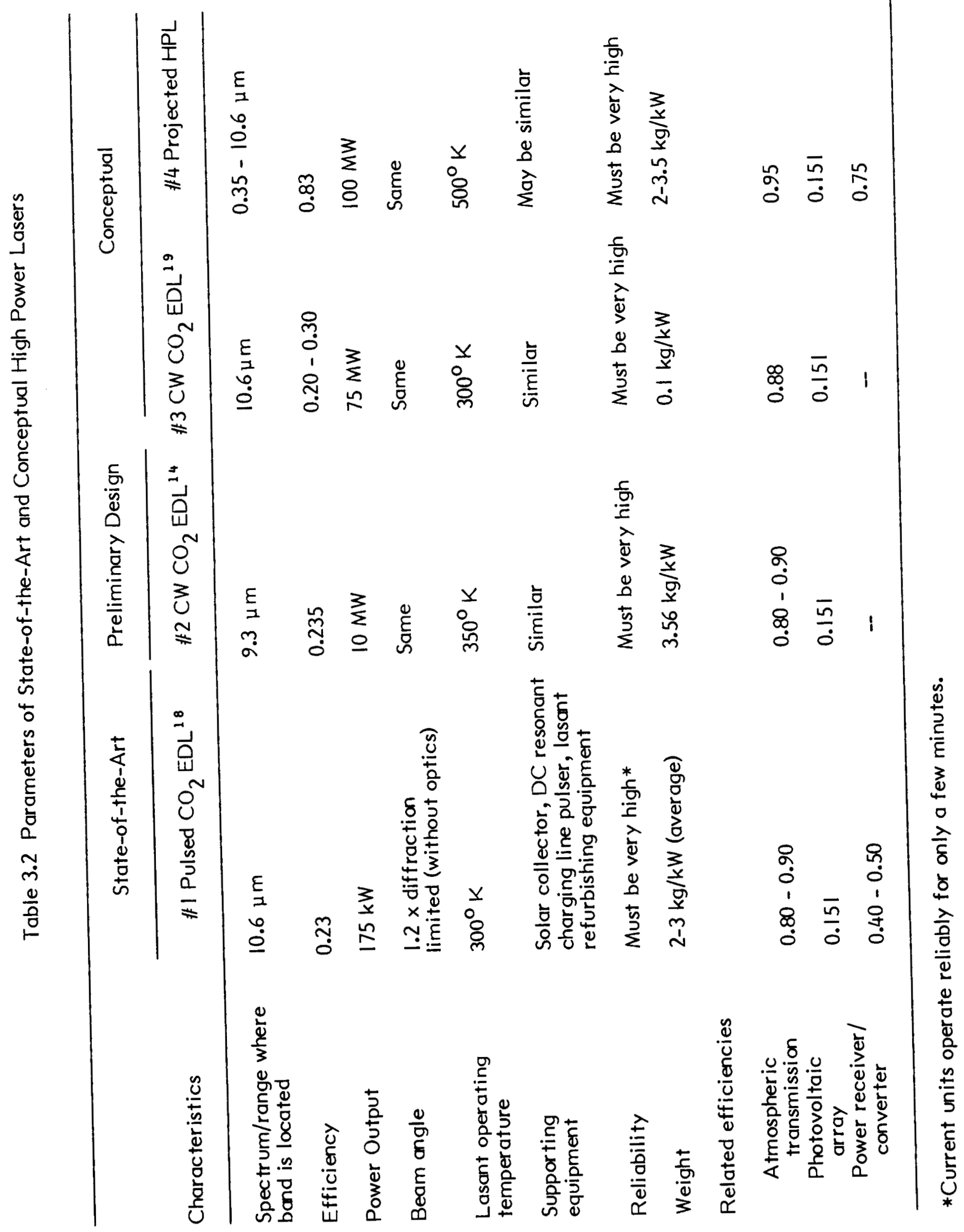


A laser that has an overall efficiency of 30 percent and an output power of 30 $M W$ will require an input power of $100 \mathrm{MW}$. In an EDL this input power would include electric-discharge power plus any auxiliary power for pumps, lasant refurbishing equipment, and control. All the power that does not go into the beam (in this case, 70 $\mathrm{MW}$ ) becomes heat. This heat must be removed by radiation; however, it may be put to some constructive use before being radiated. The penalty associated with the "use" of this waste heat is that it then must be radiated at a lower temperature, at the cost of a larger radiator. If the heat is removed by a radiator at the operating temperature of the lasing gas $\left(300^{\circ} \mathrm{K}\right.$ in the case of the $\mathrm{CO}_{2}$ laser), a large radiator surface is required. $\subseteq$ The area of this surface can be determined by $P / W$, where $P=$ power to be radiated (in this case $70 \mathrm{MW}$ ) and $W=$ the total radiant flux emitted per unit radiator area.

$W$ can be calculated using the Stefan-Boltzmann law:

where:

$$
W=\varepsilon \sigma\left(T^{4}-T_{0}^{4}\right) \rightarrow \varepsilon \sigma T^{4}\left(\text { when } T_{0} \rightarrow 0^{\circ} K\right)
$$

$$
\begin{aligned}
& \varepsilon=\text { Emissivity factor } \equiv 1.0 \\
& \sigma=\text { Stefan-Boltzmann constant }=5.6686 \times 10^{-12} \mathrm{~W}-\mathrm{cm}^{-2} \mathrm{deg}^{-4} \\
& T=\text { Temperature of radiator } \equiv 300^{\circ} \mathrm{K} .
\end{aligned}
$$

If $T_{0}$, the temperature of outer space, is assumed to be near zero, the radiating surface area is found to be $0.15 \mathrm{sq} . \mathrm{km}$. Because the heat emitted by radiator increases as the fourth power of temperature, operating at a higher temperature can reduce the required radiator area significantly. For example, if the lasant operating temperature could be increased from $300^{\circ} \mathrm{K}$ to $500^{\circ} \mathrm{K}$ without reducing laser efficiency, radiator area could be reduced by a factor of $(500 / 300)^{4}=7.7$. Figure 3.4 is a plot of the multiplying factor $(M)=\left(300^{\circ} \mathrm{K} / \mathrm{T}\right)^{4}$ versus temperature. Multiplying factors can be taken from the ordinant to determine radiator areas for radiator operating temperatures from near $0^{\circ} \mathrm{K}$ to $1000^{\circ} \mathrm{K}$.

cf If the laser-heat radiator temperature cannot be raised to the temperature of the nearby acres of solar cells (or other primary collector), it becomes a heat sink for them unless some creative topology and directional radiator technology is developed. Earth radiation also will need to be avoided. 


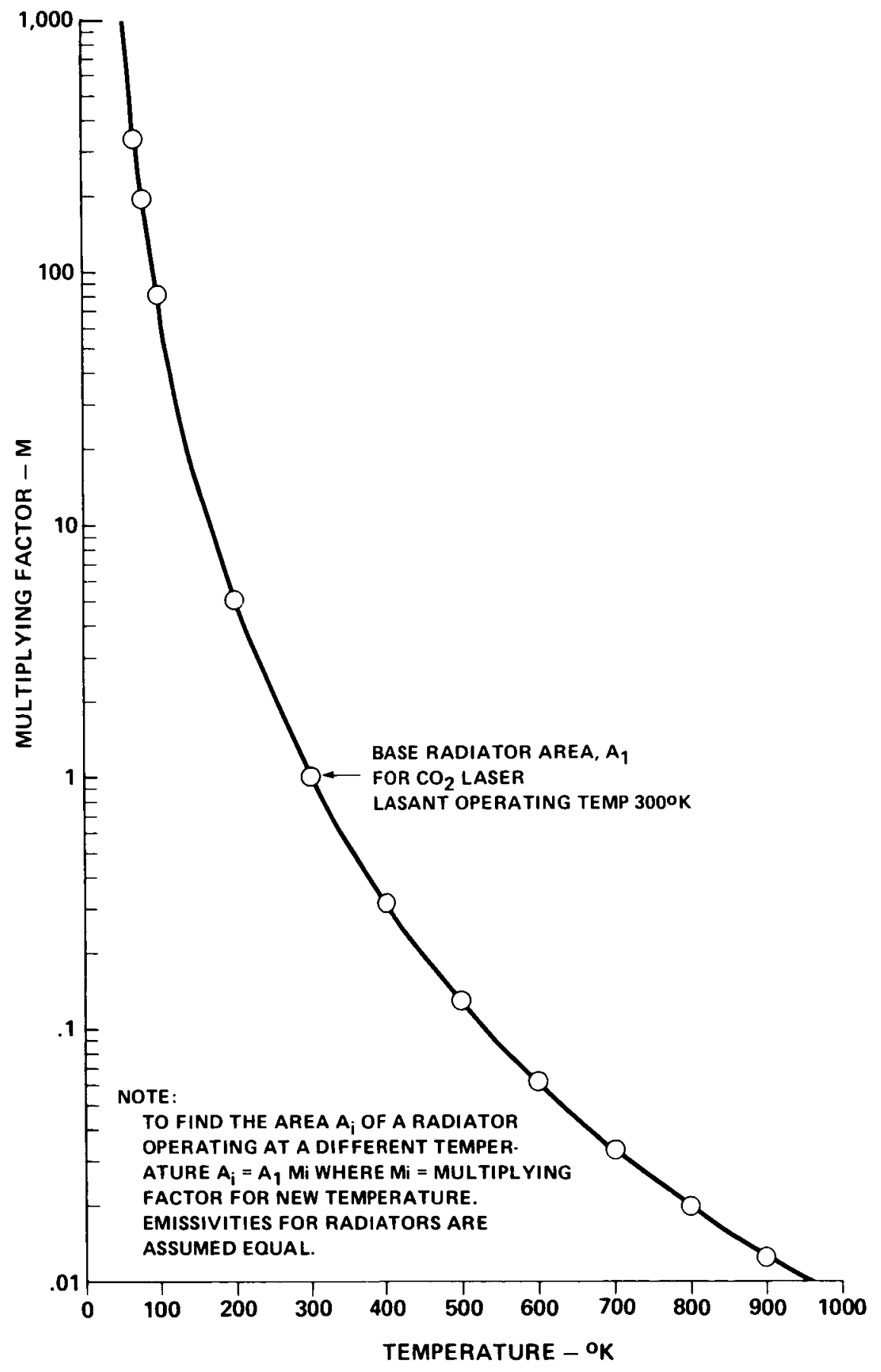

Figure 3.4 Relationship of Radiator Operating Temperature and Radiator Area 
For example, to indicate the importance of lasant operating temperatures, a subsonic, closed-cycle CO laser operating at a lasant temperature of $60^{\circ} \mathrm{K}$ (inlet temperature of $80^{\circ} \mathrm{K}$ ) would require a radiator 198 times larger than required by the $\mathrm{CO}_{2}$ laser if the heat were actually removed by the radiator at $80^{\circ} \mathrm{K} \cdot{ }^{14}$ However, if a laser could be designed to operate at $1000^{\circ} \mathrm{K}$ with the same efficiency, radiator area could be reduced by a factor of 123. In practice, the CO laser is usually operated supersonically. When the cavity is operating at $60^{\circ} \mathrm{K}$, the inlet gas to the laser is still near $300^{\circ} \mathrm{K}$ (because the gas is cooled by expanding it through nozzles to a velocity of Mach 3 to Mach 3.5), and heat is removed at this higher temperature. The price that is paid for this higher waste heat rejection temperature and reduced radiator area is a loss of laser efficiency resulting from the power needed to maintain the supersonic gas flows. System weight for a given power out is then increased by the weight of larger pumps, the increase in number of laser units, and the larger solar collectors that are required. Laser operating temperature and the efficiency of the lasant at this temperature are therefore important considerations in designing the LPTS for efficient heat rejection. - /

\subsubsection{Laser Scaling}

There appear to be no theoretical limits in laser physics to prevent the scaling of chemical and gas dynamic lasers to produce almost any amount of power needed. Electric-discharge lasers can also be scaled, but more problems are anticipated because of the electric discharge. $10, \underline{e}$ Some of the major practical

d / Dissipating waste heat while using it may be possible, making an otherwise marginal system economical. During the deployment and operation of the SPS, waste heat could be used by the onsite SPS crews, if this is planned for, and later by groups (communities) assembled to support SPS crews and to engage in energy-intensive processing and manufacturing suited to the space environment. Total energy systems in space (and at earth receiving sites) would decrease the cost of electricity from the SPS. Pursuing this solution to cost reduction, an inefficient SPS would tend to subsidize space industry. The move toward the total energy system concept (in space and on the ground) to improve the efficiency of a system that is already efficient would progress only as technology and profits permit.

ef "Discharges and electron-beam sustained discharges are potentially scalable to Targe volumes, but scale-up will impose severe requirements for electrical stability and for selective energy flow kinetics." (See reference 20.) 
limitations on power output of a given laser configuration are as follows: (a) lasant breakdown, (b) the mechanical and heat tolerance characteristics of optical components, and (c) the capability to remove the waste heat from the lasing cavity. Limitations encountered in scaling up EDL's, whether these result from natural laws, the state of technology, or economics, can be sidestepped by phase-locking a number of smaller lasers to give the desired power output.

\section{I OTHER TECHNICAL FACTORS AFFECTING CHOICE OF LPTS LASER}

The wavelength of the laser system appears to be the single most important parameter in terms of the laser's physical and performance characteristics and its effects on the environment. This is because all the important LPTS performance characteristics (e.g., the efficient propagation of radiation through the atmosphere and other media, the ability to form useful beams with cost-competitive components, and the efficient conversion of energy) are wavelength dependent. The following paragraphs briefly discuss beam shaping and propagation, optics, and energy conversion systems.

\subsubsection{Beam Shaping}

The effective propagation of energy through the atmosphere depends on the shape of the beam, the wavelength and density of the energy in the beam, the length of the atmospheric path, and the densities and/or populations of the gases and other constituents of the atmosphere. The shape and intensity pattern of a laser beam of a given wavelength, $\lambda$, is largely determined by the design and dimensional control of the laser cavity and the beam-forming optics.

Energy in a laser cavity shared through diffraction produces the phase coherence of the beam. Transverse modes of oscillation caused by the geometry of the cavity will result in an intensity pattern at the output that is peculiar to that cavity. Long cavities having low Fresnel numbers $\left(N_{f}=a^{2} / d \lambda\right.$, where $a=$ mirror radius, $d=$ distance between mirrors, and $\lambda=$ laser wavelength) can be made to oscillate in one mode only, producing a "single spot" high-quality main lobe. In high-power systems, where cavities must have large volumes, low Fresnel numbers are not always possible, in which case unstable cavities that tend to "smear" the peaks of the intensity pattern for a more uniform output are often used. 


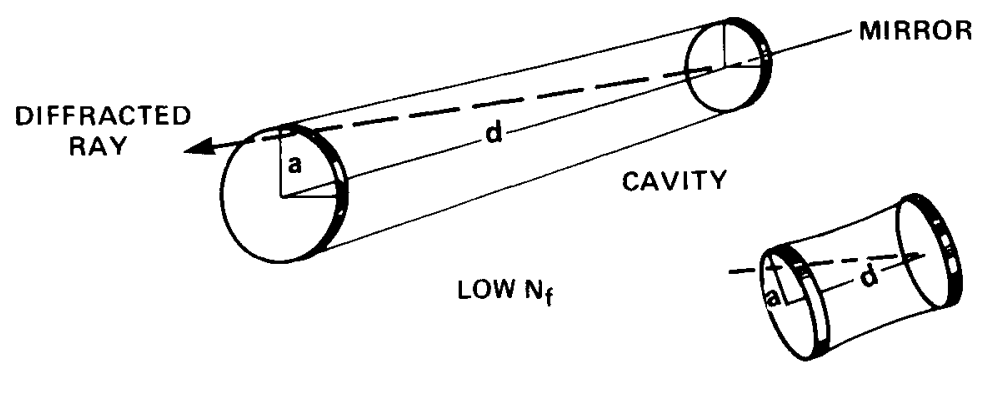

$H I G H N_{f}$

The diffraction spread ( $r$ ) of an optical aperture is given by:

$$
r=\theta R=\beta \frac{\lambda}{D} R
$$

where:

$\theta=$ resolving angle of an aperture

$D=$ aperture diameter

$R=$ range to aperture

$B=$ factor by which beam spread exceeds the diffraction limit.

As $r$ increases and transmitted power is spread over larger areas, and as a particular subsystem design allows this illuminated area $\left(A=\pi r^{2}\right)$ to increase, the diameter of the optics aperture can be allowed to decrease until a practical minimum is reached where excessive heating occurs.

Ten gigawatts of power will illuminate a circular spot on the earth that is 3.56 $\mathrm{km}$ in diameter at the sun irradiance level of approximately $1 \mathrm{~kW} / \mathrm{m}^{2}$. This power $(\lambda=10.6 \mu \mathrm{m})$ can be projected from GEO with a $50 \mathrm{~cm}$ diameter optical system with a resolving capability that is two times the diffraction limit. For an atmospheric transmission, $\dagger=0.8$, transmitted power must be $12.5 \mathrm{GW}$, and the radiance from the aperature is $\sim 6.4 \mathrm{MW} / \mathrm{cm}^{2}$. This power density, as discussed later, is many times the level needed to cause the aperture to overheat. Aperture heating can be avoided by using more apertures. For example, one hundred thousand of these apertures arrayed and positioned to point at the same spot would reduce the radiance required from each aperture to $64 \mathrm{~W} / \mathrm{cm}^{2}$. The ITEK Corporation ${ }^{21}$ has shown the feasibility of a state of the art technology, 30-m, space-based laser transmitter that uses active optics. The mirror has a 99 percent reflectivity and can withstand a flux of $10 \mathrm{~W} / \mathrm{cm}^{2}$. Table 3.3 
shows the relationship of the number of apertures (or lasers) used in an array to transmit $12.5 \mathrm{GW}$ to total aperture area, $\mathrm{m}^{2}$, minimum array diameter, $\mathrm{m}$, and radiancy $\left(W / \mathrm{cm}^{2}\right)$ from the aperture. Equation 2 shows that shorter wavelength systems can use apertures of proportionately smaller diameters except when limited by power-handling considerations. The power transmission system (LPTS-2) could use photovoltaic conversion or concentrating mirrors and thermal cycle at the earth's surface. The type of photovoltaic cell--Si, GaAs, $(\mathrm{Hg}, \mathrm{Cd}) \mathrm{Te},(\mathrm{Pb}, \mathrm{Sn}) \mathrm{Te}$, or others-would depend on the wavelength of the power transmitted. The thermal conversion unit would be effective over a broader wavelength range.

To reduce the received beam size (and increase intensity, as in the LPTS-1) to accommodate more easily high-energy density conversion systems, the transmit aperture diameter must be increased and/or optical quality must be improved to reduce diffraction spreading. Eventually, the minimum beam size will become limited by other mechanisms such as pointing jitter and atmospheric propagation effects. If the beam angular size were limited by these effects to a value greater than about 0.5 $\mu \mathrm{rad}$, there would be no reason to reduce diffraction spreading to values less than this amount.

Table 3.3 Relationship of Number of Apertures, Area, Diameter of Arrays, and Aperture Radiancy

Number of Apertures
Area $\left(m^{2}\right)$
Minimum Array

Diameter $(\mathrm{m})$
Radiancy from

Aperture $\left(\mathrm{W} / \mathrm{cm}^{2}\right)$

$\begin{array}{cccc}1 & 0.19 & 0.5 & 6.4 \times 10^{6} \\ 320 & 60.8 & 8.8 & 20 \times 10^{3} \\ 1,000 * \\ 10,000 \\ 32,000 \\ 100,000 *\end{array}$

* These values may bracket an optimum system. The physical size of the system will depend largely on mirror operating temperature and its reflectivity. 
Setting beam angle $\beta \frac{\lambda}{D} \geq 0.5 \mu \mathrm{rad}$ and using $\beta=2$, and $\lambda=10.6 \mu \mathrm{m}$, the maximum diameter aperture that can be justified for this case is $D \leq 42.4 \mathrm{~m}$, and the radius, $r$, of the illuminated spot on the ground is $\sim 17.9 \mathrm{~m}$ except as changed by atmospheric effects that can vary significantly with wavelength. $f$ The irradiance required at this single aperture (a mirror with reflectance $=0.99$ ) to provide $10 \mathrm{GW}$ of rectified power at the earth is $\sim 1.5 \mathrm{~kW} / \mathrm{cm}^{2}$ (or approximately $21.2 \mathrm{GW}$ ). In practice to reduce mirror heat load several of these units would be arrayed and positioned to point at the same area on the earth, and/or phase-locked to illuminate the desired area. This would allow each laser or laser/mirror transmission unit to be designed to handle the optimum amount of power and enable this group of power transmission units to be dispersed in space as needed for effective heat rejection. $\mathrm{g} /$

\subsubsection{Sidelobes}

The diffraction pattern of a circular aperture can be determined using equation 2 and the values for $\beta$ given in table $3.4^{24}$ Solving this equation, using these values for $B$ the radii of the first through the fifth dark and bright rings can be determined. These radii (for $D=42.4 \mathrm{~m}, \lambda=10.6 \mu \mathrm{m}$, and $R=3.58 \times 10^{7} \mathrm{~m}$ ) and the intensity and power relative to the main lobe are also shown in the table.

A sketch representing the idealized intensity distribution of power from a circular aperture is shown in figure 3.5. The actual pattern produced at the ground level by the LPTS will depend on the quality of the transmitting aperture, the intensity pattern at the output of the laser, and atmospheric effects.

f/ Thermal blooming is the spreading of a beam caused by the absorption of a small part of beam energy by the atmosphere. This spreading will increase the sea level diameter of the $\mathrm{CO}_{2}$ beam, reducing ground level average intensity (watts/unit area). Thermal blooming is less of a problem for beams pointing toward the earth than for beams pointing away from the earth because of the relatively short distance the beam travels after thermal blooming begins. Thermal blooming effects may tend to envelop and/or diffuse the sidelobe structure of a beam.

g/ A reliable and fail-safe system for pointing the LPTS- I at the receiver is required. $\bar{A}$ lthough this problem was not considered in any detail during this study, pointing accuracies for laser systems have been variously reported from 0.2 arc seconds $(9 \times$ $10^{-7}$ radians) for the Air Force Laser $\operatorname{lab}^{22}$ to $2 \times 10^{-7}$ radians ${ }^{20}$ for the $30-\mathrm{m}$, spacebased transmitter. In other sources, ${ }^{13},{ }^{23}$ currently attainable tracking accuracies for laser pointing have been estimated to be from $10^{-7}$ to $10^{-8}$ radians. The reliable and fail-safe aspect of the problem will be a significant engineering challenge. 
Table 3.4 Pattern at Earth (4.2.4 $\mathrm{m}$ Aperture at GEO, $\lambda=10.6 \mu \mathrm{m}$ )

\begin{tabular}{|c|c|c|c|c|}
\hline Lobe or Ring & $B$ & $\begin{array}{l}\text { Radius } \\
\text { (Meters) }\end{array}$ & $\begin{array}{l}\text { Relative } \\
\text { Power } \\
\text { Density }\end{array}$ & $\begin{array}{c}\text { Relative } \\
\text { Total } \\
\text { Power }\end{array}$ \\
\hline Central max & 0.000 & 00.0 & 1.00000 & 1.000 \\
\hline Ist dark & 1.220 & 10.9 & & L \\
\hline 2nd bright & 1.638 & 14.7 & 0.01745 & 0.084 \\
\hline 2nd dark & 2.233 & 20.0 & & \\
\hline 3rd bright & 2.666 & 23.9 & 0.00415 & 0.033 \\
\hline 3rd dark & 3.238 & 29.0 & & \\
\hline 4th bright & 3.694 & 33.1 & 0.00165 & 0.018 \\
\hline 4th dark & 4.241 & 37.7 & & \\
\hline 5th bright & 4.722 & 42.3 & $\overline{0.00078}$ & $\overline{0.011}$ \\
\hline 5th dark & 5.243 & 46.9 & & 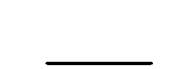 \\
\hline
\end{tabular}

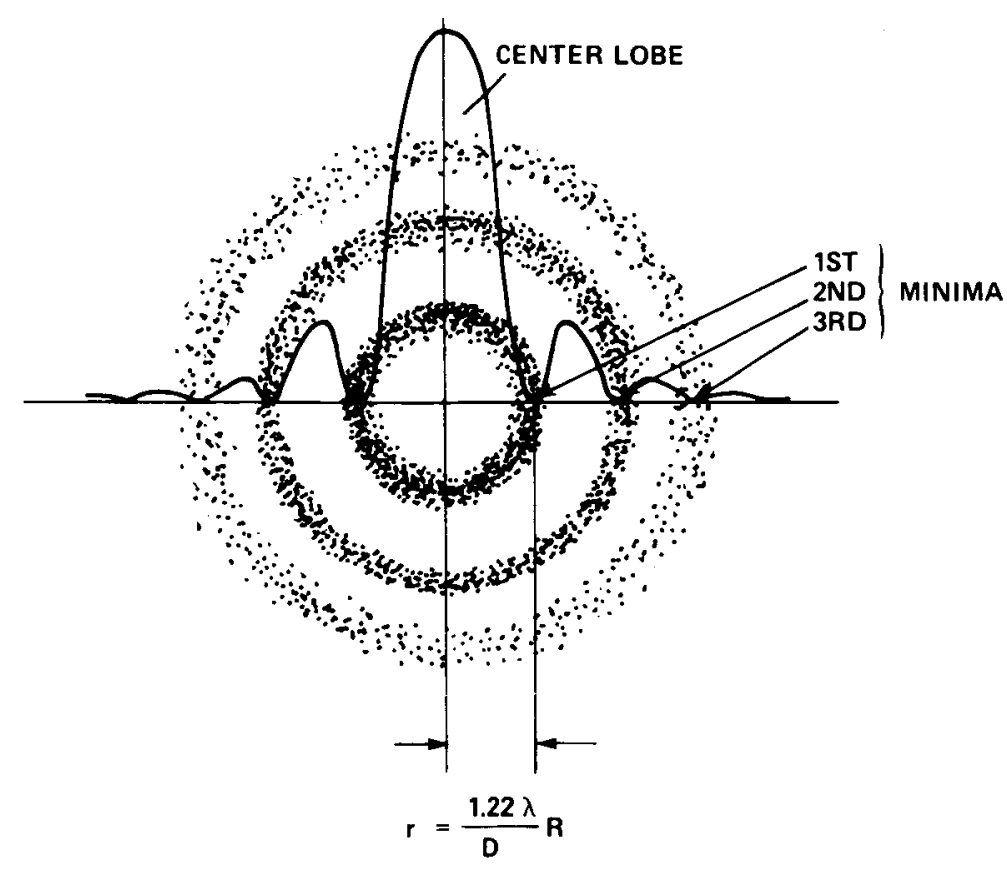

Figure 3.5 Intensity Distribution From a Circular Aperture 


\subsubsection{Propagation}

The most important factors that affect the propagation of high-power laser beams are:

- Linear absorption and scattering by the constituents of the atmosphere;

- Atmospheric turbulence, induced random wander, spreading, and beam distortion;

- Attenuation of the beam by the plasmas resulting from breakdown of the atmospheric gases; and

- Thermal blooming that results from the atmospheric absorption of some of the laser beam power.

The severity of these effects for the LPTS will depend on the atmospheric conditions at the receiving site, the wavelength of the radiation, the intensity/time characteristics of the beam, and the altitude of the receiving site. Figure 3.6 relates the atmospheric transmission of several laser wavelengths to the altitude of the receiver. $^{25}$ Frederick G. Gebhardt ${ }^{26}$ has summarized some of the effects of atmosphere on high-power laser radiation propagation as follows:

The highest peak irradiance is obtained with the 1.06- $\mu \mathrm{m} \mathrm{Nd}$ wavelength with weak turbulence and aerosol effects. As turbulence and aerosol effects increase the 3.08- $\mu \mathrm{m} \mathrm{DF}$ wavelength offers the best performance. In general, thermal blooming tends to dominate the longer 5-10- $\mu \mathrm{m}$ wavelengths while aerosol and turbulence effects become dominant and lead to wide variations in performance with varying atmospheric conditions at the shorter (visible and near IR) wavelengths.

Table 3.5 provides sea-level aerosol absorption and scattering coefficients for representative laser wavelengths. Note the increase in absorption and scattering at the shorter wavelengths.

New lasers of selected wavelengths and adaptive optical techniques to use data from measurements and modeling are already reducing turbulence and thermal blooming problems.

Site location and altitude can be chosen to reduce the incidence of cloud cover and aerosol scattering. The ability to send power economically in small "packets" will allow receiver/conversion sites to be widely dispersed, reducing power distribution costs, while making cloud cover a statistical problem that can be controlled. Lockheed, in recognizing the cloud cover problem, has stated that more than 90 percent of the continental United States has weather conditions that permit efficient laser transmissions for more than 50 percent of the time. Cloud cover is a problem that will require considerable study to develop the information needed for receiver site selection. 


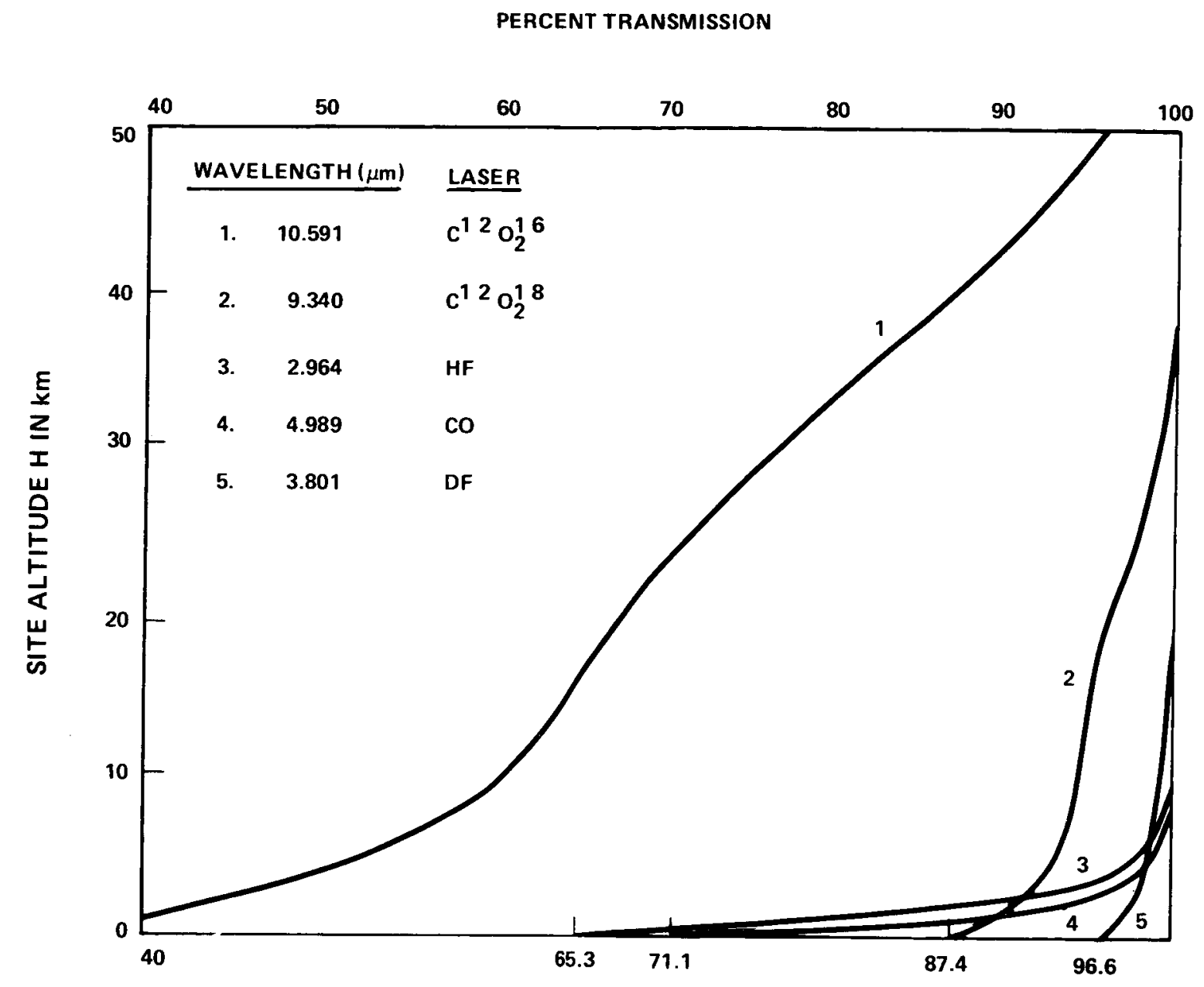

Figure 3.6 Vertical Transmittance for Receiver at

Altitude $\mathrm{H}$ for Selected Laser Wavelengths

$\left(1966,45^{\circ} \mathrm{N} \text { July Model Atmosphere }\right)^{25}$

NOTES:

- From work performed at NASA Langley Research Center

- Transmission for $2.0 \mu \mathrm{m}$ radiation is expected to fall near curve $5(3.801-$ $\mu \mathrm{m}$ for DF). The attenuation of the $4.989 \mathrm{CO}$ line is relatively low.

- Pressure broadening in the $\mathrm{CO}_{2}$ laser by the addition of $\mathrm{He}$ (curve 1 ) allows the device to be tuned off the atmospheric absorption line by a few Angstroms. This can result in improved atmospheric transmission.

- The altitude of the sites can have a significant effect on overall LPTS efficiency for some wavelengths. 
Table 3.5 Aerosol Absorption and Scattering Coefficients--Sea Level ${ }^{26}$

\begin{tabular}{ccccc}
\hline Wavelength, & \multicolumn{2}{c}{$\begin{array}{c}\text { Absorption } \\
\text { Coefficient, } \mathrm{km}^{-1}\end{array}$} & \multicolumn{2}{c}{$\begin{array}{c}\text { Scattering } \\
\text { Coefficient, } \mathrm{km}^{-1}\end{array}$} \\
$\mu \mathrm{m}$ & Clear & Hazy & Clear & Hazy \\
\hline 10.5910 & 0.0055 & 0.0270 & 0.0095 & 0.0460 \\
4.9890 & 0.0030 & 0.0146 & 0.0140 & 0.0682 \\
3.8007 & 0.0017 & 0.0083 & 0.0193 & 0.0940 \\
2.9573 & 0.0050 & 0.0244 & 0.0180 & 0.1187 \\
1.0600 & 0.0120 & 0.0580 & 0.0780 & 0.3800 \\
0.5145 & 0.0110 & 0.0530 & 0.1890 & 0.9210 \\
0.3371 & 0.0170 & 0.0830 & 0.2630 & 1.2810 \\
\hline
\end{tabular}

\subsubsection{Optics}

The HPL industry has established and is continuing to establish requirements for high-temperature materials that can be formed, cut, and polished into large precision components capable of transmitting or reflecting large amounts of power. These components include mirrors, refractors, windows, substrates for spectral filters, and mounting hardware.

In response to these requirements, the Department of Defense (DOD) has provided and sustained effective support through the Materials Office, Defense Advanced Research Projects Agency (DARPA), the Naval Research Laboratory (NRL), and Air Force and Army Laboratories since the early 1970's. This support has allowed significant reductions in the residual absorption of selected materials and has increased the strengths and temperature tolerances of some materials. For example, Reactive Atmosphere Processing (RAP) purification techniques ${ }^{27}$ developed at NRL and Hughes Research Laboratories eliminate impurity centers that may cause absorption at $10.6 \mu \mathrm{m}$. Table $3.6^{27}$ provides examples of absorption in some of the RAP-grown materials. The reduction of residual absorption of window material by a factor of 10 (e.g., from $1.5 \times 10^{-4} \mathrm{~cm}^{-1}$ to $1.5 \times 10^{-5} \mathrm{~cm}^{-1}$ ) allows the window to transmit 10 times as much power while maintaining the same operating temperature. However, for the laser powers under consideration for the SPS LPTS, it is unlikely that materials or cooling concepts for solid windows, even with the materials cited in table 3.6, will be available in the near future with the required antidistortion and strength characteristics. ${ }^{27,28}$ Some laser designs have included rotating windows to distribute incident radiation over a larger area. Edward Locke was reported 14 to have indicated that such a rotating window of zinc selenide would accommodate an incident flux of $50,000 \mathrm{~W} / \mathrm{cm}^{2}$ without risk of structural damage. In an alternate window approach to 
Table 3.6 Optical Absorption in RAP-Grown Alkali Halides at $\mathrm{Nd}^{3+}$, $\mathrm{HF}, \mathrm{DF}$, and $\mathrm{CO}_{2}$ Laser Wavelengths ${ }^{27}$

\begin{tabular}{lllll}
\hline \multicolumn{5}{c}{ Bulk Absorption Coefficient $\left(\mathrm{cm}^{-1}\right)$} \\
\hline Halide & $1.06 \mu \mathrm{m}\left(\mathrm{Nd}^{3+}\right)$ & $2.7 \mu \mathrm{m}(\mathrm{HF})$ & $3.8 \mu \mathrm{m}(\mathrm{DF})$ & $10.6 \mu \mathrm{m}\left(\mathrm{CO}_{2}\right)$ \\
\hline $\mathrm{KBr}$ & $3 \times 10^{-6}$ & $1.2 \times 10^{-4}$ & $2.2 \times 10^{-4}$ & $1.5 \times 10^{-5}$ \\
$\mathrm{KCl}$ & & $1.0 \times 10^{-3}$ & $9.5 \times 10^{-4}$ & $6.6 \pm 2 \times 10^{-5}$ \\
\hline
\end{tabular}

avoid heat and strength problems, aerodynamic windows are used to support the lasercavity-to-space pressure differential of a few hundred Torr. Because flow rates vary in proportion to the laser window area, gas supply requirements would be prohibitive for continuous operation for most window designs.

Michael Monsler ${ }^{28}$ however, describes an aerowindow design that uses dry $\mathrm{N}_{2}$ gas at one atmosphere, which may represent an approach to the problem. The optical beam is focused to reduce the size of the window opening required, thus reducing the mass flow and the amount of gas lost. Spherical optics having a focal length, $F$, of $1 \mathrm{~m}$ and a diameter, $D$, of $10 \mathrm{~cm}$ can reduce the area of the beam by $\left(\lambda F / D^{2}\right)^{2}$ For $\lambda=10.6 \mu \mathrm{m}$, this is a factor of $10^{6}$. If the breakdown threshold of the $N_{2}$ gas is $10^{8}$ $W / \mathrm{cm}^{2}$, the window could handle a beam intensity of $100 \mathrm{~W} / \mathrm{cm}^{2}$ out of the $10-\mathrm{cm}-$ diameter aperture. This represents a power of $7.85 \mathrm{~kW}$ through a window that is 0.01 $\mathrm{cm}$ in diameter. TRW is producing successful high-power aerodynamic window designs for operation in the atmosphere, and Hughes Aircraft Company and United Technologies Corporation have investigated aerowindows for spaceborne laser systems. 11,14 The vacuum of space and the logistics problem of replacing lost gas will combine to make designs for space aerowindows more difficult. Important design parameters will include lasant chamber operating pressure, beam power, and allowable gas loss. Monsler lists aerodynamic window advantages and disadvantages as:

\section{Advantages \\ Disadvantages}

- No risk of catastrophic failure

- Tanks, pump, and gas supply needed

- No thermal absorption and distortion

- Higher operating cost

- No surface finishing or contamination problems

- $\quad$ Simple available technology

- Lower initial costs 


\subsubsection{Refractors/Mirrors}

Problems encountered by refractive optical components and solid windows are similar since the radiation is transmitted through them. The effective design of a refractive element assembly for high-power laser use must reduce absorption of radiation by the element and provide for the removal of waste heat to avoid excessive beam distortion.

A good quality mirror may reflect 99 percent of the radiation it intercepts and absorb 1 percent. This generally presents no problem in ordinary applications. However, for a mirror $40 \mathrm{~m}$ in diameter that intercepts $100 \mathrm{MW}$ of power, absorbed power is $800 \mathrm{~W} / \mathrm{m}^{2}$. This is enough heat, unless it is removed, to damage the surface of the mirror and distort its figure in a short period of time. High-quality mirror surfaces are under development (expected on line around 1990) 14 that will provide reflectivities of 0.9995 . These surfaces will increase the power reflected by only a very nominal amount (+0.0095); however,the amount of power absorbed by the mirror will be decreased by a factor of 20 . This improved reflectivity of a mirrored surface enables a mirror of a given configuration to handle 20 times more radiant power. At present, high-efficiency multilayer dielectric coatings are available for laboratory applications, but they are difficult to produce for the longer wavelengths $(\lambda=10.6$ $\mu \mathrm{m}$ ) due to the uniformity required of the greater coating thicknesses.

At high flux levels, the optics may require active cooling. some of the available water-cooled, heat exchanger (HEX) mirror designs used with high-power, pulsed lasers require flow rates of several gallons per minute and hundreds of pounds of pressure drop across the HEX. For the large aperture systems, inefficiencies of state-of-theart pumps may actually add heat to the coolant at a greater rate than the absorbed laser power does. In any LPTS design, it may be possible to use much of the pulse laser technology; however, it will be important to avoid the use of power densities and components with characteristics that tend to require the heavy and logistically difficult-to-support heat removal equipment described above.

\subsubsection{Adaptive Optics}

For some flux levels the thermal distortions in the optics will exceed the figure tolerances required ${ }^{29}$ for the near (1.2 to 1.5 times) diffraction-limited performance that is desired. Adaptive optics can be used to correct for these errors and others that result from vibration, flexure, initial fabrication, and assembly. 
Control systems, figure error sensors, and actuator concepts are available. ${ }^{28,30}$ Mirror surface instrumentation concepts include real-time optical and mechanical sensors $\frac{\mathrm{h} /}{\mathrm{h}}$ and control devices. - /

Mirror material studies ${ }^{31}$ indicate a possible limit to total aperture subelement size. Therefore, each component mirror of a larger space mirror must be fully fabricated on the ground and then survive the stresses of launch or be partially fabricated in space. The G-loads at launch may limit the size of ground-constructed elemental mirrors for the large aperture arrays to less than about $1 \mathrm{~m}$ in diameter $\mathrm{j} /$ The construction of large mirrors in space will require the development of stable mounting structures, $\underline{-}$ / new materials, material fabrication and processing technology, and coating deposition techniques.

Whether material limitations or cargo hold size limitations dominate, ${ }^{18}$ the large aperture transmitters will likely be segmented arrays. As a result, there will be some undesirable sidelobe structure in the transmitted beam pattern. By minimizing dead space between array elements, the sidelobe gain can be minimized. The problem is generally analogous to that of the phased-array radar. Analysis is complicated by phase distortions within each subaperture.. !

The primary issues of large adaptive optical systems in space appear to be fabrication, initial assembly, and deployment. Meeting the tolerances, during component fabrication and assembly, required to bring the optical surfaces within the dynamic range of high precision adaptive figure control systems will be a challenge.

h/ Examples of sensors are interferometers, autocollimators, and strain gauges.

i/ Examples of control devices are piezoelectric, screw and spring force, and selfreacting actuators.

$\mathrm{j} /$ The 30-m mirror was designed (by ITEK Corporation under contract to NASA Lewis Research (enter) to be launched by Shuttle and assembled in space. ${ }^{21}$ Element sizes were limited by the dimensions of the Shuttle cargo bay to be no more than $4 \mathrm{~m}$ in diameter.

k/ This will involve the geometric arrangement of a limited amount of mass of an appropriately strong and stable material to provide the necessary stiffness.

1/ There is interest in the use of large plastic reflectors ${ }^{20},{ }^{32},{ }^{33}$ stretched taut or inflated for both power transmission and power collection; however, these have not been considered during this preliminary study. 


\subsubsection{Laser Energy Conversion Systems}

Solar energy is a very dependable source particularly for a collector in GEO. However, the energy is diffuse and the solar array of the SPS that collects it is relatively costly. Because the size of the array for a given SPS power output is inversely proportional to system efficiency, it is important that every link in the power collection, transmission, and conversion chain be selected and designed to add the most to overall system efficiency. Some of the solar and laser energy conversion options suitable for use with the LPTS (at the receiving site and in space) are discussed in the following subsections. Table 3.7 summarizes some of the physical and performance characteristics of these conversion systems and gives estimates of the development status. (Silicon and gallium arsenide solar cells have been in limited production for a number of years. Current development is oriented toward improving the cost, weight, performance, and reliability characteristics of the cells.)

\subsubsection{Photovoltaic Cells 34,35}

Semiconductors and the metal-oxide semiconductors (MOS) are two common types of photovoltaic converters. Cells of this type include silicon and gallium arsenide. These cells have electron band gaps of around $\mathrm{I} \mathrm{eV}$, which means that any photon having an energy of $\mathrm{I} \mathrm{eV}$ or greater can liberate an electron-hole pair if absorbed. Photons of wavelength less than $1.3 \mu \mathrm{m}$ will have energies greater than 1 $\mathrm{eV}$, but each photon can liberate only one electron-hole pair. Therefore, the energy of a photon that is in excess of the energy required to liberate an electron-hole pair is not converted to electricity but absorbed as heat. This results in a loss of some energy of all the photons with wavelengths shorter than $1.3 \mu \mathrm{m}$ and can represent a considerable portion of the sun's visible and ultraviolet radiation. Photons having wavelengths longer than $1.3 \mu \mathrm{m}$ have energies less than $\mathrm{I} \mathrm{eV}$ and do not liberate electron-hole pairs in the $\mathrm{I}-\mathrm{eV}$ materials. These photon energy losses combine with losses from reflections, absorption, electron-hole pair recombination, and resistance to account for the low efficiencies ( 13 to $2 \mid$ percent) of solar cells. Cells peaked to receive laser radiation will have band gaps matched to the energy of the photons received; therefore, all photons will be effective and little or no excess photon energy will be wasted. In this application, cells can be expected to have efficiencies of 30 to 45 percent. 
Table 3.7 Characteristics of Loser Energy Conversion Systems

\begin{tabular}{|c|c|c|c|c|}
\hline Conversion System & Type & $\begin{array}{l}\text { Wavelength } \\
(\mu \mathrm{m})\end{array}$ & Efficiency & $\begin{array}{l}\text { Development } \\
\text { Stage }\end{array}$ \\
\hline \multicolumn{5}{|l|}{ Photovoltaic Cells } \\
\hline Silicon & Semiconductor & $0.4-1.1$ & $0.30-0.35$ & Advanced \\
\hline Gallium Arsenide & Semiconductor & $0.4-0.9$ & $0.35-0.45$ & Advanced \\
\hline $\begin{array}{l}\text { Mercury Cadmium } \\
\text { Telluride }\end{array}$ & Semiconductor & 10.6 & 0.50 & Research \\
\hline $\begin{array}{l}\text { Lead Tin } \\
\text { Telluride }\end{array}$ & Semiconductor & 10.6 & 0.50 & Research \\
\hline Tuned Optical Diode & Semiconductor & & & Research \\
\hline Photoemissive Cells & & & $0.30-0.40$ & Research \\
\hline \multicolumn{5}{|l|}{ Heat Engines } \\
\hline Boiler & Mechanical & $\begin{array}{l}\text { UV thru } \\
\text { Far IR }\end{array}$ & 0.40 & Advanced \\
\hline Laser & Mechanical & May be & 0.50 & Exploratory \\
\hline Photon & Mechanical & $\begin{array}{l}\text { Limited } \\
\text { by Window }\end{array}$ & $0.60-0.75$ & Research \\
\hline $\begin{array}{l}\text { Wave Energy } \\
\text { Exchanger }\end{array}$ & Mechanical & Materials & 0.73 & Research \\
\hline $\begin{array}{l}\text { Electrochemical } \\
\text { Cell }\end{array}$ & Photolysis & $\begin{array}{l}0.4 \& \\
\text { Shorter }\end{array}$ & $0.25-0.40$ & Research \\
\hline TELEC & $\begin{array}{l}\text { Thermo- } \\
\text { electronic }\end{array}$ & $5-10.6$ & 0.42 & Exploratory \\
\hline
\end{tabular}


The development of mercury-cadmium-telluride and lead-tin-telluride photovoltaic cells specially designed for power conversion is being proposed. ${ }^{36}$ These cells, designed to convert $\mathrm{CO}_{2}$ radiation to electricity, would be expected to provide efficiencies as high as 50 percent (see table 3.7).

\subsubsection{Heat Engines 34}

Heat engine types potentially suitable for power conversion may include boiler, laser, photon and other engines. The efficiencies of some of these engines and their development stages are shown in table 3.7.

- Boiler--This system receives radiation by absorption in a suitable material and conducts the resulting heat to the engine.

- Laser ${ }^{34,37}$-Energy is absorbed through a window into the working gas or fluid. Window strength under high radiation densities is a problem. Because of the higher temperatures used in this engine, the Carnot efficiency is higher.

- Photon $34,38,39$--In this engine, coherent energy is absorbed in the molecule and converted directly into work. Efficiencies were initially estimated by Abraham Hertzberg at 60 to 70 percent. However problems with practical models have resulted from a lack of the needed high-temperature materials.

- Wave Energy Exchanger ${ }^{40}$--This converter uses a Brayton cycle and a bottoming Rankine cycle. Efficiency has been calculated to be 73 percent (see appendix G).

\subsubsection{Electrochemical Cell Conversion ${ }^{34}$}

The photolysis of water in aqueous photoelectrochemical cells subjected to laser radiation offers one solution to the energy conversion and storage requirement. (The storage of hydrogen is believed by some to offer one of the cleanest, simplest energy storage methods available.) Wrighton of MIT believes from his work that efficiencies of 25 to 40 percent are attainable. Unless a process involving a catalyst can be developed, only high-energy photons less than $0.4 \mu \mathrm{m}$ in wavelength can be used in this system.

\subsubsection{Tuned Optical Diodes 34,39}

This converter using the coherency of the radiation, converts the laser radiation of direct current by a rectification process. Current models of these diodes are fragile. Effort must be expended to make them rugged and to increase their power handling capability if they are to be useful for the SPS. This will reduce the number of diodes required to handle the large amounts of power to a reasonable value. Efficiencies of these devices have not been determined. 


\subsubsection{Thermoelectronic Converter $39, \mathrm{~m} /$}

This is a plasma device and has been named the Thermoelectronic Laser Energy Converter (TELEC). The TELEC was described by Britt and Yuen ${ }^{41}$ as follows:

In the TELEC process, electromagnetic radiation is absorbed directly in the plasma electrons producing a high electron temperature. The energetic electrons diffuse out of the plasma striking two electrodes with different areas. Since more electrons are collected by the larger electrode there is a net transport of current, and an EMF is generated in the external circuit. The smaller electrode functions as an electron emitter to provide continuity of the current. Waste heat is rejected from the large electrode.

The overall efficiency of TELEC was calculated to be 42 percent.

\subsubsection{Photoemissive Cells}

The growing interest in photoemissive cells results from projections indicating that these solar-to-electric power conversion devices may offer significantly improved efficiency 30 to 40 percent for solar radiation compared to 13 to 21 percent for photovol taic units.

\subsection{LPTS PERFORMANCE/COST CONSIDERATIONS}

Electric discharge lasers can be scaled and the output from several units phased to handle the quantity of power that is planned for the SPS. Operational lasers that have power outputs on the scale of interest are large, not very efficient, require skilled operators, and are unreliable. Therefore, if lasers are to be useful for transmitting SPS power, significant performance improvements must be made. The following paragraphs discuss LPTS power output, efficiency, costs, and weights.

$\mathrm{m} /$ Most of the TELEC work has been supported by NASA Ames and NASA Lewis Research Centers. Currently, under NASA Contract No. 3-21149, a 10-kW TELEC cell is being tested by NASA Lewis Research Center using the Lewis HPL facility. ${ }^{39}$ 


\subsubsection{Power Output}

One of the major requirements for the LPTS is the ability to deliver high power continuously and reliably. During this investigation, security restrictions prevented the release of information on demonstrable high-power laser equipment rated at more than several tens of kilowatts. However, all persons contacted for information concerning laser scaling indicated that lasers could be scaled. $\underline{n}$ / Chemical and gas dynamic lasers are the easiest to scale but are not suitable for the LPTS because of the fuel requirement for the chemical laser and low efficiency for the gas dynamic laser. The electric discharge laser can also be scaled and this scaling appears to be limited only by gas breakdown, window heating, and the required uniformity of electric discharge. Maximum flux density in $\mathrm{CO}_{2}$ before breakdown can be around $3 \times 10^{10}$ $W / \mathrm{cm}^{2} .44$ If window breakdown tends to occur at about $200 \mathrm{~kJ} / \mathrm{cm}^{2}$, then for $\mathrm{CW}$ operation, flux density can be no more than $2 \times 10^{5} \mathrm{~W} / \mathrm{cm}^{2}$, which is well below gas breakdown. If maximum aperture, limited by the uniformity requirement of the electric discharge, is no more than $1 \mathrm{~m}$, the maximum output of the laser would then be no greater than $1.57 \times 10^{9} \mathrm{~W}$. This is approximately 7.4 percent of the $21.2 \mathrm{GW}$ needed to be transmitted toward the ground power conversion system to enable it to receive, rectify and output the required $10 \mathrm{GW}$ of power. Thus, fourteen of these lasers are needed for each SPS LPTS. Heat removal requirements may be estimated as shown below.

\subsubsection{Window Waste Heat Removal}

For a window that transmits 99 percent of the radiation, I percent of the 1.57 GW, transmitted by one of these lasers, or $15.7 \mathrm{NiW}$, will be absorbed. This amount of heat $(15.7 \mathrm{MJ} / \mathrm{sec})$ must be removed continuously and at a temperature within the safe operating range of the window.

n/ Groups interested in propulsion for ground-to-space, space, and airborne transportation have postulated missions on having laser powers ranging from $5 \mathrm{MW}$ to 1.0 GW. $3242 \quad 43$

의 Extremely low-absorption solid windows or long, small-diameter aerodynamic windows are needed to minimize the window heating problem. An aerodynamic window needs to be long and of small diameter to reduce gas loss. 


\subsubsection{Lasant Waste Heat Removal}

If one of the laser units converts 40 percent of the electric discharge power to radiation, then 60 percent of the power discharge (or $1.5 \times 1.57 \times 10^{9} \mathrm{~W}=$ $2.36 \times 10^{9} \mathrm{~J} / \mathrm{sec}$ ) is absorbed in the lasant and must be removed continuously at the lasant temperature of approximately $300^{\circ} \mathrm{K}$ for $\mathrm{CO}_{2}$. The area of a $300^{\circ} \mathrm{K}$ radiator required to remove this heat would be $5.4 \mathrm{sq} . \mathrm{km}$. Fourteen of these laser units would require $75.6 \mathrm{sq} . \mathrm{km}$. (This has neglected the heat generated in circulating the lasing gas.) Referring to figure 3.4, lasers having lasant operating temperatures of $500^{\circ} \mathrm{K}$ and $1000^{\circ} \mathrm{K}^{\mathrm{P}}$ / would require 9.1 and $0.58 \mathrm{sq} . \mathrm{km}$, respectively. It would be possible to use a heat pump to increase further the radiator operating $\Delta T$ (radiator to space) and reduce radiator area. This, in turn, would reduce LPTS efficiency, add to its complexity, and require larger solar collectors. Detailed performance/cost analyses will be required to define heat rejection equipment for an LPTS.

\subsubsection{Reflector Waste Heat Removal}

In an actual LPTS design, it is anticipated that the power output of an individual laser unit would be considerably smaller than the $1.57 \mathrm{GW}$ units described. In this case more units would be used. For example, if 10 laser units each with a mirror $42.4 \mathrm{~m}$ in diameter were designed to beam $1.57 \mathrm{GW}$ of power to earth, each optical reflector would intercept and reflect over $100 \mathrm{~kW} / \mathrm{m}^{2}$. If I percent of this energy is absorbed, this represents more than $1 \mathrm{~kJ} / \mathrm{m}^{2} \mathrm{sec}$ of additional heat that would have to be removed at the operating temperature of the reflector.

For some laser energy conversion devices, like the photon engine, coherent radiation will be required. Therefore, when several laser units are required, they will need to be locked in phase to maintain the coherence. Lasers can be scaled and phased to generate the amounts of power required, but a broad program of research and development is needed to improve the power-handling capability of the LPTS lasers and components and to reduce costs.

\subsubsection{Laser Efficiency}

The efficiency of the LPTS is important to the SPS because the sizes of the solar collector, prime power unit, and waste heat radiator, and number of lasers are

P/ A Brayton cycle used in conjunction with the cooling system for a hightemperature lasant could be made to contribute laser drive power and thereby increase system overall efficiency. 
inversely related to efficiency. The overall (end-to-end) efficiencies of the four LPTS's shown in table 3.2 are compared with the efficiency of the Johnson Space Center (JSC) MPTS. The efficiency chain used for this comparison is shown in figure 3.7 "Miscellany" in figure 3.7 is an efficiency-like figure of merit that accounts for summer solstice, cosine, $l^{2} R$, and panel areo losses and is assumed to be the same for both MPTS and LPTS systems, even though $I^{2} R$ and panel area losses may not be present for some LPTS designs. LPTS \#1, \#2, and \#3 are factors of 7.1, 5.9, and 3.6, respectively, less efficient than the JSC MPTS concept currently under consideration. LPTS \#4 is as efficient as the MPTS; however, the efficiency assumed for the laser of this LPTS is considered to be very high. Using a propagation efficiency of 95 percent (clear day) for 2- $\mu \mathrm{m}$ wavelength radiation and a conversion efficiency of 75 percent for the photon engine, and 80 percent for miscellany, results in a required laser efficiency of 83 percent if the LPTS is to compete with the MPTS using the JSC estimates for that system. At this time there are no known lasers or any prospects for lasers that will meet this efficiency goal. The free-electron laser (to be discussed) and the CO laser, capable of (electric discharge power to radiation conversion) open-cycle efficiencies of 50 percent or better, ${ }^{19,34}$ are currently the best prospects. Machinery required to provide the $\mathrm{CO}$ laser's supersonic gas flow reduces its overall efficiency to 20 to 30 percent. The laser's multiline emission characteristics further limits its efficiency in applications where several phase-locked units are required.

Although no laser exists that will meet the required efficiency goals, several low-level efforts are under way that are beginning to provide a technology base needed for solutions to the efficiency problems. These efforts are discussed briefly below.

\subsubsection{Free Electron Laser (FEL)}

Dr. John Madey of Stanford University and Dr. John Rather of W. J. Schafer Associates, Inc., have briefly discussed FEL efforts that their organizations and other groups are pursuing. The FEL, which may be more like a microwave tube than the usual gas laser, generates laser radiation in an evacuated lasing chamber. The wavelength of operation can be chosen at any point over a broad band from the ultraviolet through the far infrared. Projected overall efficiency for the FEL is in the range of 20 to 70 percent. An experimental unit is already operating. (More information concerning this device is provided in appendix $C_{\text {.) }}$ 


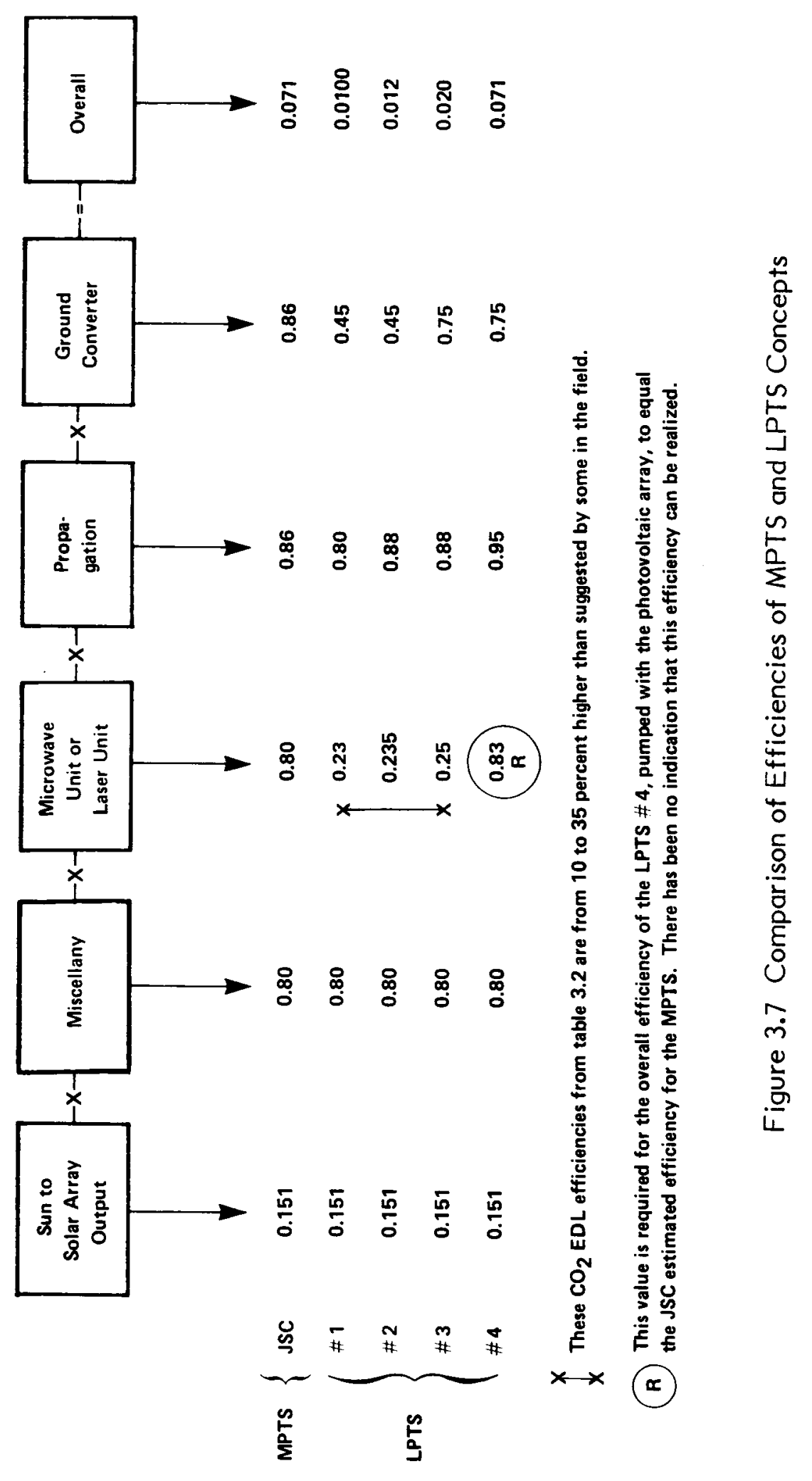




\subsubsection{Short-Wavelength Electric Discharge Lasers}

Dr. David Huestis, and associates of the Stanford Research Institute, are involved in the development of high-power lasers operating in the ultraviolet (rare gases) and visible (mercury halides) bands. Table 3.1 shows the current efficiencies of some of these lasers. Work is needed in this general spectral band to identify new lasants that will operate at higher temperatures with improved efficiencies. (For further detail see appendix D.)

\subsubsection{Satellite Power Relay System}

Mr. Wayne Jones of Lockheed is conducting a study for the NASA Lewis Research Center concerning the performance of a satellite power relay system concept that he has developed. This system reduced the transportation costs to space by its being deployed in low earth orbit (LEO). The system provides greater versatility in power distribution and power packet size. However, this system results in increased complexity involving pointing, tracking, and sophisticated system control requirements. Appendices $F$ and $G$ consider the transmission of power by laser from LEO.

\subsubsection{Direct Solar Pumping of a Laser}

Dr. Walter $\mathrm{H}$. Christiansen of University of Washington and Dr. Robert Taussig of Mathematical Sciences Northwest are investigating the solar pumping of lasers where the pumping, blackbody source is a cavity heated by sunlight. 9 / Efficiency is expected to be in the 10 to 20 percent range and some researchers have indicated higher efficiencies are possible. (More detail is provided in appendix E.) Other organizations known to be considering the solar pumping of lasers are the McDonnell Douglas Astronautics Company (a laser communications system) ${ }^{45}$ W. J. Schafer Associates, Inc., the Stanford Research Institute, and the Lockheed Missiles and Space Company, Inc.

g/ Supported by NASA Lewis Research Center Contract NAS-3-21/34. 


\subsubsection{Projected LPTS Efficiencies}

Using the above solar-pumped laser efficiencies, the end-to-end efficiency of two versions ( $a$ and $b$ ) of LPTS concept $\# 5$ is shown in figure 3.8. The solar-pumped laser of this concept is a combination solar collector and laser. The efficiency of 10 percent of the solar-pumped laser version \#5a, is a conservative value. When this 10 percent efficiency is combined with the optimistic values for propagation and ground conversion efficiencies, the overall efficiency of version $\# 5 \mathrm{a}$ is close to the overall efficiency of the JSC MPTS. Using a more optimistic efficiency value of 20 percent (version \#5b), propagation and ground converter efficiencies can be reduced to the more probable values shown and yet yield an overall efficiency that is higher than that of the MPTS.

A significant opportunity exists for improving the performance of the LPTS by working on "up-front" efficiency. For example, the overall (end-to-end) efficiency of an LPTS that uses a $\mathrm{CO}_{2}$ EDL (efficiency - 18 percent) pumped with an energy exchanger (EE efficiency - 73 percent) and an EE ground conversion unit would be 6.1 percent. The overall efficiency of the LPTS with a free-electron laser (FEL efficiency between 20 and 70 percent) substituted for the $\mathrm{CO}_{2} \mathrm{EDL}$ would fall in the range of 6.8 to 23.9 percent (see appendices $C$ and $G$ ). ${ }^{\prime}$ '

\subsubsection{Costs}

Because of limited HPL laser production experience, cost data of the kind needed to evaluate the laser cost feasibility are generally unavailable. The prices of multikilowatt lasers range from $\$ 45$ per watt for $1.5 \mathrm{~kW}$ units to $\$ 30$ per watt for $5 \mathrm{~kW}$ units. ${ }^{16}$ At the lower cost, the lasers alone for the LPTS would result in costs that are more than two orders of magnitude higher than current preliminary cost goals. It will be necessary to conduct a cost study that will provide realistic cost data on HPL's and support equipment produced at the rates required for the SPS program. It is anticipated that several laser options will be considered for SPS for some time to come, including (1) the FEL pumped by a solar array or an EE, (2) EDL's $\left(\mathrm{CO}, \mathrm{CO}_{2}\right.$, and perhaps others) pumped by an EE, and (3) the solar-pumped (through an intermediate blackbody) laser. Obtaining realistic cost data necessarily will involve establishing better definitions of these lasers.

r] The EE used to pump the microwave system (based on the above efficiency estimate) would increase the overall efficiency of the MPTS from its current 7.1 percent to 34 percent. 


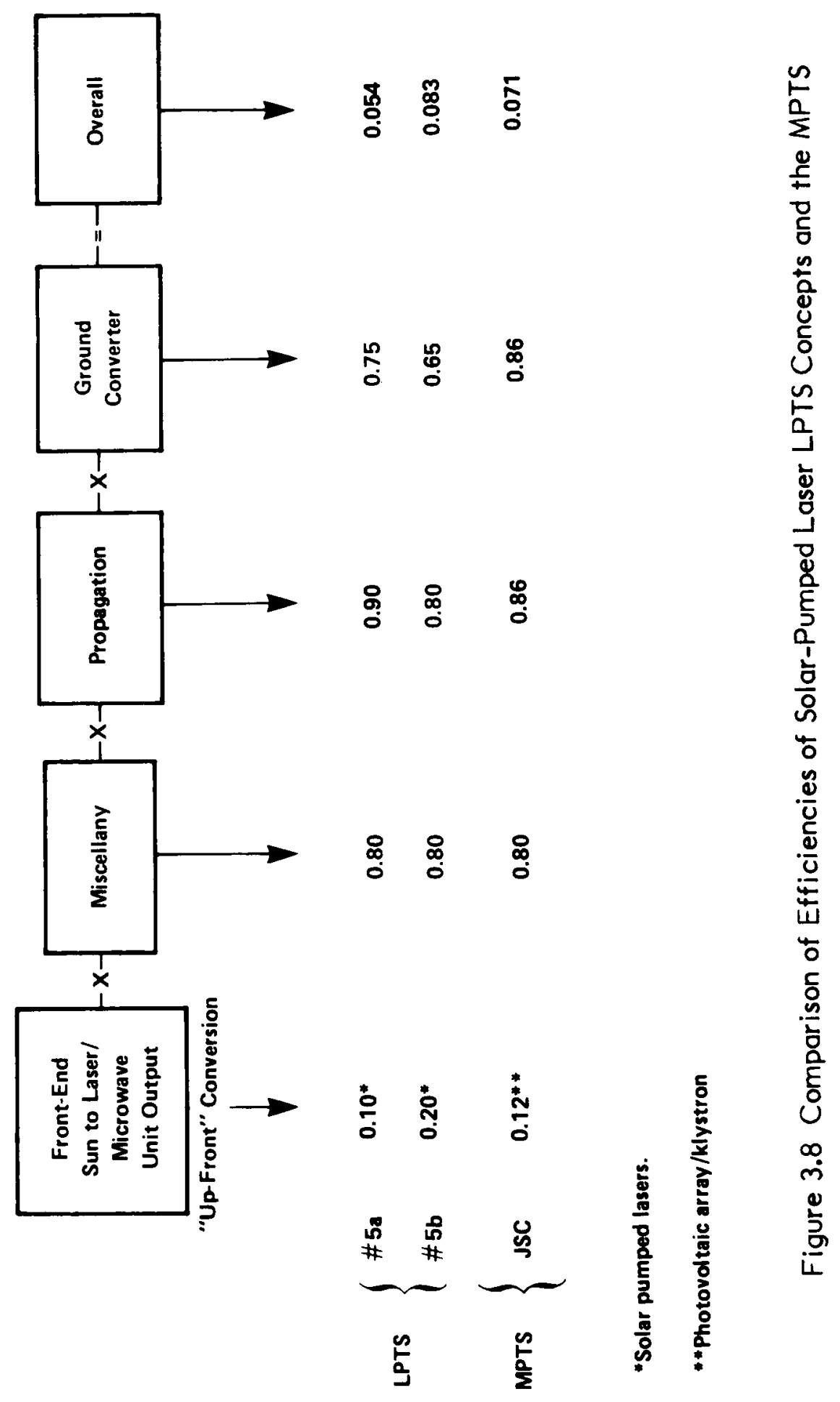


During a laser aircraft propulsion study by Hertzberg and Sun, ${ }^{19}$ estimates of costs for an LPTS were developed and given in terms of $\$ / \mathrm{kW}$. The total costs of the baseline system, $\$ 1,342 / \mathrm{kW}$, were presented in three parts: laser, optics (for a wavelength of $10.6 \mu \mathrm{m}$ ), and radiator (for removing waste heat at $300^{\circ} \mathrm{K}$ ). This cost is a factor of five greater than the NASA preliminary cost estimate ${ }^{7}$ for the MPTS. Since a major part of the costs was for optics and radiator (not the laser), these parts of the system were considered more closely. Optics costs can be reduced by using a shorter wavelength laser, and the size and cost of the radiator can be reduced by rejecting waste heat at a higher temperature (i.e., $500^{\circ} \mathrm{K}$ ).

The diameter of the optics can be reduced in proportion to wavelength $(\lambda)$ as $\lambda$ is reduced and a desired beam width is maintained, provided that the optics (now smaller in area) can withstand the increased flux density that resul ts.

Large precision mirrors for terrestrial use are usually massive and made of high strength, low-thermal-expansion material to maintain mirror figure under the constant gravitational force, other forces that may be present, and mirror temperature fluctuations. As a mirror designed for these conditions is scaled up (or down), the volume of material in the mirror is changed roughly as the cube of the mirror diameter $\left(D^{3}\right.$ or wavelength $\lambda^{3}$ ). If the mirrors were to be ground, polished, and surfaced for the same wavelength, the $D^{3}$ relation would not be an unrealistic first estimate for labor costs. The mirrors for the LPTS, however, need to be only massive enough to withstand launch into space where, in a gravity-free environment, the mirrors will be deployed or assembled from segments and deployed. The severity of mirror surface requirements will be roughly inversely proportional to $\lambda$. Mirrors would be designed from high-temperature, ultra-low expansion (ULE) materials, equipped with figure sensors, actuators, and the necessary data-processing electronics to create an adaptive mirror surface. Material and labor costs for these mirrors designed for space are likely to be more nearly related to $\lambda^{2}$ s/ than the cube of the LPTS wavelength $\left(\lambda^{3}\right)$. Actual cost, however, is expected to be related to $\lambda^{x}$ where $2 \leq x \leq 3$. For a given wavelength, $\lambda$, optics cost, $\mathrm{O}_{\mathrm{Ci}}$, is given by:

$$
O_{C i}=O_{C o}\left(\frac{\lambda_{i}}{\lambda_{0}}\right) x
$$

sf Both have high-quality surfaces. The $\left(\lambda^{2}\right)$ est imate is a simple one based on mirror area (mirror diameter proportional to $\lambda$ ) and would seem to be rather conservative. 
where subscript o refers to the baseline system and subscript i refers to the new system. When

$$
\begin{aligned}
& \lambda_{o}=10.6 \mu \mathrm{m}, \\
& \lambda_{i}=2.0 \mu \mathrm{m}, \text { and } \\
& x=2, \\
& O_{\mathrm{Ci}} / \mathrm{O}_{\mathrm{Co}}=0.036 .
\end{aligned}
$$

Now referring to figure 3.4 , radiating waste heat at a temperature of $500^{\circ} \mathrm{K} \pm$ / will reduce the area of the radiator to approximately 0.13 of that for a radiator operating at $300^{\circ} \mathrm{K}$. When these cost-reducing modifications were incorporated into the Hertzberg/Sun design, total system costs were reduced by a factor of 7.4 , and the system was brought to well within the cost range of the NASA MPTS concept. 7 Although this first order analysis has left many questions unanswered, it indicates that an economically competitive LPTS may be feasible and suggests a promising direction that a more detailed study might take. - /

\subsubsection{Weights}

Estimates of laser mass to laser output power, $\mathrm{kg} / \mathrm{kW}$, of lasers suitable for the LPTS have ranged from $0.1 \mathrm{~kg} / \mathrm{kW}_{L} 19$ to $3 \mathrm{~kg} / \mathrm{kW}_{\mathrm{L}} 18$ to $3.56 \mathrm{~kg} / \mathrm{kW}_{\mathrm{L}} \cdot 14, \underline{\mathrm{v}} /$ These laser assembly estimates (which include some laser auxiliary equipment but not the solar collector/prime power unit, waste heat radiators, and projection optics) bracket a reasonable range when compared with the $1.85 \mathrm{~kg} / \mathrm{kW}_{M}$ of the microwave transmitter. The mass-to-power ratios, $\mathrm{kg} / \mathrm{kW}_{M}$, for the microwave system and $\mathrm{kg} / \mathrm{kW}$ for the laser system are shown in the table 3.8 for the spaceborne parts of the JSC MPTS and for a Hughes Aircraft Company LPTS and related power collection subsystems. $^{14}$ A value for transmission optics to provide beam forming and control functions determined from Lockheed data $^{23}$ has been added to the Hughes system. The solar collector/prime power in combination with the laser unit (Hughes system) provides a solar-laser radiation conversion efficiency of approximately 3 percent.

t/ The free-electron laser is expected to be capable of operating at any selected spectral location, from ultraviolet to the far infrared, and at temperatures well in excess of $500^{\circ} \mathrm{K}$.

U/ A similar analysis may be valid for the MPTS.

$\mathrm{v} /$ Appendix C estimates the weight of the free-electron laser at $0.1 \mathrm{~kg} / \mathrm{kW}$. The weights of drive and control electronics, transmission optics, and radiators for waste heat removal are not included in this estimate. 
To provide $10 \mathrm{GW}$ at the busbar, the output from the microwave transmitter must be $13.52 \mathrm{GW}$. If the efficiency of the LPTS from laser output to busbar output is defined as 47 percent (this assumes EE ground conversion), output of the laser system to provide $10 \mathrm{GW}$ / $/$ at the busbar must be $21.2 \mathrm{GW}$. If it can be assumed that the ratio of mass to output laser power $\left(\mathrm{kg} / \mathrm{kW}_{L}\right)$ of the LPTS front end (laser, laser radiator, solar collector, and prime power) decreases in a linear relation with increases in pump-laser efficiency, mass $\left(\bar{M}_{L}\right)$ of the system for a new efficiency can be determined by:

$$
\bar{M}_{L}=\left(21.2 \times 10^{6} \mathrm{~kW}_{\mathrm{L}}\right)(16.63 \mathrm{~kg} / \mathrm{kW} L)\left(\frac{3 \%}{\varepsilon_{L}}\right)+\bar{m}_{\mathrm{o}}
$$

where:

$$
\begin{aligned}
3 \% & =\text { efficiency of baseline system front-end } \\
\varepsilon_{L} & =\text { new efficiency } \\
\bar{m}_{0} & =\text { mass of transmission optics } \\
& =\left(21.2 \times 10^{6} \mathrm{~kW} W_{L}\right)\left(0.06 \mathrm{~kg} / \mathrm{kW}_{L}\right) \\
& =1.27 \times 10^{6} \mathrm{~kg} \text { (for all efficiencies). }
\end{aligned}
$$

\begin{tabular}{|c|c|c|}
\hline & MPTS, $\mathrm{kg} / \mathrm{kW} W_{M}$ & LPTS, $\mathrm{kg} / \mathrm{kW} L$ \\
\hline Component & $\begin{array}{l}\text { System Eff. }=7.1 \% \\
\text { Front-End Eff. }=12 \%\end{array}$ & $\begin{array}{l}\text { System Eff. }=1.4 \% \\
\text { Front-End Eff. }=3.0 \%\end{array}$ \\
\hline $\begin{array}{l}\text { Power transmitter } \\
\text { Microwave } \\
\text { Laser } \\
\text { Laser radiator } \\
\text { Transmission optics }\end{array}$ & 1.85 & $\begin{array}{l}3.56 \\
2.41 \\
0.06\end{array}$ \\
\hline $\begin{array}{l}\text { Power collection } \\
\text { subsystem } \\
\text { Solar cell array } \\
\text { Solar collector } \\
\text { Prime power }\end{array}$ & 3.85 & $\begin{array}{l}6.33 \\
4.33\end{array}$ \\
\hline Totals & 5.70 & 16.69 \\
\hline
\end{tabular}

Table 3.8 Masses of Spaceborne Components of the JSC MPTS, a $\mathrm{CO}_{2}$ EDL LPTS, and Related Power Collection Subsystems

W/ $10 \mathrm{GW}$ is used as a reference value and is not intended to be indicative of optimum LPTS or MPTS outputs 
Mass of the MPTS microwave spaceborne components, $M_{M}$ (solar array and microwave transmitter), for an efficiency different from that of the baseline system can be determined by:

where:

$$
\bar{M}_{M}=\left(13.53 \times 10^{6} \mathrm{~kW}_{M}\right)(5.7 \mathrm{~kg} / \mathrm{kW} \mathrm{M})\left(\frac{12 \%}{\varepsilon_{M}}\right)
$$

$12 \%=$ efficiency of baseline system front end

$\varepsilon_{M}=$ new efficiency.

Solving equations 4 and 5 for the mass of the baseline laser and microwave systems, $\bar{M}_{L}=352.6 \times 10^{6} \mathrm{~kg}$, and $\bar{M}_{M}=77 \times 10^{6} \mathrm{~kg}$. Figure 3.9 is a plot of the LPTS spaceborne mass versus front-end efficiency.

If it is assumed that the mass of the power conversion unit (Brayton cycle, $E E$, or blackbody cavity) is proportional to solar collector mass, the efficiency of the EEpumped $\mathrm{CO}_{2} \mathrm{EDL}$, and efficiency ranges of the EE-pumped $\mathrm{FEL}$, and the solar-pumped (blackbody cavity) laser can be located on the curve. The width of the curve allows for an approximate \pm 40 percent variation in the masses of the prime power unit (Brayton, EE, or blackbody), or \pm 21 percent of the masses of the prime power unit/laser unit combinations.

The projected JSC MPTS is given its relative position on this figure, and the position of a hypothetical MPTS, where the transmitter is pumped by an energy exchanger, was calculated using equation 5 and is also shown. These points are connected by the broken curve representing probable MPTS weights at other MPTS efficiencies. The photovoltaic pumped $\mathrm{CO}_{2}$ EDL shown is the LPTS that is usually compared to the MPTS. From equations 4 and 5 and figure 3.9 the following observations are made:

- At all efficiencies $\left(\right.$ MPTS $_{\text {EFF }}=$ LPTS $_{\text {EFF }}$ ), based on current NASA MPTS efficiency/mass estimates, the MPTS is lighter. (Advanced solar energy collection/conversion systems developed to provide electric power at increased efficiencies to an LPTS can provide the same advantages to an MPTS).

- As efficiencies of both the LPTS and the MPTS increase, the absolute difference in their masses decreases.

- The spaceborne mass of an LPTS having a front-end efficiency of 14 percent is equal to that of the NASA photovol taic MPTS concept. As LPTS efficiencies move above 14 percent, reduced LPTS mass (and mass-related costs), when compared to the photovol taic MPTS, will begin to compensate for atmosphere/cloud-cover losses.

- LPTS transmission optics is a relatively small part of the total LPTS mass until LPTS front-end efficiencies become quite high. 


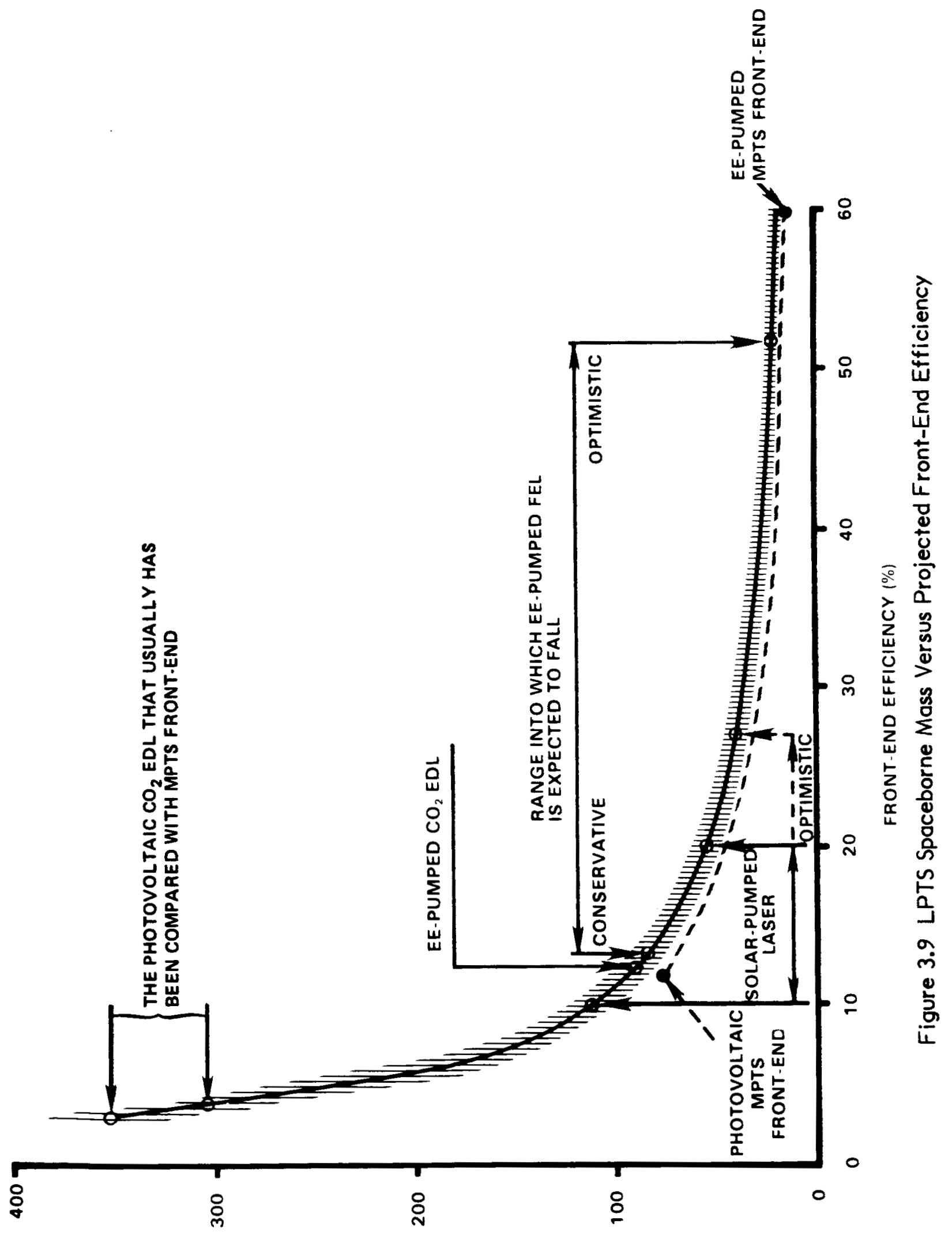

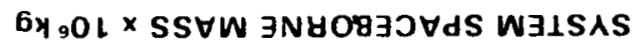


Summary Statement

Laser-transmitting units can be designed to provide adequate power, and advanced concepts involving lasers, solar pumping of lasers, and power conversion may provide the needed improvement in system "up-front" conversion efficiency to qualify the LPTS both technologically and economically as a serious option for SPS power transmission. 


\section{EVALUATION OF IMPACTS/ISSUES}

The Laser Power Transmission Subsystem (LPTS), working in conjunction with the other subsystems of the Satellite Power Systern (SPS), could provide large amounts of electrical power to U.S. power grids. The use of this system of power generation could result in certain technological, environmental, societal, and economic impacts. This section identifies and compares these impacts, issues, and, as appropriate, parameters for the LPTS-I (concentrated beam), the LPTS-2 (dispersed beam), and the Microwave Power Transmission Subsystem (MPTS).

\subsection{TECHNOLOGICAL IMPACTS}

Laser technology and laser equipment have made significant advancement since 1960 when, as discussed in section II, the first laser was demonstrated. High-power laser development has been concerned mainly with producing high-energy pulses rather than sustained, high-power beams. Researchers and users, interested only in short bursts of energy, can assign secondary importance to equipment efficiency and solve cavity and window heating problems by adjusting the time between bursts. Solar to laser radiation conversion efficiency and the disposal of waste heat are two of the major problems that must be solved before a competitive LPTS can be produced. There is reason to believe-based on work currently being done in lasers, solar pumping of lasers, and power conversion--that after the laser technical community becomes aware of and understands the SPS Power transmission system requirements, a realistic LPTS prototype design pointing the directions to be taken can be developed using state-of-the-art technology.

The control and removal of the waste heat will be similar for LPTS-I and LPTS-2 except the heating in the LPTS-2 beam-forming optics may be greater, because the optics of this system can be smaller, but will intercept approximately the same amount of power as the LPTS-1. Heat removal problems in the MPTS should be less severe than in the laser systems since the MPTS antenna is larger than the LPTS optics, and its power transmission elements are currently more efficient.

Other important parameters concerning space and ground equipment, power propagation, and the overall subsystem for the LPTS-1, LPTS-2, and MPTS are shown in table 4.1. Two columns appear under each of the laser systems: state-of-the-art (SOA) and projected (P). The MPTS has only one column (projected) because the values of the parameters being used are projected ones. Referring to the key of table 4.1 the SOA power output for lasers is rated to be medium ( 75 to $175 \mathrm{~kW}$ ) but projected to be 
Table 4.1 Comparison of LPTS and MPTS Parameters

Parameters

LPTS- 1

(Concentrated)

SOA

\section{LPTS-2}

(Dispersed)

SOA $P$
MPTS

$P$

Spaceborne equipment

Power output individual

Laser/microwave units

0

$+$

0

0

Efficiency

Spectrum versatility

Array technology

Optics/antenna suitability

Weight reduction potential

Size reduction potential

Ground equipment power conversion efficiency

Propagation

Atmospheric transmission

Cloud penetration

Subsystem

State of development

early
conceptual

early conceptual

advanced conceptual

Power delivery flexibility

0

0

System safing potential

Relative pointing

accuracy required

Pointing accuracy potential

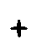

$+$

$+$

$+$

0

$$
\begin{array}{ll}
\frac{\text { Key }}{+} & \text { High } \\
0 & \text { Medium } \\
- & \text { Low }
\end{array}
$$


high (10 to $100 \mathrm{MW}$ ) by the time SPS is scheduled for deployment. Power output projected for klystrons is rated to be medium $(72 \mathrm{~kW})$.

\subsection{ENVIRONMENTAL IMPACTS}

The impacts of the SPS power transmission systems on the earth's atmospheric environment range from the ground level to the far reaches of the outer atmosphere where the satellite and power transmission systems are located. For systems using MPTS, the microwave beam may interact with the electrons in the ionosphere, thereby having the potential of causing degradation of over-the-horizon transmission, ionospheric reflection of VHF frequencies, and degradation of transmission through the ionosphere. 46 The frequency of the laser beam, on the other hand, is closer to that of the natural sunlight and, consequently, would not be expected to affect the outer atmosphere in the same manner as the microwave beam.

The stratospheric ozone absorbs strongly at wavelengths of 0.290 to $0.320 \mu \mathrm{m}$ (UV region) and $9.6 \mu \mathrm{m}$ (infrared region). 47 It filters out biologically harmful UV radiation and also plays an important part in maintaining the heat balance of the earth. The MPTS does not transmit power at any of these frequencies (and therefore it is believed there will be only a small effect, if any, on the ozone layer). The LPTS can be designed to transmit at a frequency that does not interact strongly with the stratospheric ozone.

When the microwave beam reaches the earth's surface, its average intensity would be substantially less than a solar constant. As such, it is unlikely to have any significant effects on the local or global climate. For the LPTS-I, the power flux in the beam may be several hundred times that of solar, with the flux level highly localized to an area no greater than $50 \mathrm{~m}$ in diameter, and requiring an exclusion area on the order of 500 to $1,000 \mathrm{~m}$ in diameter. The waste heat radiated would most likely change the ambient temperature and might also affect local wind patterns. The LPTS2 ground pattern would cover an area approximately the size of the MPTS pattern; the average power intensity would be lower than that for the LPTS-1. Both systems would contribute radiation that would not ordinarily reach the earth. However, considering the global scale and assuming no nonlinear effects, the total amount of additional radiation should have a negligible effect, if any, on global climate.

The microwave and laser radiation affect the atmosphere differently. The less energetic microwaves do not produce ionization or cause dissociation of atoms or molecules in the atmosphere, but they react with ambient electrons in the ionosphere. The laser radiation (visible through the infrared) may interact with some gaseous molecules in the lower atmosphere, but photons will not be energetic enough to cause 
ionization. Ozone production in the stratosphere may be enhanced by the laser radiation making a positive, though small, contribution to the environmental quality. a/ In areas where air pollution is a problem, the additional LPTS radiation may enhance the production of photochemical smog causing a further (though extremely small) deterioration of ambient air quality. 48

If a visible band is used in the LPTS, particulate scattering of the radiation in the beam may cause beams to be visible at night many miles from the ground receiver station. This is not a problem in an infrared LPTS or the MPTS.

A major SPS concern is the effect of the power transmission system on health and public welfare. The threshold limit value for occupational microwave energy exposure is $10 \mathrm{~mW} / \mathrm{cm}^{2}$ in the United States. ${ }^{49,50}$ The sidelobes of the MPTS will subject large populations to continuous low-level microwave exposure, so the effects of microwave exposure on humans must be understood before a full assessment of the MPTS can be made. The intense heat of the LPTS-1 beam can be a public safety problem. However, danger from the beam can be mitigated by designating and fencing exclusion areas. $\underline{b}$ The site can be sized so that observation of the power beam from outside the site would not result in any eye damage, and fences can be high enough to keep animals out and most birds from flying through the beam. However, potential danger may still exist when an aircraft flies through the beam. A radiation level as high as $1.5 \mathrm{~W} / \mathrm{cm}^{2}$ is permitted for aircraft. High-speed aircraft flying at low altitudes may be able to safely dissipate radiation heat loads that are several times this value. Specular reflections from objects flying through the beam may cause eye or skin damage.

One of the direct impacts of SPS power transmission on terrestrial ecosystems is the modification of the natural environment resulting from the construction and operation of ground-based energy conversion stations. These

a) The effect on ozone of various candidate wavelengths and for the very intense laser power under consideration deserves further study.

b/ Once the public is accustomed to the presence of the high-radiantintensity, relatively stationary laser beams, concern for them as hazards may be similar to that for high-voltage power transmission lines.

c/ The eye is opaque to wavelengths longer than $1.7 \mu \mathrm{m}$, and the human body can tolerate added heat inputs of $0.1 \mathrm{~W} / \mathrm{cm}^{2}$ for a short time. An acceptable visible and infrared radiation exposure level is $10.0 \mathrm{~mW} / \mathrm{cm}^{2}$ per 8 -hour day based on tissue heating. 
effects are site specific and depend heavily on geographic location, climate, and total land area involved. Adverse environmental impact can be mitigated generally by selecting appropriate sites.

Because birds and other animals passing through the LPTS-I beam would be incinerated, it may be necessary to extend the height of the perimeter fence to prevent their access to the beam. However, many animals may not be able to sense the small additions of LPTS-2 or MPTS radiation; if they do, they may even find the new warmer environment more desirable. At present, no significant amount of information is available to assess the long-term effects of low-level microwave exposure on animals. Regarding habitat modification, no plant or animal species would be able to survive under the intense heat of the LPTS-1. However, since this system requires a much smaller land area than the other systems, the overall impact on the plant and animal communities is expected to be relatively small. For the MPTS, the rectenna site would change the natural environment to the extent that a modification of the natural habitat may result. Portions of the site would be shaded by the rectenna, while other areas within the site would receive microwave radiation. This can be expected to cause changes in plant and animal communities; however, the extent to which changes would occur has yet to be investigated.

Preliminary investigations of the MPTS indicate that its extended sidelobes may cause extensive RFI/EMI on earth. 51 This type of interference is not expected from the LPTS.

Laser beam interaction with materials at the power conversion site may produce hazardous airborne contaminants similar to those generated during arc-welding on similar metals. 52 Many of these airborne contaminants are trace metals that are potentially hazardous to public health. In addition, for the LPTS-I system, large quantities of water may be required to cool the power conversion systems. Unless adequate treatment is provided, the cooling water may be a source of thermal and chemical pollution.

Major impact elements associated with the laser and microwave systems discussed above are summarized in table 4.2. The extent of impact is designated as "adverse impact" or "little or no impact." No "positive impact" was identified.

\subsection{SOCIETAL IMPACTS}

An important aspect of the SPS power transmission system ground equipment is to collect and convert radiated power into electricity. The MPTS will require land areas of up to $200 \mathrm{sq}$. $\mathrm{km}$ for the rectenna site, whereas the LPTS-I will require sites of smaller magnitude $(0.2$ to $0.8 \mathrm{sq} . \mathrm{km})$ that can be located close to the potential power users to reduce the power transmission and distribution costs. Land near 
Table 4.2 Comparison of Environmental Effects

\begin{tabular}{|c|c|c|c|}
\hline Impact Elements & $\begin{array}{c}\text { LPTS-1 } \\
\text { (Concentrated) }\end{array}$ & $\begin{array}{c}\text { LPTS-2 } \\
\text { (Dispersed) }\end{array}$ & MPTS \\
\hline lonosphere (RFI/EMI) & 0 & 0 & - \\
\hline Long-range communications & 0 & 0 & - \\
\hline Ozone layer & 0 & 0 & 0 \\
\hline \multicolumn{4}{|l|}{ Climate modification } \\
\hline $\begin{array}{l}\text { Local } \\
\text { Global }\end{array}$ & $\overline{0}$ & $\begin{array}{l}0 \\
0\end{array}$ & $\begin{array}{l}0 \\
0\end{array}$ \\
\hline Atmospheric photochemistry & - & 0 & 0 \\
\hline Light scattering & - & - & 0 \\
\hline Continuous insolation & - & - & 0 \\
\hline Albedo & - & - & 0 \\
\hline Health & 0 & 0 & - \\
\hline Safety & - & 0 & 0 \\
\hline \multicolumn{4}{|l|}{ Ecosystems } \\
\hline $\begin{array}{l}\text { Biota } \\
\text { Habitat modification }\end{array}$ & $\overline{0}$ & $\begin{array}{l}0 \\
-\end{array}$ & - \\
\hline RFI/EMI & 0 & 0 & - \\
\hline Air pollution & - & 0 & 0 \\
\hline Water pollution & - & 0 & 0 \\
\hline \multicolumn{4}{|l|}{ Key } \\
\hline $\begin{array}{ll}- & \text { Adverse impact } \\
0 & \text { Little or no impact } \\
+ & \text { Positive impact }\end{array}$ & & & \\
\hline
\end{tabular}


populated areas is a valuable resource for which the SPS will have to compete. A smaller parcel of land will be easier to acquire and its use will have less impact on the local community. The LPTS-1 is superior to the other two concepts in terms of land area requirements.

It would be relatively easy to operate and maintain the energy conversion systems for the MPTS and LPTS-2. Special protective devices can be developed for maintenance staff and other workers who enter these receiver/converter sites. Standard eye protection devices are available for laser radiation. The use of these or upgraded devices and the enforcement of existing safety standards 53 for laser operations will reduce potential hazards. Two ground power conversion units may be required for the LPTS- 1 so that repair and maintenance will not require the shutdown of the entire system.

Both the laser and microwave energy conversion systems should benefit the communities in which they are located by providing additional employment opportunities. The establishment of a significant and reliable source of electricity will undoubtedly attract new industries and commercial operations to the area. On the negative side, some local residents will be displaced through easements and land acquisitions. The LPTS-1, however, will displace a relatively smaller number of people because it requires less land.

People who believe that laser beams are highly destructive may oppose the LPTS-1. Therefore, for this subsystem, public forums may be needed to inform the public that the design features of the LPTS-I can and will ensure public safety. If the design features cannot offer this assurance, the LPTS is not a viable option. The public is less likely to object to the MPTS and LPTS-2 because of the smaller power density at the energy conversion site. If the frequency selected for the laser is in the visible band, particulate scattering of radiation in the beam may cause it to be visible, especially at night. $\mathrm{d} /$ These visible beams may be unacceptable to some people for aesthetic reasons. The aesthetic qualities of the energy conversion sites will be similar to those of conventional power plants or antenna fields.

Security systems to ensure public safety will be needed at the energy conversion sites. However, the site for the LPTS-1 will present fewer security problems (even though security may need to be more intense) because its land area is smaller.

d/ A small amount of visible light mixed with infrared beams would make them visible also and, in this way, offer warning to aircraft pilots and assurance to local residents. 
Since both the national and international communities are very sensitive to the use of space for military purposes, there will be concern whether the laser, especially LPTS-1, can be used as, or converted into, a weapon system. However, any such decision to use the laser transmitters as weapons will have to be deliberate and made during system design. Since the SPS is an energy system concept that is subject to full disclosure and public participation, any weapon mode designed into the SPS will be subjected to public scrutiny.

Finally, because of its narrow band and line-of-sight transmission, few problems should be experienced in obtaining a "frequency allocation" for the LPTS.

The societal impacts of the SPS power transmission systems are summarized in table 4.3.

\subsection{ECONOMIC IMPACTS}

Major differences in economic impacts of the LPTS's and the MPTS, assuming they all work equally well, include the costs of development, production, energy payback, and real estate acquisitions.

Development costs are expected to be similar for all three systems. LPTS-2 and MPTS production and site acquisition costs should be similar because both require large, expensive power receiver/converters. The production of LPTS- 1 and the acquisition of a site for it should cost less because of its compact receiver design. The smaller production effort for the LPTS-I should result in less energy being invested and therefore a shorter energy payback time. Table 4.4 summarized the relative advantages and disadvantages in terms of impacts of selecting LPTS-1, LPTS-2, or MPTS concerning major system acquisition activities and energy payback. 
Table 4.3 Comparison of Societal Effects*

\begin{tabular}{|c|c|c|c|}
\hline Impact Elements & $\begin{array}{l}\text { LPTS-1 } \\
\text { (Concentrated) }\end{array}$ & $\begin{array}{c}\text { LPTS-2 } \\
\text { (Dispersed) }\end{array}$ & MPTS \\
\hline \multicolumn{4}{|l|}{ Land use } \\
\hline $\begin{array}{l}\text { Area requirement } \\
\text { Land availability }\end{array}$ & $\begin{array}{l}0 \\
0\end{array}$ & - & - \\
\hline \multicolumn{4}{|l|}{$\begin{array}{l}\text { Operation and maintenance of } \\
\text { energy conversion systems }\end{array}$} \\
\hline $\begin{array}{l}\text { Ease } \\
\text { Worker health and safety }\end{array}$ & $\begin{array}{l}0 \\
-\end{array}$ & $\begin{array}{l}0 \\
0\end{array}$ & $\begin{array}{l}0 \\
0\end{array}$ \\
\hline Displacement of people & 0 & - & - \\
\hline Public acceptance & - & + & 0 \\
\hline \multicolumn{4}{|l|}{ Aesthetics } \\
\hline $\begin{array}{l}\text { Visible beam } \\
\text { Infrared beam } \\
\text { Site }\end{array}$ & $\begin{array}{l}- \\
0 \\
-\end{array}$ & $\begin{array}{l}0 \\
0 \\
-\end{array}$ & - \\
\hline Security & + & 0 & 0 \\
\hline Weapons aspect & - & 0 & 0 \\
\hline Frequency assignment & + & + & - \\
\hline
\end{tabular}

Key

- Adverse impact

0 Little or no impact

$+\quad$ Positive impact

* Many of these entries were based only on considered opinion. 
Table 4.4 Economic Advantages and Disadvantages

\begin{tabular}{lccc}
\hline Elements & $\begin{array}{c}\text { LPTS-1 } \\
\text { (Concentrated) }\end{array}$ & $\begin{array}{c}\text { LPTS-2 } \\
\text { (Dispersed) }\end{array}$ & MPTS \\
\hline $\begin{array}{l}\text { Development } \\
\text { Production }\end{array}$ & 0 & 0 & 0 \\
Real estate requirements & + & 0 & 0 \\
Energy payback & + & 0 & 0 \\
\hline
\end{tabular}

Key

- Adverse impact

0 Little or no impact

+ Positive impact 


\section{v. CONCLUSIONS}

Significant advancements in high-power lasers have been made during the last 10 years. Most of the gains in laser power have resulted from the Department of Defense High Energy Laser Program and the Department of Energy (and predecessor agencies) Laser Fusion Programs. These programs have been concerned predominately with pulsed lasers where efficiency is of secondary importance. Although this work has not produced laser equipment considered suitable for the Satellite Power System (SPS) power transmission application, considerable technological advancements in lasants, components, techniques, and design have resulted.

Currently the $\mathrm{CO}_{2}$ electric discharge laser (EDL) comes closest to meeting the SPS Laser Power Transmission Subsystem (LPTS) requirement. a/ This laser can be scaled up and, if needed, integrated into a phased array to provide the required power. The efficiency of this laser, from 18 to 25 percent, is considered to be too low when pumped with a photovol taic array. Most of the ongoing projects discussed in section III-in the areas of high-power optical components, high-power short wavelength lasers, solar-pumped lasers, and the free-electron laser--are increasing the technology base needed for the development of a viable SPS LPTS option.

Although past laser progress, current laser work, and prediction for future laser performance provide confidence that an LPTS is technologically feasible during the SPS development time frame, and may be economically feasible, there may be environmental impacts, public health impacts, and societal concerns discussed in section IV that could limit or prevent its deployment. These impacts and concerns will result almost entirely (for LPTS-1) from the real or feared effects of the intense beam and the concentrated heat at the power receiving/conversion site. The major concerns over LPTS-2 are expected to result from the large land area required for the power receiving/conversion site and modifications to community environment and ecosystems.

a/ The NASA Ames Laser Research Group ${ }^{54}$ prefers the supersonic CO EDL over the $\mathrm{CO}_{2} \mathrm{EDL}$ for space-to-ground power transmission, because cycle efficiency is higher, the ${ }^{2}$ shorter wavelength results in smaller transmission optics, and with proper absorbers in the cavity, atmospheric transmission is superior. (For applications requiring the phase-locked operation of two or more units, only one line of the laser's multiline output can be used. However, techniques are being investigated to limit the effect of single-line operation on CO EDL efficiency.) 
If the LPTS is pursued and if it survives, like the MPTS it will need to have its real problems identified and resolved.

The results of this preliminary study have indicated that it is technologically feasible using scaling and phased-array techniques to develop an LPTS for the SPS, and with the use of emerging technology (the solar-pumped laser, the free-electron laser, and the energy exchanger) it may be as economical as the current photovoltaic MPTS. Realizing that there are already problems concerning the environmental and social acceptance of the MPTS, further study devoted to the LPTS Is believed to be warranted.

Several specific technical areas where expanded research and development efforts are needed for the LPTS include:

- Integrated front-end designs for efficiency:

- Solar-pumped lasers,

- Laser concepts that use electrons and charged particles eliminating recirculation losses

- Efficient solar power conversion equipment

- Efficient short wavelength lasers;

- Windows with improved transmission characteristics (reduced absorption);

- Aerodynamic windows that require small gas flows and exhibit low gas losses;

- High-reflectance mirrors (low absorption);

- Space mirror fabrication/processing techniques; and

- Efficient laser power ground converters.

To recognize the LPTS as a potential power transmission subsystem option will broaden the search for a transmission wavelength to include the ultraviolet, visible, and infrared spectrums as well as the microwave spectrum, increasing the chances that a suitable transmission band(s) will be identified for the SPS. 


\section{REFERENCES}

1. U.S. Energy Research and Development Administration, Final Report of the ERDA Task Group on Satellite Power Stations, ERDA-76/148, November 1976.

2. Bloomquist, C. E., Survey of Satellite Power Stations, U.S. Department of Energy, Division of Solar Energy, DSE/2071-1, September 1976.

3. Glaser, Peter E., Development of the Satellite Solar Power Station, Statement Before the Subcommittee on Space Science and Applications and the Subcommittee on Energy Research, Development and Demonstration of the Committee on Science and Technology, U.S. House of Representatives, February 20, 1978.

4. Koomanoff, Frederick A., "Memorandum to PRC Regarding Task Assignment State of the Art Study of Possible Application of Laser as Transmission Medium for SPS," February 28, 1978.

5. Billman, K. W. (ed.), "Radiation Energy Conversion in Space," Progress in Astronautics and Aeronautics Series, Vol. 61, AIAA, New York, 1978.

6. Drummond, J. E., "Solar Power Satellites Revisited," Proceedings of the Fifth Energy Technology Conference and Exposition, U.S. Department of Energy, February 27 to March 1, 1978.

7. National Aeronautics and Space Administration, Johnson Space Center, Satellite Power System (SPS) Concept Evaluation Program, a Recommended Preliminary Baseline Concept (Systems Definition Study), January 25, 1978.

8. Emmett, John L., "Frontiers of Laser Development," Physics Today, March 1971, pp. 24-31.

9. Hertzberg, Abraham, "High-Power Gas Lasers: Applications and Future Development," Journal of Energy, November-December 1977, Vol. I, No. 6, pp. 331346.

10. Anderson, John D., Department of Aerospace Engineering, University of Maryland, College Park, Maryland, Conference on April 14, 1978.

11. Kelch, G. W., and Young, W. E., Closed-Cycle Gas Dynamic Laser Design Investigation, Report CR-135130 by United Technologies Corporation, Pratt and Whitney Aircraft Group, for NASA Lewis Research Center, January I, 1977.

12. Beesley, M. J., Lasers and Their Applications, Barnes \& Noble, 1971.

13. Lancashire, R. B. et al., "The NASA High-Power Carbon Dioxide Laser--A Versatile Tool for Laser Applications," Optical Engineering, Vol. 12, No. 5, September/October 1977.

14. Baily, Philip K., and Smith, Richard C. (Hughes Aircraft Company), Closed-Cycle Electric Discharge Laser Design Investigation, NASA CR-135-408, sponsored by NASA Lewis Research Center, March 1978. 
15. Billman, K. W., and Rowley (NASA/Ames Research Center), A Comparison of Near Vertical Atmospheric Transmission of Selected $\mathrm{CO}$ and $\mathrm{CO}_{2}$ Laser

Wavelengths, 11 June 1976.

16. Locke, Edward V., "Multi-kilowatt Industrial $\mathrm{Co}_{2}$ Lasers: A Survey," Proceedings of the Society of Photo-Optical Instrumentation Engineers, 1976, Vol. 86, Pp. 210 .

17. Center, Robert (Mathematical Sciences Northwest), Private Communication, April 1978.

18. Karnes, David M. et al. (McDonnell Douglas Astronautics Company), "Laser Power Transmission System," unpublished notes developed during and after the Laser Power Transmission System conferences, April 1978.

19. Hertzberg, Abraham, and Sun, Kenneth, "Laser Aircraft Propulsion," paper prepared at the University of Washington under NASA Grant No. NGL-49-002044.

20. McCusker, M. V. et al., New Electronic-Transition Laser Systems, Stanford Research Institute, May 1976.

21. Berggren, R. R., and Lenertz, G. E. (ITEK Corporation), Feasibility of a 30Meter Space-Based Laser Transmitter, NASA CR-134-903, October 1975.

22. Rhea, John, "Search for High Power Laser Weapons Continues," Microwave Systems News, October/November 1976.

23. Jones, Wayne S. (Lockheed Missiles and Space Company), Laser Power Conversion System Analysis Briefing for U.S. Department of Energy, June 28, 1978.

24. Jenkins, F. A., and White, H. E., Fundamentals of Physical Optics, McGraw-Hill, New York, 1937.

25. W. J. Schafer Associates, Inc., A Study to Recommended NASA High Power Laser Technology and Research, Final Report, 1976.

26. Gebhardt, Frederick G., "High Power Laser Propagation," Applied Optics, June 1976, Vol. 15, No. 6, pp. 1479-1493.

27. Miles, Perry, "High Transparency Infrared Materials -- A Technology Update," Optical Engineering, September/October 1976, Vol. 15, No. 5, pp. 451-459.

28. Monsler, M., "High Power Optics," Proceedings of the Society of Photo-Optical Instrumentation Engineers (Laser Systems), 1975, Vol. 69, pp. 95-106.

29. Bennett, H. E., and Soileau, M. J., "Fabricating Infrared Optics," Optical Engineering, September/October 1976, Vol. 15, No. 5, pp. 442-445.

30. Meyers, G. E. et al. (Rockwell International), Analysis and Design of High Power Laser Adaptive Phased Array Transmitter, NASA CR 134-952, March 1977. 
31. McNamara, R. C. et al., Materials for Large Space Optics, Phase 1, Air Force Systems Command Report CASD-AFS-77-008, Final Report on Contract No. F33615-77-C-5277 with General Dynamics Corporation, January 1978.

32. Rather, John D. G., Space Transportation, Solar Power From Space, and Space Industrialization: A Better Way, W. J. Schafer Associates, Inc., report, December 1976.

33. Rockwell International, Satellite Power System (SPS) Concept Definition Study, Final Report (Volume IV: SPS Concept Evaluation), April 1978.

34. Hansen, C. Frederick, NASA Research on Laser Power Transmission in Space, Ames Research Center, Moffett Field, California.

35. Stirn, Richard J., "Photovoltaic Conversion of Laser Energy," Second NASA Conference on Laser Energy Conversion (edited by Kenneth W. Billman), NASA SP-395, Ames Research Center, Moffett Field, California, January 27-28, 1975.

36. McFee, Ray (McDonnell Douglas Astronautics Company, Huntington Beach, California), Private Communication, April 1978.

37. Byer, Robert L., "Initial Experiment with a Laser Driven Stirling Engine," Second NASA Conference on Laser Energy Conversion (edited by Kenneth W. Billman), NASA SP-395, Ames Research Center, Moffett field, California, January 27-28, 1975.

38. Hertzberg, Abraham, "Advanced Photon Engines," Second NASA Conference on Laser Energy Conversion (edited by Kenneth W. Billman), NASA SP-395, Ames Research Center, Moffett Field, California, January 27-28, 1975.

39. Billman, Kenneth W. (NASA Ames Research Center), "Laser Energy Conversion," Astronautics and Aeronautics, July/August 1975.

40. Hertzberg, Abraham, and Lah, Chah-Veng, A High Temperature Binary Cycle for Ground and Space Power Applications.

41. Britt, E. J., and Yuen, C., Thermoelectric Laser Energy Conversion for Power Transmission in Space, Rasor Associates, Inc., report, Sunnyvale, California.

42. McDonnell Douglas Astronautics Company, Space Station Systems Analysis Study, Data Package 6 Cluster Support, July 1977.

43. Kemp, N. H., et al., Laser-Heated Rocket Studies, Physical Sciences, Inc., contract NAS-3-1969-5, May 1976.

44. Schneider, Stanley (McDonnell Douglas Astronautics Company, Huntington Beach, California), Private Communication, April 1978.

45. Elson, Benjamin M., "Laser Communication Timing Revised," Aviation Week and Space Technology, March 20, 1978.

46. Ching, B. K., "Space Power Systems--What Environmental Impact?" Astronautics and Aeronautics, February 1977, pp. 60-65. 
47. Federal Task Force on Inadvertent Modification of the Stratosphere (IMOS), Fluorocarbons and the Environment, Government Printing Office, Washington, D.C., 1975.

48. Wei, Michael S., (Planning Research Corporation, McLean, Virginia), Private Communication, May 1978.

49. U.S. Department of Labor, Occupational Safety and Health Administration General Safety and Health Standards, OSHA 2206 (29 CFR 1910), January 1976.

50. Michaelson, S. M., "Standards for Protection of Personnel Against Nonionizing Radiation," American Industrial Hygiene Association Journal, 1974, Vol. 35, pp. 766-784.

51. Pacific Northwest Laboratory, Initial Assessment--Electromagnetic Compatibility of Aspects of Proposed SPS Microwave Power Transmission System (MPTS) Operation, PNL-2482, 1978.

52. Sliney, D. H. et al., "Environmental Health Hazards from High-Powered Infrared Laser Devices," Archives of Environmental Health, April 1975, Vol. 30, pp. 174-199.

53. American Conference of Environmental Industrial Hygienists, A Guide for Control of Laser Hazards, Paul M. Harrod Company, Baltimore, Maryland, 1975.

54. Monson, D. J., NASA Ames Research Center, System Efficiency and Specific Mass Estimates for Direct and Indirect Solar-Pumped, Closed-Cycle, HighEnergy Lasers in Space, January 1978. 
American Conference of Governmental Hygienists, A Guide for Control of Laser Hazards, 1973.

Anderson, John D., Jr., Gas Dynamic Lasers: An Introduction, Academic Press, New York, 1976.

Billman, K. W. et al., Introductory Assessment of Orbiting Reflectors for Terrestrial Power Generating, NASA TMX-73, 230, April 1977.

Christiansen, W. H., A New Concept for Solar Pumped Lasers, Supported by NASA Grant NGL-48-002-044.

Hansen, C. Frederick, and Lee, George, "Laser Power Stations in Orbit," Astronautics and Aeronautics, July 1972, pp. 42-45.

International Telephone and Telegraph, Reference Data for Radio Engineers, Howard W. Sams \& Company, 1975.

Jones, T. G. et al., "Electron-Beam-Stabilized CW Electric Discharge Laser in Supersonically Cooled CO/N $/$ Ar Mixtures," AIAA Paper No. 74-562, Proceedings of the AIAA 7th Fluid and Plasma Dynamics Conference, Palo Alto, California, June 17$19,1974$.

Kemp, N. H., and Root, R. G., Analytical Study of Laser Supported Combustion Waves in Hydrogen, Physical Sciences, Inc., report for NASA Lewis Research Center under Contract NAS 3-20318, August 1977.

Lancashire, R. B. et al., "The NASA High-Power Carbon Dioxide Laser--A Versatile Tool for Laser Applications," Proceedings of the Society of Photo-Optical Instrumentation Engineers, Vol. 86, August 24-25, 1976

Mattick, Arthur T., Absorption of Solar Radiation by Alkali Vapors, supported by NASA Grant NGL48-002-044.

Meinel, A. D., and Meinel, M. P., "Is It Time for a New Look at Solar Energy?" Bulletin of the Atomic Scientists, October 1971, pp. 32-37.

Meyers, G. E. et al. (Rockwell International), Analysis and Design of a High Power Laser Adaptive Phased Array Transmitter, Final Report, Contract NAS-3-18937, March 1977.

Monson, D. J., "Potential Efficiencies of Open- and Closed-Cycle CO, Supersonic, Electric-Discharge Laser," AlAA Journal, Vol. 14, No. 5, pp. 614-620.

Nakand, H. H. et. al., New Electronic-Transition Laser Systems, Final Report, Stanford Research Institute, December 1976.

Palmer, A. L. et al. (Hughes Research Laboratories), Excimer Lasers, Final Report, Contract NAS-3-19707, November 1977. 
Plummer, Michael J., and Glowacki, Walter J., "Theoretical Investigation of the CO Supersonic Electric Discharge Laser," AlAA Paper No 73-623, Proceedings of the 6th Fluid and Plasma Dynamics Conference, Palm Springs, California, July 16-18, 1973.

Rather, J. D. G., "New Candidate Lasers for Power Beaming and Discussion of Their Applications" to be published in Progress in Aeronautics and Astronautics.

Ross, Dieter, Laser Light Amplifiers and Oscillators, Academic Press, New York, 1969.

Rowe, W. D., Deputy Assistant Administrator for Radiation Programs, Environmental Protection Agency, Statement Before the Subcommittee on Space Science and Applications and the Subcommittee of Advanced Energy Technology and Energy Conservation Research, Development and Demonstration of the Committee on Science and Technolgy, U.S. House of Representatives, April 13, 1978.

Selby, J. E. et al., Atmospheric Transmittance from 0.25 to $28.5 \mathrm{~m}$-- Supplement LOWTRAN 3B (1976), Air Force Systems Command Report No. AFGL-TR-76-0258, November 1, 1976.

Sliney, David $H$. et al., Environmental Health, Hazards from High-Powered, Infrared, -win: Devices, Archives of Environmental Health, Vol. 30, April 1975.

Skolnik, Merril L., Statement Before the Subcommittee on Space Science and Applications and the Subcommittee on Energy of the Committee on Science and Astronautics, U.S. House of Representatives, May 7, 22, and 24, 1973.

U.S. Army, Control of Health Hazards from Lasers and Other High Intensity Optical Sources, Army Regulation No. 40-60, effective March 15, 1973.

U.S. Army Environmental Hygiene Agency, Laser Protective Eyewear, Aberdeen Proving Ground, Maryland.

U.S. Army Missile Command, High Specific Energy Pulsed Electric Discharge Laser Research, Final Report, Contract No. DAAH01-75-C-0503, December 1975.

Wolfe, William L., Handbook of Military Infrared Technology, Office of Naval Research, U.S. Governmental Printing Office, 1965.

Yesil O., and Christiansen, W. H., Solar Pumped Continuous Wave Carbon Dioxide Laser, supported by NASA Grant NGL-48-002-044. 
The major questions concerning the Satellite Power System (SPS) microwave subsystem are related to the impacts of its directed (and scattered) radiation on electronic and electromagnetic systems, the ionosphere, the troposphere, and its longterm effects on ecosystems and public health.

\section{ELECTROMAGNETIC COMPATIBILITY (EMC)}

Reliable functioning of advanced broadcast, communications, and navigation networks and of data processing, instrumentation, and consumer electronics could be affected by SPS microwave transmissions. Some of the early SPS microwave studies as reported by Gordon Woodcock of Boeing ' indicated that the radio-frequency interference problems could be handled but needed continuing effort. More recent investigations $^{2,3}$ appear to have isolated some EMC problems that may or may not yield to continued effort. These problems are summarized in the statements below: ${ }^{2}$

- $\quad$ "Incidental energy from an SPS Power transmission which falls outside the rectenna area could produce harmful effects on some electronic systems throughout the hemisphere from which the SPS is visible."

- $\quad$ "Spurious emissions, at frequencies outside a band presumed to be allocated to microwave power transmission, could cause harmful interference to existing or planned uses of the microwave spectrum."

- $\quad$ "SPS microwave power transmission will modify the natural ionosphere and might substantially alter the propagation of radio signals over a wide range of frequencies."

- $\quad$ EMC problems caused by "SPS microwave power transmission will require modification of existing international radio rules."

More detailed information can be obtained from a review of reference 2.

\section{EFFECTS ON UPPER ATMOSPHERE}

The potential impacts of microwave energy on the upper atmosphere were recently cited in statements 4,5 before the Committee on Science and Technology of the U.S. House of Representatives. L. M. Duncan of Los Alamos Scientific Laboratory (LASL), in his presentation of lonosphere/Microwave Interactions at the March 1978 Department of Energy SPS Environmental Effects Review (Johnson Space Center, Houston, Texas), summarized on one slide the following potential impacts: 
- $\quad$ "Critical interference with communication and radar propagation (HF, VHF, UHF) and navigation systems (VLF)";

- $\quad$ "Scintillations of ground-to-satellite communications (including the SPS uplink pilot beam)";

- "Generation of ionospheric disturbances (density modifications, artificial spread-F, enhanced airglow)";

- Modification of the atmospheric electric field structure, possibly leading to local thunderstorm enhancements."

Ionospheric disturbances can be expected to affect the propagation of electromagnetic waves, even though the proposed SPS frequency $(2.45 \mathrm{GHz})$ was expressly chosen to reduce lower frequency ionospheric effects and higher frequency tropospheric effects.

\section{EFFECTS OF MICROWAVE EXPOSURE}

The magnitude of the difference between the U.S. microwave exposure standard for an 8-hour day $\left(10 \mathrm{~mW} / \mathrm{cm}^{2}\right)^{6,7}$ and that of the U.S.S.R. $\left(0.01 \mathrm{~mW} / \mathrm{cm}^{2}\right)^{6}$ indicates some lack of understanding of microwave effects as well as differences in the evaluation and interpretation of analytical and experimental data. Dr. Richard D. Phillips, of Pacific Northwest Laboratories, in reporting ${ }^{8}$ results of a recent microwave bioeffects review, ${ }^{9}$ indicated that the impact of microwave radiation on public health and the environment is one of the critical SPS issues and that a safe microwave exposure level must be specified. Dr. Phillips continued to report that:

No experimental study has ever been performed that even remotely approaches the 30 years or more that SPS would be operational. Research will have to be conducted to determine whether chronic, lifespan exposures to microwaves at $1 \mathrm{~mW} / \mathrm{cm}^{2}$ produce adverse biological effects. Only intensive experimental study, carefully planned and conducted can reveal whether the SPS can be safely implemented. 


\section{REFERENCES}

1. Woodcock, Gordon R., "Solar Satellites - Space Key to Our Power Future," Astronautics and Aeronautics, July-August 1977, Vol. 15, No. 7/8, pp. 30-43.

2. Battelle Pacific Northwest Laboratories, Electromagnetic Compatibility Aspects of Proposed SPS Microwave Power Transmission System (MPTS) Operations, PNL-2482, under DOE Contract No. EY-76-C-06-1830, February 1978.

3. Battelle Pacific Northwest Laboratories, Electromagnetic Compatibility, Tropospheric and lonospheric Aspects of SPS MPTS Operations (Preliminary Study), PNL-2616, under DOC-DOE Interagency Agreement, March 1978.

4. Koomanoff, Frederick A., Statement Before the Committee on Science and Technology, House of Representatives, Subcommittee on Space Science and Applications, and Subcommittee on Advanced Energy Technologies and Conservation Research, Development and Demonstration on HR 1060I ("Solar Power Satellite Research, Development and Demonstration Program Act of 1978"), April 12-13, 1978.

5. Gordon, William E., Statement Before the Committee on Science and Technology, House of Representatives, Subcommittee on Space Science and Applications, and Subcommittee on Advanced Energy Technologies and Conservation Research, Development and Demonstration on HR 10601 ("Solar Power Satellite Research, Development and Demonstration Program Act of 1978"), April 12-13, 1978.

6. Michaelson, Sol M., "Standards for Protection of Personnel Against Nonionizing Radiation," American Industrial Hygiene Association Journal, Vol 35.

7. American Conference of Governmental/Industrial Hygienists, TLV's Threshold Limit Values for Chemical Substances and Physical Agents in the Work Room Environment with Intended Changes for 1976.

8. Phillips, Richard D., Statement Before the Committee on Science and Technology, House of Representives, Subcommittee on Space Science and Applications, and Subcommittee on Advanced Energy Technologies and Conservation Research, Development and Demonstration on HR 1060I ("Solar Power Satellite Research, Development and Demonstration Program Act of 1978"), April 12-13, 1978.

9. Phillips, Richard D., et al., Compilation and Assessment of Microwave Bioeffects on The Satellite Power System, Battelle Pacific Northwest Laboratories Report AD-02-01/EA 81028, December 1977. 


\section{APPENDIX B}

\section{NASA BASELINE SATELLITE POWER SYSTEM CONCEPTS}

Preliminary baseline satellite power systems concepts studies were conducted at the Johnson Space Center and the Marshall Space Flight Center. The results of these studies were similar in many respects as shown by summaries of the two baseline concepts (table B.I) and the point design resumes (table B.2). a

Table B.I SPS Preliminary Baseline Concepts

SPS Concept Factors

$\mathrm{JSC}^{\mathrm{I}} \quad \mathrm{MSFC}^{2}$

Orbit

Geostationary

Geostationary

(constructed

(constructed

in LEO)

in GEO)

Microwave antenna

2

1

Power at busbar

$10 \mathrm{GW}$

$5 \mathrm{GW}$

Size of solar blanket

$108.8 \mathrm{~km}^{2}$

$82 \mathrm{~km}^{2}$

Solar cell type

Si

GaA IAs

Concentration ratio

1

2

Solar cell efficiency

$15.1 \%$

$15.2 \%$

System efficiency

$7.13 \%$

$6.08 \%$

a/ These concepts are currently being updated and combined into a joint JSC/MSFC Reference System, ${ }^{3}$ a preliminary description of which was presented at NASA Headquarters, 13 July 1978. 
Table B.2 MPTS Point Design Resumes

Parameter

JSC Values I

MSFC Values ${ }^{2}$

Input power

8.5 GW/antenna

8.6 GW/antenna

Efficiency total MPTS

0.59

0.59

Microwave antenna efficiency

0.80

0.78

Propagation efficiency

0.86

0.83

Rectenna efficiency

0.86

0.85

Array diameter

$1.0 \mathrm{~km}$

$1.0 \mathrm{~km}$ 


\section{REFERENCES}

1. National Aeronautics and Space Administration, Johnson Space Center, Satellite Power System (SPS) Concept Evaluation Program, A Recommended Preliminary Baseline Concept (Systems Definition Study), January 25, 1978.

2. National Aeronautics and Space Administration, Marshall Space Flight Center, Preliminary Baseline SPS Concept Recommendations to DOE/NASA, January 24, 1978.

3. Marshall Space Flight and Johnson Space Center, Solar Power Satellite Baseline Review, presented at NASA Headquarters, Washington, D.C., July 13, 1978. 


\title{
FREE ELECTRON LASERS
}

\author{
John M. J. Madey \\ Senior Research Associate \\ W. W. Hansen Laboratory \\ Stanford University
}

The Free Electron Laser (FEL) was proposed by Madey in 1971 as a tunable source of radiation at optical wavelengths. ' The first demonstration of laser action was reported by the FEL group at Stanford in 1976. A 24-MeV electron beam was used to amplify the radiation from a $10.6-\mu \mathrm{m} \mathrm{CO}$ laser. $^{2}$ In 1977 the Stanford group reported the first operation of a FEL oscillator. The oscillator was powered by a 43$\mathrm{MeV}$ electron beam at $3.4 \mu \mathrm{m}^{3}$

Although high peak power has been achieved in the experiments at Stanford, the average power has been low due to the limited electron current available from the superconducting accelerator. To obtain high average power, the free-electron laser will have to be installed within a high current electron accelerator such as an electron storage ring. Electron storage rings have operated at beam energies and currents well in excess of the values required for laser operation. The feasibility of a storage ring free-electron laser hinges on the effect of laser operation on the characteristics of the circulating electron beam. This question is now being investigated at Stanford in an analysis scheduled for completion in March 1979.

Storage rings are quite massive. For example, the one at the Physical Sciences Laboratory of the University of Wisconsin, Stoughton, Wisconsin, weighs approximately 12 metric tons. It is believed that this weight, which includes 10 metric tons of iron and 1.2 metric tons of copper, could be reduced by a factor of 3 for a total weight of approximately 4 metric tons. This unit, driven at $1,000 \mathrm{MeV}$ and $4 \mathrm{~A}$, will provide 40 $\mathrm{MW}$ of power when operating at an extraction ratio of I percent. Extraction ratios of 10 to 30 percent are believed feasible. At a I percent extraction ratio, the weight of the FEL unit less power source is $0.1 \mathrm{~kg} / \mathrm{kW}$. Possible efficiencies have been estimated by various researchers at 20 to 70 percent. High-efficiency units insulated to operating at temperatures of $1000 \pm 200^{\circ} \mathrm{K}$ will help minimize the waste heat rejection problem of FEL equipments operating in space. No lasant is involved, so units can be vented to space and operated at ambient space pressure to simplify the window problem. 
FEL units now in service have operated for periods of several weeks at a time without interruption for service or repair. The following information relates FEL potential to experimental results and provides a brief summary of the FEL-related work completed, in progress, and proposed at Stanford University.

\section{FEL POTENTIAL}

The FEL exploits the interaction between free electrons and light in a periodic magnetic field. The laser is tunable by variation of the electron energy. The device has the capability to work at high average power at high efficiency.

The FEL requires a high-quality, high-current electron beam. Some of the problems associated with such a beam are the massive size and cost of high-current, high-energy accelerators and the comparatively small fraction of the electron energy that can be converted to radiation in a single pass through the periodic magnet. A low overall efficiency is implied if the electron beam makes only a single pass through the laser.

The electron storage ring appears to be the most promising means of generating an electron beam with the required characteristics. Storage rings in the energy range required for laser operation are both compact and inexpensive and can be filled using a low average current accelerator. Moreover, the electron beam in a storage ring laser can be re-accelerated on a steady-state basis to replace the energy lost to radiation in the laser leading to the possibility of very high overall efficiency.

The aim is to install the laser magnet within the storage ring (see figure $\mathrm{C} .1$ ) and to use an RF electric field to maintain the energy of the electron beam.

MIRROR

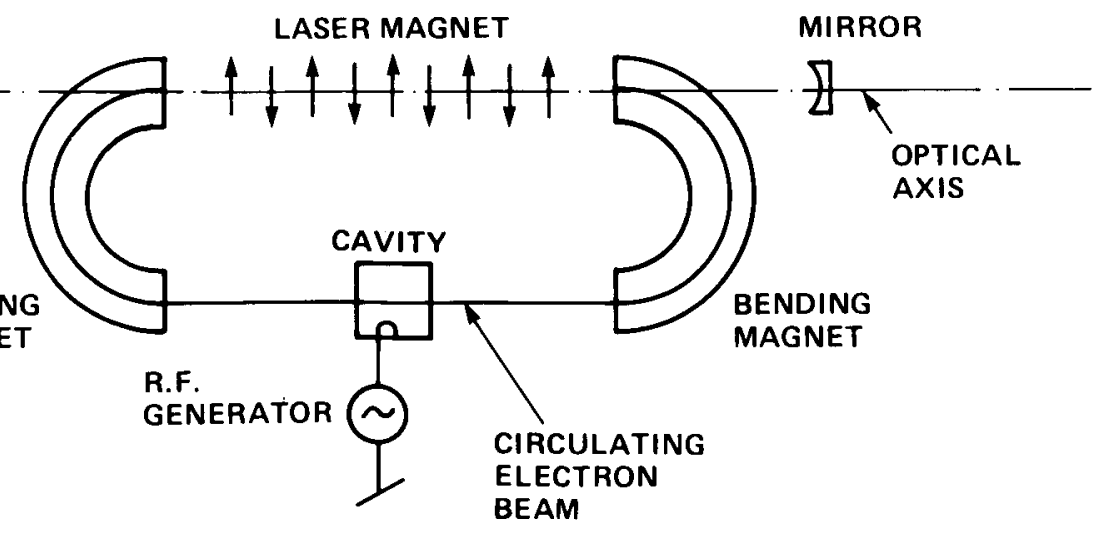

Figure C.I Schematic of Electron Storage Ring 
The Princeton-Stanford ring stored an average current of $0.4 \mathrm{~A}$ at $500 \mathrm{MeV} .^{4}$ In the present series of FEL experiments at Stanford, a maximum of 0.1 percent of the electrons' energy has been converted to radiation, whereas Kwan and Dawson predict that 30 percent or more of the energy can be extracted under the appropriate circumstances. ${ }^{5}$ At an extraction ratio of 0.1 percent, the average output power of a laser based on the Princeton-Stanford ring would exceed $100 \mathrm{~kW}$, and a 30 percent extraction ratio would imply an output of $30 \mathrm{MW}$. The estimated overall efficiency for a $100 \mathrm{~kW}$ FEL based on the Princeton-Stanford ring exceeds 20 percent. $^{6}$

The smallest storage ring ever built was the ADA ring at Frascati $^{7}$ (orbit diameter $\sim 1.3 \mathrm{~m}$, beam voltage $\sim 250 \mathrm{MeV}$ ). The largest ring currently operational is at Stanford ${ }^{8}$ (orbit diameter $\sim 60 \mathrm{~m}$, beam voltage $\sim 4 \mathrm{GeV}$ ). The Tantalus 1 ring at the University of Wisconsin operates at a beam voltage of $240 \mathrm{MeV}$ and an average beam current of $100 \mathrm{~mA}$. A ring of this type would provide a beam suitable for laser operation in the visible and the ultraviolet ranges.

\section{SCIENTIFIC ISSUES OF FEL-RELATED WORK}

\section{Completed}

Development of Techniques for Analysis of Laser Operations

- Identification of the FEL mechanisms as a "single-particle" interaction"

- Development of the small signal quantum theory ${ }^{1}$

- Development of criteria for the applicability of the classical approximation at high power ${ }^{10}$

- Development of numerical and analytical methods for the analysis of laser operation in the strong signal regime ${ }^{11,12}$

Experimental Demonstration of Laser Action

- Verification of small signal gain formula

- Operation of a FEL oscillator in the "single-pass" mode and study of saturation characteristics ${ }^{3}$

Analysis of Storage Ring Operation

- "One-dimensional" analysis (electron energy spread and bunch length), including derivation of stability theorem and estimation of the energy spread for a constant period laser magne $t^{10,13}$ 
In Progress

Analysis of Storage Ring Operation

- Selection of laser magnet and storage ring geometry to optimize electron energy spread and bunch length

Proposed

Analysis of Storage Ring Operation

- "Three-dimensional" analysis - extension of analysis to include electron transverse momentum and finite beam radius

Resonator Design

- Selection of resonator geometry to optimize coupling to electron beam

- Analysis of resonator and output coupler geometry, mirror materials and coatings for operation at high power. 


\section{REFERENCES}

1. Madey, J. M. J., "Stimulated Emission of Bremsstrahlung in a Periodic Magnetic Field," J. Appl. Phys., 1971, Vol. 42, p. 1906.

2. Elias, L. R. et al., "Observation of Stimulated Emission of Radiation by Relativistic Electrons in a Spatially Periodic Transverse Magnetic Field," Phys. Rev. Letts., 1976, Vol. 36, p. 717.

3. Deacon, D. A. G. et al., "First Operation of a Free Electron Laser," Phys. Rev. Letts., 1977, Vol. 38, p.892.

4. Barber, W. C. et al., "Operation of the Electron-Electron Storage Ring at 550 MeV," HEPL Report No. 458, 1966.

5. Kwan, T. et al., "Free Electron Lasers," submitted to Phys. Fluids, 1977.

6. Elias, L. R. et al., "A Discussion of the Potential of the Free Electron Laser as a High Power tuneable Source of Infrared, Visible, and Ultraviolet Radition," Proceedings of the Synchrotron Radiation Facilities. Quebec Summer Workshop, June 15-18, 1976.

7. Bernardini, C. et al., "The Frascati Storage Ring," Nuovo Cimento, 1960, Vol. 18, p. 1293.

8. Proceedings of IX International Conference on High Energy Accelerators, Stanford University, 1974.

9. Gover, A., "Collective and Single Electron Interactions of Electron and Electromagnetic Waves in Periodic Structures," submitted to Appl. Phys., 1977.

10. Madey, J. M. J., and Deacon, D. A. G., "Free Electron Lasers," Cooperative Effects in Matter and Radiation, Plenum Press, New York, 1977, p. $3 \longdiv { 1 3 . }$

II. Hopf, F. A. et al., "Strong Signal Theory of a Free Electron Laser," Phys. Rev. Letts., 1976, vol. 37, p. 1342.

12. Colson, W. B., "One Body Electron Dynamics in a Free Electron Laser," submitted to Phys. Letts., 1977.

13. Deacon, D. A. G. et al, "The Free Electron Laser," Laser Spectroscopy, SpringerVerlag, New York, 1977. 


\title{
APPENDIX D
}

HIGH-ENERGY VISIBLE AND ULTRAVIOLET LASERS

PUMPED BY ELECTRON BEAMS AND ELECTRON-BEAM-CONTROLLED DISCHARGES

\author{
David L. Huestis \\ Molecular Physics Laboratory \\ SRI International
}

During the past six years, remarkable progress has been achieved in the development of large, efficient lasers, operating in the visible or near-ultraviolet, pumped by electron beams and electron-beam-controlled discharges. This developmental research has been conducted at a number of university, industrial, not-forprofit, and government laboratories. The applications foreseen by the client agencies (mainly DOD and D.OE) have ranged from underwater communications to laser weapons and from laser-induced fusion to laser isotope separation. Some applications restrict the choice of the laser wavelength. Some require very high optical beam quality for long-range transmission or tight focusing. Common requirements for all these applications include high electrical efficiency and scalability to very large energies.

The rapid recent progress is illustrated in table D.I, in which the recently discovered, potentially efficient, and potentially high-energy lasers are listed. The best understood of these lasers is $\mathrm{KrF}$, which has also yielded the highest output energy (400 J/pulse), energy density (10 J/1), and efficiency (10 percent). Pulse repetition frequencies of up to $100 \mathrm{~Hz}$ have been forecast. If one emphasizes the issue of atmospheric transmission, the $\mathrm{KrF}$ wavelength $(248 \mathrm{~nm})$ is unfortunately too short. The next most studied laser is $\mathrm{XeF}$, which has produced about one-half the output energy at somewhat less than half the energy density and efficiency. The molecular iodine laser, whose discovery coincided with the rare gas halides, has performed substantially less well. The $\mathrm{Ar} / \mathrm{N}_{2}, \mathrm{~N}_{2}^{+}$and rare gas oxide ( $\mathrm{XeO}, \mathrm{KrO}$, and ArO) lasers, discovered earlier, also appear to have intrinsic limitations to their efficiency and scalability. Recent additions to the list of active candidate lasers are the mercury halides, $\mathrm{HgCl}, \mathrm{HgBr}$, and $\mathrm{Hgl}$. The possibility of very high efficiency $>20$ percent in principle) for discharge pumping of these systems makes them the most attractive and most intensively studied new laser systems. The elevated temperatures at which they operate $\left(200^{\circ} \mathrm{C}\right)$ is a nuisance in a ground-based laser, but may be an advantage in a space-based system. Their performance at even higher temperatures has not yet been investigated. 
Table D.I Recent History of Demonstration of Electron-Beam- and discharge-Pumped

Visible and Ultraviolet Lasers

\begin{tabular}{clc} 
Year & Molecule & Wavelength (nm) \\
\hline 1973 & $\mathrm{Ar}_{2}$ & 126 \\
& $\mathrm{Kr}_{2}$ & 147 \\
& $\mathrm{Ke}_{2}$ & 173 \\
\hline 1974 & $\mathrm{Ar}^{\prime} \mathrm{N}_{2}$ & 358 \\
& $\mathrm{~N}_{2}^{+}$ & 428 \\
& $\mathrm{XeO}$ & 538 \\
& $\mathrm{KrO}, \mathrm{ArO}$ & 558 \\
& & \\
\hline 1974 & $\mathrm{KrF}$ & 248 \\
& $\mathrm{XeBr}$ & 282 \\
& $\mathrm{XeCl}$ & 308 \\
& $\mathrm{I}_{2}$ & 343 \\
& $\mathrm{XeF}$ & 351,353 \\
& & \\
\hline 1976 & $\mathrm{ArF}$ & 193 \\
& $\mathrm{KrCl}$ & 222 \\
& $\mathrm{Br} 2$ & 290 \\
& & \\
\hline 1977 & $\mathrm{~F} 2$ & 158 \\
& $\mathrm{ArCl}$ & 175 \\
& $\mathrm{Hgl}$ & 5041 \\
& $\mathrm{HgBr}$ & \\
& $\mathrm{HgCl}$ & \\
\hline
\end{tabular}


Simultaneous with and essential to the recent demonstration and development of these laser systems have been profound advances in our understanding of the microscopic processes within the laser medium that determine the laser performance. The selective energy flow pathways from electrical energy to production of the upper laser level are not comprehensively characterized in electron-beam-pumped laser systems. The pathways in discharge-pumped laser media are understood less completely. Based on this acquired experience, one may confidently predict continued rapid progress.

With respect to the high-power laser requirements for the SPS power transmission application, several potentially efficient lasers have been demonstrated in wavelength regions that may be suitable. New requirements of wavelength, power, efficiency, size, weight, and cost should be established for choosing candidates for further study and development.

In laser development, emphasis must always be placed on understanding the microscopic processes within the laser medium. Unfortunately, many candidate molecules receive little attention prior to the establishment of laser interest. As a result, first priority should almost always be placed on the details of the mechanisms, rates, and cross sections of the important collisional and radiative processes within any new potential laser medium. This approach can be used to evaluate and select laser media holding greatest promise.

To date little investigation has been made into the performance of the various laser systems at elevated temperatures. In addition to the obvious experimental inconveniences, these are some added impediments to the laser performance that must be overcome. The most serious probiem for most laser media would probably be reduced optical extraction efficiency due to a more dispersed vibrational and rotational distribution in the upper laser level and higher lower laser population for bound-to-bound transitions. These questions will begin to be addressed as the zinc and cadmium halide candidate laser systems, operating an a minimum of $500^{\circ} \mathrm{C}$ and $400^{\circ} \mathrm{C}$, respectively, are investigated.

Finally, too little emphasis is now being placed on the development of highenergy photo-pumped lasers. To obtain the necessary high optical quality and volumetric energy density, the laser medium must be a gas vapor as opposed to the traditional dye-solvent media now used. In the case of the SPS, direct solar pumping may be one of the more efficient solar-to-laser power conversion techniques. In the process of investigating the laser media (table D.I), it was discovered that these excited media are much more efficient as fluorescent lamps (up to 50 percent) than they are as lasers ( 10 percent or less to date). If a suitable target medium can be identified, laser systems with high overall efficiency can be developed. 


\title{
APPENDIXE
}

\section{SOLAR PUMPING OF LASERS}

by

\author{
C. N. Bain
}

Planning Research Corporation

There has been a growing interest in pumping lasers with direct sunlight almost since the time of the demonstration of the first laser (a ruby laser pumped by flashlamp). Efforts in this direction are beginning to pay off in equipment and concepts for systems. One such example is the U.S. Air Force Space and Missile Systems Organization's (SAMSO's) solar-pumped Nd:YAG laser communication system,' which is being developed under Program $405 \mathrm{~B}$ by the McDonnell Douglas Astronautics Company. This effort is augmenting the technology of solar pumped lasers, even though it is a very low power system compared with the high-power laser transmission systems needed for the Satellite Power System (SPS).

The direct solar pumping of lasers is an inefficient process because the bandwidth of the absorption spectrum is usually very narrow. As a result, only a small part of the sun's energy can be converted to radiation by a given laser medium. The absorption bands of some of the most efficient gas lasers lie outside the spectral region of peak solar intensity. One example ${ }^{2}$ is the fundamental absorption band of $\mathrm{CO}_{2}$, a $0.1 \mu \mathrm{m}$ band centered at $4.256 \mu \mathrm{m}$, which coincides spectrally with much less than 0.1 percent of the sun's radiation. If it is assumed, for example, that the laser could be made capable of converting 0.1 percent of solar radiation to laser radiation, at an efficiency of approximately 20 percent (for an overall efficiency of 0.020 percent), then a 3,500 sq. $\mathrm{km}$ solar array would be required to provide $1.0 \mathrm{GW}$ of laser power. Now, if the remainder of the power transmission system is 47 percent efficient, required laser power for a 10-GW SPS system output is $21.2 \mathrm{GW}$, and the required solar array area is approximately $74,000 \mathrm{sq} . \mathrm{km}$. Admittedly, this is a large array, but the more difficult problem with this system probably would be the size of the radiators for the removal of waste heat rather than the size of the array.

To illustrate the significance of selecting an appropriate spectral band (and lasing medium), John Rather of W. J. Schafer Associates, Inc., 3 discusses the performance of a solar-pumped laser based on trifluoromethyl iodide $\mathrm{CF}_{3} \mathrm{l}$. This 
medium has an absorption band $0.15 \mu \mathrm{m}$ wide centered at $0.275 \mu \mathrm{m}$ and will convert approximately 0.5 percent of the solar radiation collected to laser radiation. This efficiency is a factor of about 25 greater than that of the $\mathrm{CO}_{2}$ laser discussed above. Rather has proposed a lightweight Mylar or Kapton "light-bucket" with a narrow-band reflective coating for use with this type of system. Wavelengths outside the $0.15-\mu \mathrm{m}$ band would pass through the reflector eliminating a large part of the waste heat dissipation problem. These laser systems, if developed, would be useful in those applications in which efficiency is only of secondary concern.

To overcome some of the limitations of direct solar pumping, W. H. Christiansen of the University of Washington, Robert Taussig of Mathematical Sciences Northwest, Inc., and others have proposed methods of solar pumping that use an intermediate blackbody. The blackbody cavity may take the shape of the inside of a cylinder (see figure E.1). The cylinder, designed to hold heat losses to a minimum, is constructed of graphite or other high-temperature material with an effective insulating layer on the outside. Focused sunlight is coupled to the cavity through a hole in its side and heats the cavity to a given temperature in the range of $1,500^{\circ} \mathrm{K}$ to $3,000^{\circ} \mathrm{K}$ for optimum pumping, as determined by the absorption bands of the lasant to be used. Without considering the laser, cavity heat losses are continually replaced by the focused (broadband) sunlight being received. For a cavity design having uniform inside wall temperatures, the effective radiant heat exchange between adjacent walls is very small. Any heat exchange that does take place tends to improve inside wall temperature uniformity and thereby reduces the rate of this heat exchange. If a selective absorber (a lasant) that absorbs, for example, in a $0.1-\mu \mathrm{m}$ band, centered at $1.9 \mu \mathrm{m}$ is inserted along the axis of the cavity, as shown in figure E.2, it will absorb radiant heat from the cavity through this narrow-wavelength (1.85- to $1.95-\mu \mathrm{m})$ band. - The heat absorbed by the laser is replaced by the focused sunlight. Thus, the characteristics of the blackbody cavity and the lasant's absorption make it possible to combine these two devices (cavity and laser) for the efficient conversion of a broadband radiant source (sunlight) to a narrow-band radiant source for laser pumping.

The major losses for a solar-pumped laser system located in space are:

- Radiation losses from the cavity's outside surface. These losses can be minimized by a layer of insulation around the outside of the cavity, by radiation shielding, and by operating the cavity (other things equal) at the low end of the useful temperature range.

a Radiation emitted from the surface of the blackbody cavity peaks at approximately T.9 $\mathrm{\mu m}$ when cavity temperature is $1,500^{\circ} \mathrm{K}$. 


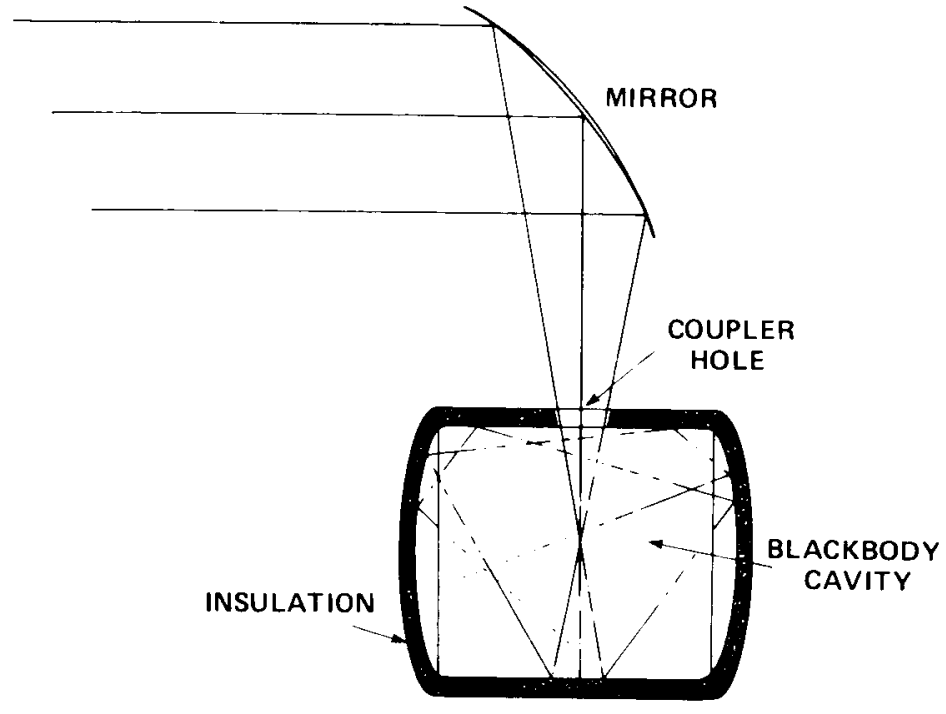

Figure E.I Solar-Heated Blackbody Cavity

- Losses out of the coupling hole. These losses can be minimized by operating the cavity at the lower end of its useful temperature range and using a fast (low $F / n o$.) optical system for the collection of solar radiation.

- Absorption by the laser tube. This is a broadband loss. Materials for the laser tube must be able to withstand the high temperature. Sapphire is a strong, high-temperature material that will transmit radiation out to wavelengths of 5.5 to $6.0 \mu \mathrm{m}$. Other candidate materials ${ }^{2}$ include magnesium oxide and the alkali metal salts. Thin, strong, highly transparent materials with selectively reflecting coatings will reduce these absorption losses. The extent to which this loss can be reduced will depend on the availability of materials and processes as well as on the required operating temperature of the cavity.

- Absorption by the lasant. Undersirable heating in the lasant represents a system heat loss and can result in a significant further loss in laser efficiency. 


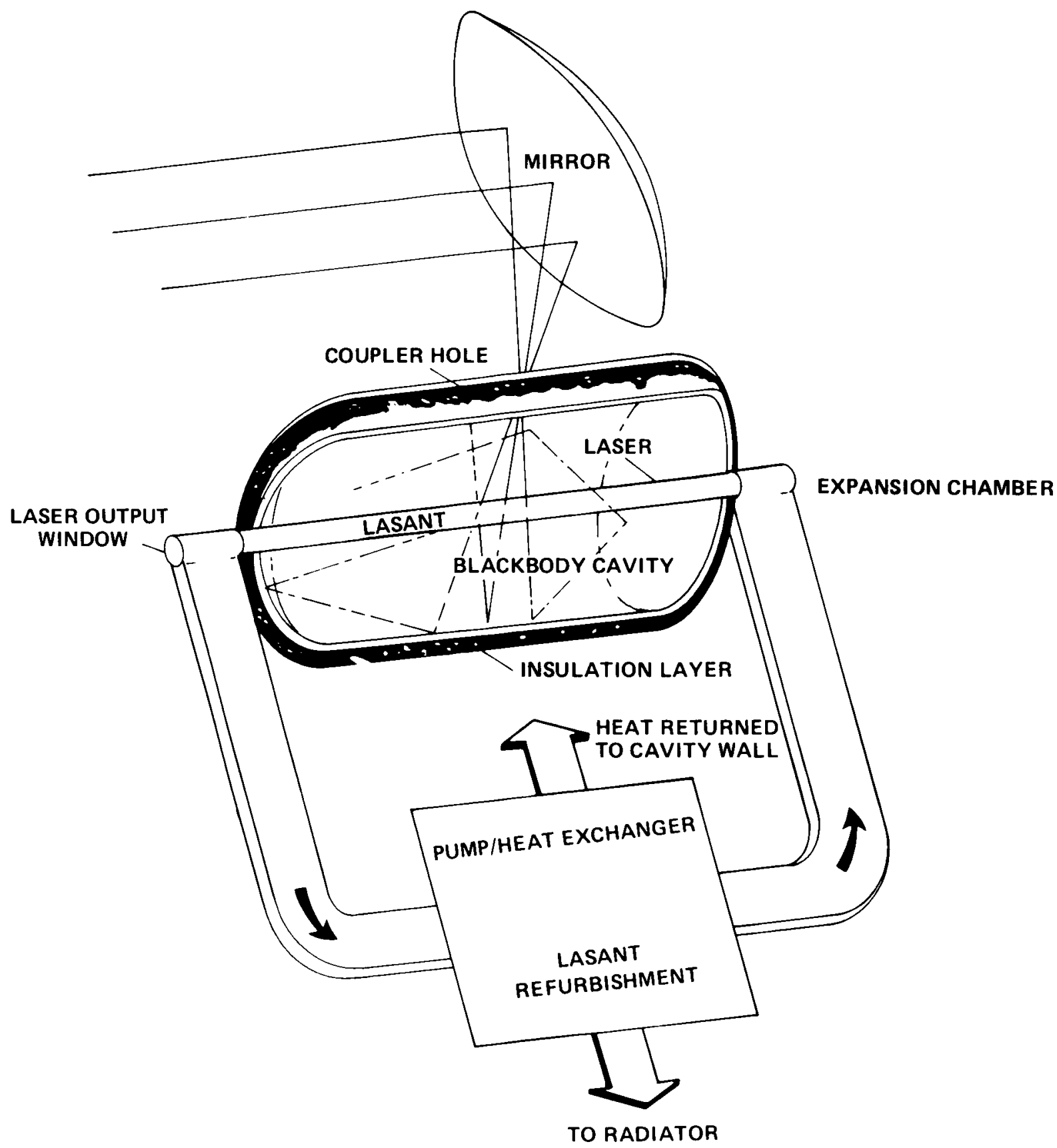

Figure E.2 Solar-Pumped Laser Concept 
To maintain the lasant at an efficient operating temperature, the heat absorbed by the lasant and laser tube must be removed. As in other systems, this can be accomplished by flowing the lasant through the tube and, in the process, conducting the heat away from the tube. While outside the tube, the lasant is reconditioned as required and cooled so that when it is expanded back into the laser tube, it is at the proper operating temperature and pressure. It may be possible, depending on cavity operating temperature, as suggested by figure E.2, to increase overall system efficiency by returning part of the waste heat to the blackbody cavity. Other uses for the waste heat include the generation of electricity for the circulation and reconditioning of the lasant, for laser pointing, for station keeping, and for the operation of other auxiliary equipments.

Reference 2 has identified one of the most important quantities affecting the efficiency of cavity-pumped lasers as the ratio of the power absorbed by the laser tube walls $\left(P_{T}\right)$ to the power absorbed by the medium $\left(P_{M}\right)$, which is expressed as $P_{T} / P_{M} \cdot$ Consequently, to keep this ratio low, tube (cavity) materials should be highly transparent, and techniques such as increasing lasant pressure and adding abosrbers to the lasant should be used to broaden the absorption band of the medium. Figure E.3 is taken from reference 2 and shows the efficiency $(n)$ of a solar-pumped laser versus $P_{T} / P_{M}$ for a blackbody cavity temperature of $2000^{\circ} \mathrm{K}$ and laser efficiencies $\left(\eta_{L}\right)$ of 0.10 and 0.20 . To improve efficiencies in solar-pumped lasers, study design and development efforts are needed in:

- $\quad$ Solar-pumped systems;

- Lasants, to isolate candidates with broadband absorption characteristics and high efficiencies;

- Optical materials for high-temperature, strong, highly transparent laser cavity enclosures;

- High-temperature coatings with selective transmission/reflection characteristics; and

- High-temperature materials for the cavity and for the equipments to reclaim/remove waste heat. 


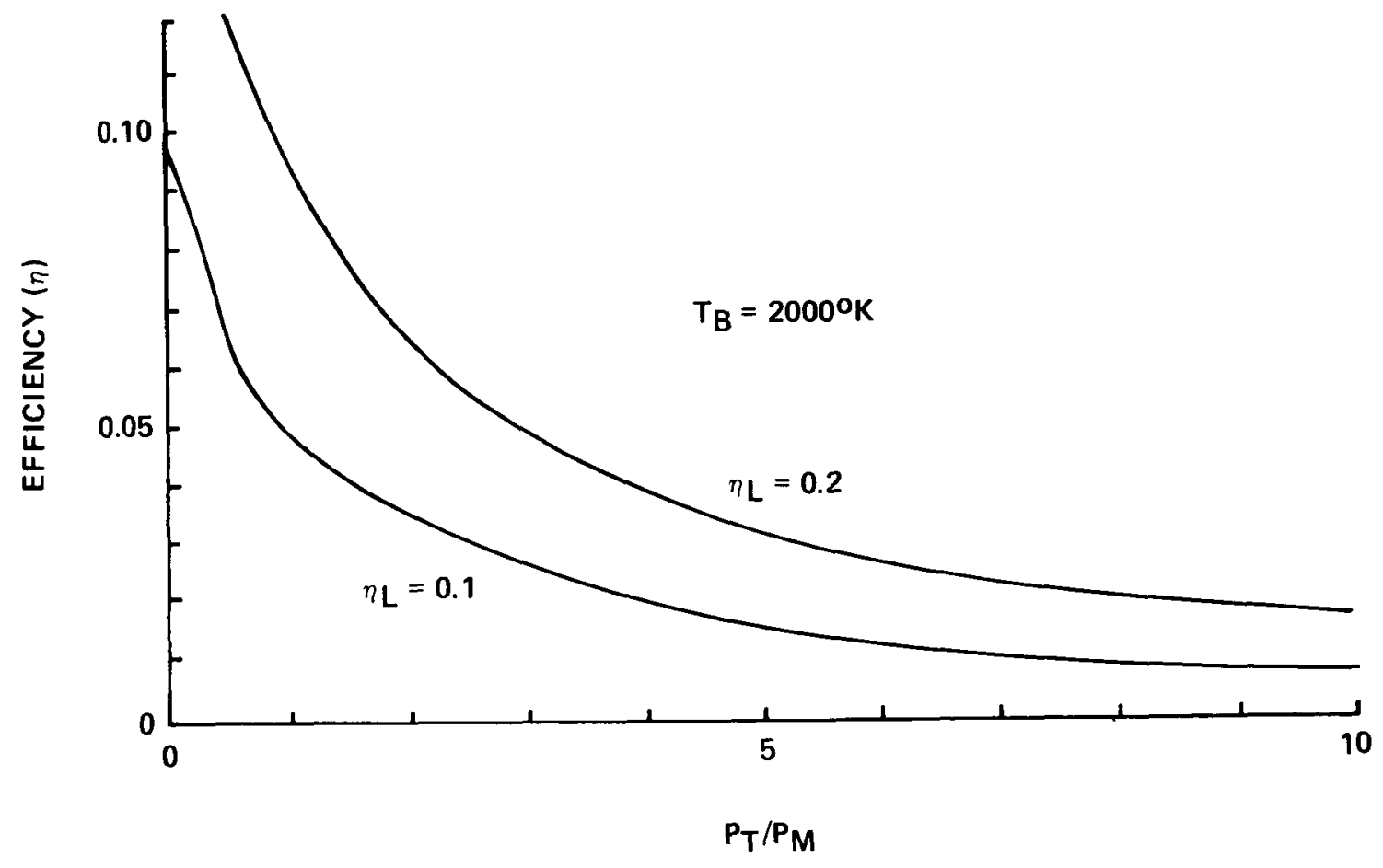

KEY

$T_{B}=$ BLACKBODY CAVITY TEMPERATURE

$\eta_{L}=$ LASER EFFICIENCY = LASER POWER OUT/ABSORBED POWER IN LASER MEDIUM

Figure E.3 Efficiency Versus $P_{T} / P_{M}$ 


\section{REFERENCES}

I. Edson, Benjamin M., "Laser Communications Timing Revised," Aviation Week and Space Technology, March 10, 1978.

2. Christiansen, Walter $H_{\text {., }}$ A New Concept in Solar-Pumped Lasers, work completed under NASA Contract NGL-48-002-044, at Mathematical Sciences Northwest, Inc.

3. Rather, John D. G. (W. J. Schafer Associates, Inc.), New Candidate Lasers for Power Beaming and Discussion of Their Applications (preprint). 
APPENDIX F

LASERS VERSUS MICROWAVES

FOR SOLAR SPACE POWER

by

John D. G. Rather

W. J. Schafer Associates, Inc.

Early in the history of the Solar Space Power System (SPS) concept, tasers were briefly considered as an alternative to microwaves for the beaming of power to the earth. Lasers were rejected as a reasonable option on the basis of what we believe to be a premature and incomplete analysis. With recent progress in the laser state-ofthe-art, SPS decision makers should now reevaluate the laser and its potential for transmitting SPS power. The microwave concept presently being considered for SPS may be so far removed from the optimum concept that it cannot compete with nuclear fusion or other solar options. However, these are many reasons for believing that an SPS of an appropriate design may be an extremely competitive source of power.

Just recently Drummond 'has reassessed the microwave SPS idea and found that much greater cost-effectiveness can be achieved by the use of smaller satellites in much lower $(3,000 \mathrm{~km})$, sun-synchronous orbits. Lower orbits are also advantageous when using lasers for the primay power link and can lead to a cost-effective near-term availability of solar space power. 2,3 It is logical, therefore, that these possibilities be carefully considered before key concept and design decisions are made. Accordingly, we advocate not only that the SPS study program be continued and expanded, but also that it be broadened to encompass these technological options. In fact broadening the technology base from which the SPS concept is drawn is urgent and should result in revisions to the current program plan. In the remainder of this report some of the reasons underlying the foregoing beliefs are outlined.

Typical objections to lasers as an SPS power transmission system alternative are:

(1) Lasers may be much less efficient than microwave sources

(2) The state-of-the-art of high-power lasers may be far behind that of the microwave sources

(3) Clouds and bad weather might cause insurmountable problems

(4) Lasers may be much more dangerous from standpoints of environmental and personal safety 
(5) Laser (weapons) in space might provoke international instabilities.

Detailed responses are available for all of these objections. Here we shall briefly outline the answers.

\section{EFFICIENCY}

Efficiency can be a misleading term. What is really important to the viability of the SPS is the cost of energy $(\$ / \mathrm{kW} h r)$ delivered to the nation's power grid. From work done to date, it appears that a five gigawatt geosynchronous SPS implies a mass of about 60 million pounds in high orbit. The transmitting antenna would be 0.6 miles in diameter and weigh 30,000 tons. The receiver array on the earth needs to be some eight miles in diameter, thus requiring the purchase of large amounts of real estate. All of these components appear to be very expensive and they depend for their feasibility upon a $\$ 10$ billion development effort to produce a heavy-lift rocket vehicle.

Because lasers involve electromagnetic radiation whose wavelength is some 10,000 times shorter than microwaves, the transmitting and receiving components can also be 10,000 times smaller in diameter. Thus a transmitter ten meters in diameter in geosynchronous orbit can potentially send laser power at two micrometers wavelength to a collector 40 meters in diameter at favorable locations on the earth with better than 90 percent efficiency averaged over time. The transmitter properties are well understood, and it is estimated that the transmitter would weigh about 10 tons instead of 30,000 tons. Thus we see intuitively that very great cost-effectiveness can be achieved through the laser approach even if the absolute conversion efficiencies from solar radiation to laser radiation and from laser power collected to electricity are not quite as great as microwave efficiencies.

But the laser efficiency argument does not stop here. Laser technology has moved forward at an accelerating pace for nearly two decades. At least two types of electrical lasers appear to be able to produce coherent radiation with "wallplug" efficiencies approaching 50 percent. These would still depend upon Brayton cycle or photovoltaic electricity production from sunlight (similar to microwaves), with the accompanying waste heat problems. But several other important new ideas exist for converting sunlight to laser radiation by direct conversion processes that would have extremely high overall cost-effectiveness and excellent conversion efficiency. Although funding for studies of these ideas has been miniscule (about $\$ 100 \mathrm{~K}$ ), enough has been accomplished to foster strong beliefs that they are feasible. There is an urgent need to further this work. 
The optimum present conception of a laser power system employs large, very low-weight sunlight concentrators which may be inflatable or otherwise easily deployable. The total weight of an entire 100 megawatt system potentially available in 5 to 7 years, has been estimated at less than 300,000 pounds. 2,3 Hence a few space shuttle payloads could give an impressive early demonstration of space-to-earth power transmission. Similar units could be added indefinitely to achieve whatever level of total power is desired.

A final point about efficiency and cost-effectiveness is that lasers can accomplish many tasks other than simply beaming power to the earth. Since the tradeoffs between transmitter and receiver size are favorable, it is quite possible to beam power to aircraft or spacecraft for many purposes including propulsion. Moreover, it should also be possible to tune the laser to a resonant wavelength of the water molecule to produce direct photochemical storage of beamed energy in the form of hydrogen and oxygen, thus skipping the electrical reconversion step altogether. If electrical reconversion is required, however, at least 50 percent conversion efficiency appears feasible.

\section{STATE-OF-THE-ART}

The open literature on lasers contains reports that single lasers have transmitted at least half a megawatt of power over appreciable distances. Suffice it to say that the power transfer in the JPL microwave experiment (wherein $30 \mathrm{~kW}$ of microwave power was transmitted one mile to a receiving array) has been greatly exceeded in laser demonstrations. More importantly, much scientific literature supports scalability of several types of lasers to very high power levels.

One important point that must be noted is that much laser research and development has been directed toward short-duration very power-intensive applications. The space power system, on the other hand, will require very long-duration operation and an infinite fuel supply, making solar energy the natural choice. Until 1977, very little research was done on high power solar pumped lasers. Several recent studies $2,3,4,5$ have shown, however, that many interesting options are available.

Also of great importance is the quantum jump in laser capabilities expected from the Free Electron Laser (FEL). This technology has suddenly emerged as a prime candidate for many high power laser applications. The possibility definitely exists for producing 50 percent efficient laser radiation at any chosen wavelength from an optically perfect device having potential for low weight per megawatt of power produced. Many such devices are expected to be available within a few years. 


\section{WEATHER}

Before discussing weather effects, it is important to understand that the laser SPS is conceptually very different from the microwave system. Many 100 megawatt satellites replace a few gigantic ones. Random orbits at altitudes of a few thousand kilometers can be shown to be not only feasible but also advantageous. Hence, small, low-cost receivers on the ground can be widely distributed along the existing power grid, and they can accept power from "satellites of opportunity" overhead. Commutating power from one receiver to another is no more important or difficult than shutting down a $100 \mathrm{MW}$ generator at one steam plant or dam and bringing another one on line somewhere else. Whenever possible, it is desirable to bring power down near the load point, but there is no problem (other than cost) in trunking power long distances on super-voltage DC transmission lines if the need arises.

The only clouds that would pose a significant problem for a two micron wavelength power beaming system are rain clouds, because infrared radiation tends to better penetrate clouds and high-power laser beams tend to evaporate aerosols. The laser beam would therefore penetrate most common clouds with little difficulty. Rain clouds are rare both in space and in time. There are numerous sites in the Western U.S. where, considering joint probability of rain cloud coverage, efficient laser beam transmission can be assured at all times. It thus seems feasible to bring power down to local users much of the time and to import power in times of inclement weather by trunking power from prime sites in the west. The trunking network could also be used to provide an important daily asset by load leveling across three time zones.

\section{SAFETY AND ENVIRONMENT}

Many people think of laser beams as uncontrolled, destructive sources of raw energy. This vision has no relationship to the type of system that we are discussing here. Certainly we don't want to destroy the receivers that collect and use the energy!

The SPS beam from space to ground will be completely controllable by the "adaptive optics" of the projector. Adaptive optical techniques are now quite advanced. In fact, they make the utilization of large, high power optical projection systems in space possible. Unless the proper feedback information is supplied, the computer controlling the optical figure and the beam pointing will immediately relax the adaptive surface, spreading harmlessly weak infrared radiation over a large area and reducing its flux density to a safe level well below that of sunlight. 
When the beam is focused to the receiver, the power flux in the beam will be perhaps a few thousand times solar. This flux level will be highly localized in an area about 50 meters in diameter, with extremely weak sidelobes. Sidelobes are worrisome in the case of microwaves because they extend for many kilometers. The local laser heating will be similar to that above a steel blast furnace or other hot industrial process. Aircraft and Spacecraft will normally be steered to avoid the laser beam; however, should any craft approach the laser beam, it will be immediately detected by glint from the very low level sidelobes a few hundred meters before entering the beam. The adaptive optics would then be relaxed to protect the craft. Some birds might occasionally be lost; however, most creatures should be able to sense heat as they approach it and turn away before they are injured.

Two micron wavelength radiation is not transmitted by the human eye. The eye is opaque to wavelengths longer than about 1.7 microns. Thus, observation of the satellite from outside the receiving site should result in no eye damage. It has already been indicated that solar energy reaches the ground virtually unimpeded at two microns, so interactions with the ionosphere and atmosphere are expected to be negligible.

\section{WEAPONS ASPECTS}

Whenever we deal with a device that projects large amounts of energy, we deal with a potential weapon. As shown above, fail-safe controls are possible through the use of adaptive optics. Therefore, any use of the laser transmitter as a weapon will have to be a deliberate one. While the high-power laser could lend itself to defensive and surgical type offensive strikes, it cannot be used effectively as a weapon of mass destruction. Even if laser space power devices provided all the electrical power needs of the United States in 2025 A.D., the total integrated energy fluence available in an hour would be a tiny fraction of the destructive potential of the existing nuclear ICBM's. The weapons aspects of the SPS in both defensive and offensive roles and the national and international implications of these roles need to be evaluated and put in context.

We have briefly outlined the importance of keeping open the design of a solar space power system until the utility of lasers for power transmission can be fully evaluated. We hope that several new possibilities have been illuminated and that future SPS studies will be structured so that each of these important options is given the attention it deserves. 
REFERENCES

I. Dromond, J. E., "Solar Power Satellites Revisited," Proceedings of Fifth Energy Technology Conference and Exposition, U.S. Department of Energy, February 27 to March 1, 1978.

2. Rather, J. D. G., Gerry, E. T., and Zeiders, G. W., "Investigation of Possibilities for Solar Powered High Energy Lasers in Space," Final Report, NASA Contract \#NASA-3048, May 25, 1977.

3. Rather, J. D. G., "New Candidate Lasers for Power Beaming and Discussion of Their Applications," to be published in Progress in Astronautics and Aeronautics.

4. Manson, D. J., "Systems Efficiency and Specific Mass Estimates for Direct and Indirect Solar-Pumped Closed-Cycle High-Energy Lasers in Space," to by publisted in Progress in Astronautics and Aeronautics.

5. Hertzberg, A., unpublished manuscript, Mathematical Sciences Northwest, Seattle, Washington.

F-6 
APPENDIX G

SPACE LASER POWER SYSTEM

by

Wayne S. Jones

Program Manager, Advanced Systems Studies

Lockheed Missiles and Space Company, Inc.

Lockheed Palo Alto Research Laboratory

Palo Alto, California 94304

\section{INTRODUCTION}

The Lockheed Missiles \& Space Company (LMSC), Inc., has completed the parametric analysis portion of a study of a space laser power system for the NASA Lewis Research Center. This study evaluated the use of laser beams for transmitting energy to earth from an orbiting space platform similar to the Solar Power Satellite (SPS), which uses microwaves. The Space Laser Power System (SLPS) has the advantage of needing only to be deployed in low earth orbit (avoiding transportation to synchronous-equatorial orbit), and the much shorter wavelength requires significantly less land use on the earth (200 versus 80,000 acres). The overall efficiencies of the SLPS obtained during the parametric analyses were approximately equal to those of the SPS. This appendix presents some of the background and a summary of the parametric analysis.

\section{BACKGROUND}

The use of lasers to transmit energy over long distances has been of interest since laser devices with significant power outputs appeared to be feasible. Kantrowitz ${ }^{l}$ examined the use of ground lasers to provide energy to launch vehicles during their ascent orbit. Pirri ${ }^{2}$ also was an early investigator of beaming laser energy to propulsion vehicles. In each case, the laser energy was converted to suit the specific application. More recent investigations have been, and are being, conducted for the NASA Lewis Research Center, Defense Advanced Research Projects Agency, and Air Force Rocket Propulsion Laboratory. These and other studies and experimental programs have made significant advances in critical technologies such as laser devices, large optics, and pointing and tracking. With the recent technology advancements, it is becoming more and more evident that the use of lasers to transmit energy offers potential advantages that are not available in other techniques. 
Currently LMSC, under contract to the NASA Lewis Research Center, is investigating the transmission of energy from space for use as electrical energy on earth similar to the SPS mission using microwaves. Two significant advantages of the SLPS are that the major portion of the orbital weight would operate in a low earth orbit (LEO), avoiding the cost of transportation to a synchronous-equatorial orbit (GEO), and that land-use requirements on earth are very small when compared with those of an SPS. A discussion of the laser power system is contained later in this appendix; however, it should be noted that the SLPS concept is in its infancy relative to the SPS concept, and the system presented is preliminary and falls short of its full potential. Optimization was directed toward overall system efficiency only, whereas true optimization would include parameters of weight in orbit, cost of initial investment, life-cycle operation costs, orbital assembly, and transportation. Additionally, new laser concepts with significantly higher potential efficiencies are on the horizon.

\section{OBJECTIVE}

The objective of the SLPS is to (a) convert solar energy in space to laser energy, (b) transmit the laser energy to earth, and (c) convert the laser energy into electrical energy for nromal consumer use.

PURPOSE

The purpose of the SLPS is to augment current electric generating stations using fossil fuels. For example, more than 90 percent of the continental United States has weather conditions that will permit efficient laser beam transmissions for more than 50 percent of the time. By converting the laser energy to heat, fossil fuel consumption could be dramatically reduced on current operating machinery. Higher efficiencies could also be obtained by the introduction of innovations to operate at higher temperature. These innovations will be discussed as the system evolves.

\section{SYSTEMS OVERVIEW}

An overview of the SLPS concept is shown in figure G.I. The SLPS is composed of three basic and remote elements: the power staellite, the relay satellite, and the ground station. The power satellites are placed in a low, sun-synchronous orbit that provides solar energy 100 percent of the time. In addition to the power satellite, relay satellites that receive the beam and retransmit the energy are used so that the power satellite does not have to be within the line of sight of the using ground station. The illustration depicts a condition in which the using ground stations are on the far side of 
the earth located within the United States covering about $45^{\circ}$ of longitude. Under these conditions, two sets of relay satellites could be used so that the obscured power satellites could transfer the energy first to a LEO relay, which in turn would transmit to a relay satellite station in synchronous-equatorial orbit adjusted to the ground site. As the number of ground stations and earth coverage increase, the ratio of relay satellites to power satellites decreases until the ratio is one to one. Other relay deployment schemes can be developed so that all orbital equipment is near earth, and any point on the earth (including both poles) can be reached. The coverage of satellites in synchronous-equatorial orbit is limited, primarily by the zenith angle at the ground site for the transfer medium. The candidate subsystems considered in the analysis for the three primary elements are discussed next.

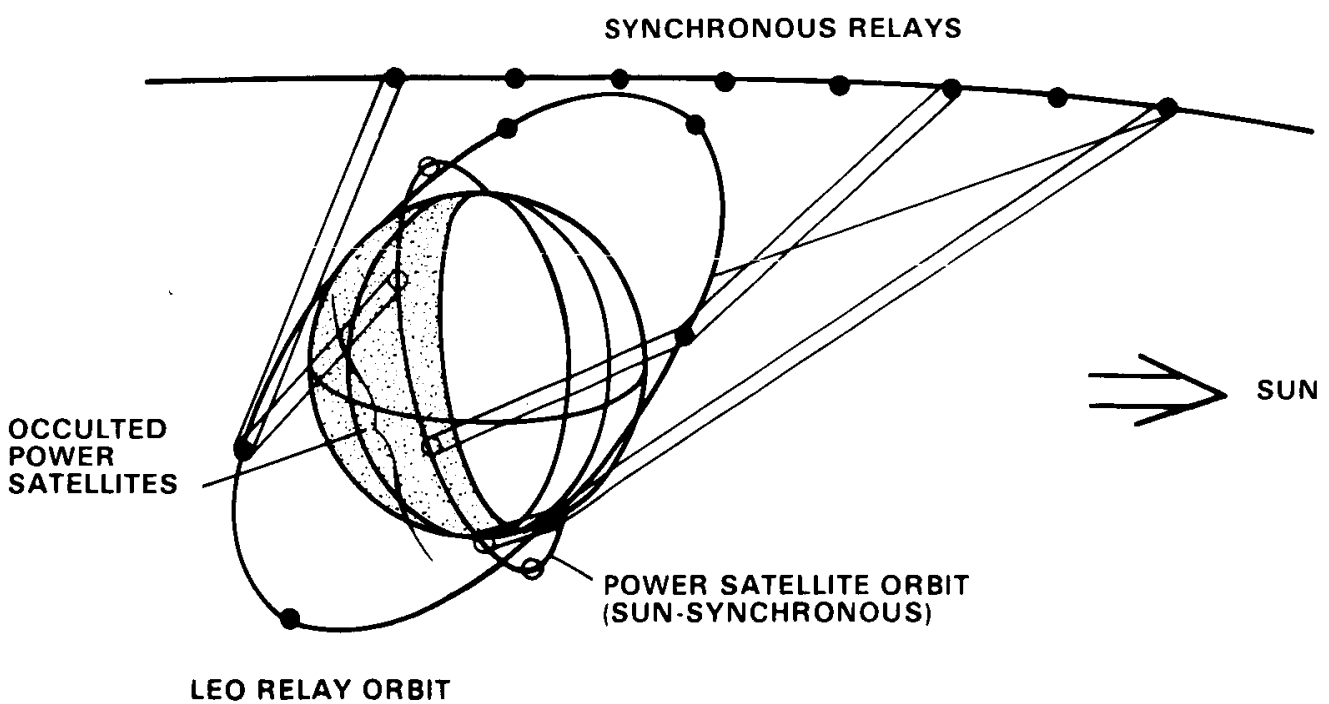

Figure G.I System Overview 


\section{Laser Satellite}

The primary subsystems of the laser power satellite are the laser device and, if required, its electrical power supply, the optical subsystem, the pointing and tracking subsystem, and a beam control subsystem. The laser subsystems considered in this analysis included the carbon dioxide electric discharge laser $\left(\mathrm{CO}_{2}-\mathrm{EDL}\right)$, the carbon monoxide electric discharge laser (CO-EDL) and solar-pumped laser. The $\mathrm{CO}_{2}-\mathrm{EDL}$ and the solar-pumped laser operate at wavelengths of $10.6 \mu \mathrm{m}$; the CO-EDL operates at $5 \mu \mathrm{m}$. Both EDL's require minimal electrical power supplies to stimulate lasing, whereas the solar-pumped laser is pumped directly by solar energy.

Other subsystems, such as refrigeration, pumps, and compressors, require significant amounts of electrical power. The electrical power supply in this analysis considered the use of silicon solar cells, gallium arsenide solar cells, Brayton cycle, and energy exchanger with a turbine, and an energy exchanger with a binary cycle. The binary cycle included both a Brayton cycle, in which the compressor was an energy exchanger, and a bottoming Rankine cycle. Silicon solar cells have typical efficiencies ranging from the current 10.4 percent to a postulated 18 percent at the beginning of life. These degrade rapidly in LEO. Gallium arsenide cells have a beginning of life efficiency of approximately 18 percent operating at 500 suns concentration and $200^{\circ} \mathrm{C}$. The Brayton cycle alone has an efficiency of somewhat less than 40 percent. An energy exchanger with a binary cycle will reach efficiencies on the order of 73 percent. The energy exchanger with a binary cycle was selected as the prime candidate in the current analysis.

The optical system must necessarily include large-diameter, lightweight, adaptive-type optics to achieve transmission that is as near diffraction limited as possible. The first study of large, lightweight, adaptive mirrors for space use was accomplished under a contract by ITEK Corporation for the NASA Lewis Research Center and showed the feasibility of segmented optics controlled to provide the necessary accuracy. Many studies since the original study have also demonstrated the feasibility of large optics. The optics sizes are determined by (a) the wavelength, (b) the distance over which energy must be transferred, (c) the jitter of the system, (d) the optical qualities, and (e) other parameters. The current assessment of the technology is that mirrors of the size and quality required for this application are feasible. 
Pointing and tracking have been investigated extensively in the case of the SLPS. All elements must be cooperative, which means that as the beam is transmitted, each receiving element is in communication with the sending element so the real-time corrections can be made. The studies have shown that pointing and tracking accuracies that would be required for this application are very much in the realm of feasibility.

Beam control, though not an obvious subsystem, is important. To point, track, and maintain the narrow beam diameter, the condition of the beam as it leaves the transmitter must be known. In addition, there must be control of beam jitter, whether it is mechanically or optically induced. Experiments in beam stabilization have shown that a beam can be stabilized to less than $1 \mu$ rad accuracy. Several experimental programs are under way investigating the methods and techniques of sampling the beam for correction of wavefront errors to maintain the narrow beam necessary.

\section{Relay Satellites}

Relay satellites are basically orbital optical systems including a spacecraft to handle the electrical power, the communication, and all the other housekeeping and necessary functions of normal spacecraft. Two types of relay satellites were considered, which are commonly referred to as the monocle and the bifocal. The monocle is a single mirror that reflects and refocuses at the same time. The bifocal, which is the selected option for this application, consists of receiving and transmitting sets of optics. The receiving set is off-axis, segmented, adaptive, and must be of near-diffraction-limited quality to avoid inducing additional wavefront errors. This set of optics must be abie to receive from any direction. The laser beam is then reduced and transferred to the transmitter mirror. The transmitter mirror, which also must be able to point in any direction, expands the beam, and, as the beam leaves the primary aperture, it is sampled for correction of wavefront errors and refocused to the range of the next target. The transmitting mirror is cassegrainian and adaptive to maintain near-diffraction-limited beam divergence. Cooperative pointing and tracking subsystems are an integral part of both the receiver and the transmitter. The transmitter unit includes a ranger to determine focal range. 
Ground sites basically have a receiver and an energy conversion device to convert the laser energy into electrical energy. Depending on the conversion device, the receiver may or may not be optical. Candidates considered for the ground site for the conversion of the laser energy included photovoltiac, thermionic, thermal electronic, Brayton cycle, and the energy exchanger with a binary cycle. The efficiencies were approximately 40 percent for the photovoltaic and the thermionic, approximately 45 percent for the thermal electronics, something less than 40 percent for a straight Brayton cycle, and a calculated 73 percent with the energy exchanger and binary cycle. The binary cycle was selected because of its high efficiency. The receiver for this type of energy conversion system would be optical but not of the optical quality normally believed to be required for optic devices.

\section{SYSTEM SUMMARY RESULTS}

Evaluation of five different systems was initiated. The systems were $\mathrm{CO}_{2}-\mathrm{EDL}$ with the energy exchanger and binary cycle, CO-EDL with an energy exchanger and binary cycle, solar-pumped $\mathrm{CO}_{2}$ with an energy exchanger and binary cycle, $\mathrm{CO}_{2}-\mathrm{EDL}$ with solar cells, and CO-EDL with solar cells. Both solar arrays were gallium arsenide with 500 suns concentration operating at $200^{\circ} \mathrm{C}$. Because of the lower efficiencies of the solar cell arrays, both systems showed an overall efficiency of just over I percent and were eliminated from consideration. The other three systems-- $\mathrm{CO}_{2}, \mathrm{CO}$, and solar pumped with binary systems--showed overall efficiencies of about 5 percent, 5.5 percent, and slightly over 6 percent, respectively. These efficiencies are comparable to the overall efficiency of the current SPS system. The weights of the three systems were all about equal; however, they were about 50 percent heavier than the SPS system of an equivalent power output on the ground.

To summarize the three systems, it is believed that efficiencies greater than 5 percent are assured. Also, all three laser types produce similar type weights. The $\mathrm{CO}_{2}$-EDL has more available performance and design data, the lowest atmospheric transmission losses, and a spectrum suited for phased array. The CO-EDL has somewhat less available performance and design data. The transmission losses are higher than those for $\mathrm{CO}_{2}$, and the multiple lines will produce phased array difficulties; however, smaller apertures are required because of the shorter wavelength. The solar-pumped $\mathrm{CO}_{2}$ laser has meager performance and design data; however, based on analysis, it has the highest overall efficiency with a potential of even higher efficiencies. Because of the availability of data and the increased 
credibility, it was recommended that the preliminary design of a $\mathrm{CO}_{2}-\mathrm{EDL}$ system be pursued in the concept development and cost analysis to follow.

Two examples of the advantage of the laser system over the microwave system are illustrated in figure G.2 and table G.1. Figure G.2 shows that the SPS uses a 1,000-m-diameter transmitting aperture and the receiver on the ground is approximately $7.7 \mathrm{~km}$ in diameter (this is without consideration of the zenith angle, which will increase the size). The laser system uses a 50-m-diameter aperture in space with a beam size of less than $28 \mathrm{~m}$ on the ground. Again the zenith angle will increase the diameter required in one direction. Table G.l shows transportation costs as they will affect the SPS and SLPS. The costs shown are not current costs; however, the ratio of costs between transportation to LEO and from LEO to synchronous orbit should remain fairly close. For a 10-GW SPS system, the orbital weight is 200 million pounds. The orbital weight for a 10-GW SLPS system is 314 million pounds, something better than 50 percent greater. The cost to get the microwave system to a $28^{\circ}$ LEO at $\$ 14 / \mathrm{lb}$ is $\$ 2.8$ billion. The laser system would necessarily have to go to a $97^{\circ} \mathrm{LEO}$, which would cost about 50 percent more per pound, of $\$ 2 \mathrm{l} / \mathrm{lb}$. The cost of this would be $\$ 6.6$ billion, which is substantially more than the microwave system. From LEO to GEO, however, the cost is about $\$ 59 / \mathrm{lb}$. In the case of the microwave system, all 200 million pounds go to synchronous orbit, which costs $\$ 11.8$ billion. In the case of the laser system, only one relay satellite goes to GEO, which is $\$ 0.01$ billion in transportation costs. The total for the two systems show that the SLPS saves more the 50 percent in transportation costs.

Many other areas will influence the final outcome of the analysis. One large SLPS item, space assembly in LEO, will reduce costs because there will be no assembly or crew facility required at GEO. The erection costs themselves, because of the simplicity of a solar concentrator versus solar arrays, should be much less for the SLPS. Current SPS analysis shows that approximately $125 \mathrm{sq}$. mi (80,000 acres) of land are required for a site (including a safety zone) for the micrwave system. In the case of the laser system, with an area of approximately 0.3 sq. mi (200 acres), the flux level at the edge of the site would be three orders of magnitude less than the current safety standards for corneal exposure to 10.6- $\mu \mathrm{m}$ laser irradiation. 


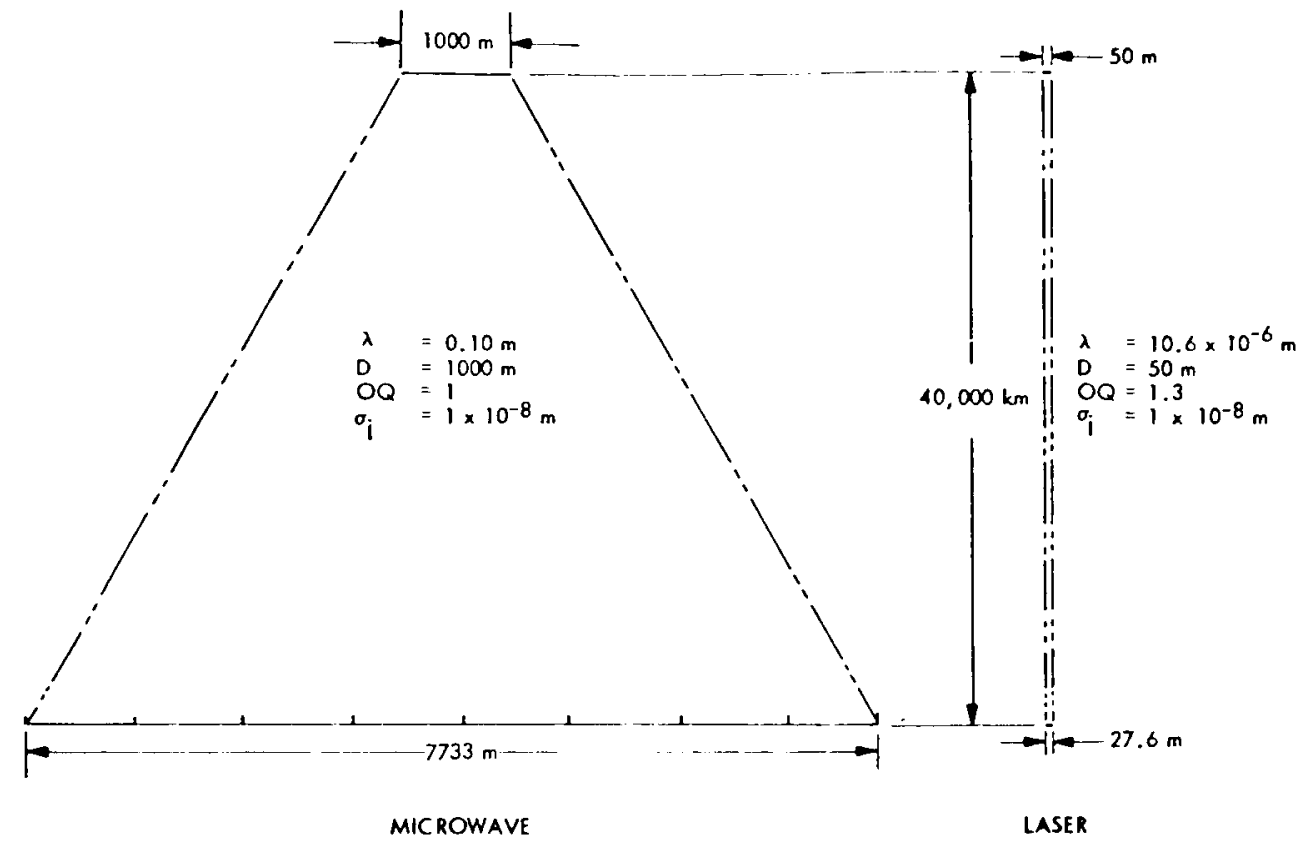

Figure G.2 SPS-SLPS Comparison

Table G.I SPS and SLPS Transportation Costs*

Transmission System

Transportation Costs, \$B

SPS SLPS

Microwave to $28.5^{\circ}$ LEO at $\$ 14 / \mathrm{lb}$

02.8

Laser to $97^{\circ}$ LEO at $\$ 21 / \mathrm{lb}$

6.57

LEO to GEO at $\$ 59 / / \mathrm{b}$

$\underline{11.8}$

$\underline{0.01}$

Total

14.6

6.58

* Weights of SPS and SLPS are 200 billion pounds and 314 billion pounds, respectively. 


\section{SUMMARY}

Based on preliminary analyses using a conservative approach, it appears that the SLPS may be more cost effective than the SPS. Efficiencies of the SPS could possibly be increased with the use of the same energy conversion system used in the SLPS. However, it is not clear that the cost of the SPS would be significantly affected because the additional weight would have to be transported to synchronous orbit, which is one of the most expensive parts of the SPS system.

\section{REFERENCES}

I. Kantrowitz, A. R., "Propulsion to Orbit by Ground-Based Lasers," Astronautics and Aeronautics, May 1972.

2. Pirri, A. N., and Weiss, R. F., "Laser Propulsion," AlAA Paper Number 72-719, June 1972. 